\title{
Arcsecond resolution images of the chemical structure of the low-mass protostar IRAS 16293-2422
}

\section{An overview of a large molecular line survey from the Submillimeter Array}

\author{
J. K. Jørgensen ${ }^{1,2}$, T. L. Bourke ${ }^{3}$, Q. Nguyễn Lương ${ }^{4,5}$, and S. Takakuwa ${ }^{6}$ \\ 1 Centre for Star and Planet Formation, Niels Bohr Institute, University of Copenhagen, Juliane Maries Vej 30, \\ 2100 Copenhagen Ø., Denmark \\ e-mail: jeskj@nbi.dk \\ 2 Natural History Museum of Denmark, University of Copenhagen, Øster Voldgade 5-7, 1350 Copenhagen K., Denmark \\ 3 Harvard-Smithsonian Center for Astrophysics, 60 Garden Street MS42, Cambridge, MA 02138, USA \\ ${ }^{4}$ Laboratoire AIM, CEA/DSM, IRFU/Service d'Astrophysique, 91191 Gif-sur-Yvette Cedex, France \\ 5 Argelander Institute for Astronomy, University of Bonn, Auf dem Hügel 71, 53121 Bonn, Germany \\ 6 Academia Sinica Institute of Astronomy and Astrophysics, PO Box 23-141, Taipei 10617, Taiwan
}

Received 26 April 2011 / Accepted 30 August 2011

\begin{abstract}
It remains a key challenge to establish the molecular content of different components of low-mass protostars, like their envelopes and disks, and how this depends on the evolutionary stage and/or environment of the young stars. Observations at submillimeter wavelengths provide a direct possibility to study the chemical composition of low-mass protostars through transitions probing temperatures up to a few hundred $\mathrm{K}$ in the gas surrounding these sources. This paper presents a large molecular line survey of the deeply embedded protostellar binary IRAS 16293-2422 from the Submillimeter Array (SMA) - including images of individual lines down to $\approx 1.5-3^{\prime \prime}(190-380 \mathrm{AU})$ resolution. More than 500 individual transitions are identified related to 54 molecular species (including isotopologues) probing temperatures up to about $550 \mathrm{~K}$. Strong chemical differences are found between the two components in the protostellar system with a separation between, in particular, the sulfur- and nitrogen-bearing species and oxygen-bearing complex organics. The action of protostellar outflow on the ambient envelope material is seen in images of $\mathrm{CO}$ and $\mathrm{SiO}$ and appear to influence a number of other species, including (deuterated) water, HDO. The effects of cold gas-phase chemistry is directly imaged through maps of $\mathrm{CO}, \mathrm{N}_{2} \mathrm{D}^{+}$and $\mathrm{DCO}^{+}$, showing enhancements of first $\mathrm{DCO}^{+}$and subsequently $\mathrm{N}_{2} \mathrm{D}^{+}$in the outer envelope where CO freezes-out on dust grains.
\end{abstract}

Key words. circumstellar matter - ISM: molecules - stars: formation - ISM: jets and outflows - submillimeter: ISM ISM: individual objects: IRAS 16293-2422

\section{Introduction}

Developing the understanding of the chemical structure and evolution of star-forming regions remains an important task. Understanding the molecular composition of protostars and, in particular, the innermost regions of the circumstellar envelopes and disks relates to some of the key scientific questions concerning star and planet formation, for example, what level of chemical complexity can arise around protostars (e.g., van Dishoeck \& Blake 1998; Ceccarelli et al. 2007; Herbst \& van Dishoeck 2009). Also, for studying the physics of the star formation process, it is desired to know which molecular species are tracing specific components of young stellar objects, such as their envelope, disks etc. This paper presents the results of a large Submillimeter Array (SMA) survey of the molecular line emission on few hundred AU scales toward the deeply embedded low-mass protostar IRAS 16293-2422 and discusses some of the signatures of the physics and chemistry occurring in this deeply embedded protobinary system.

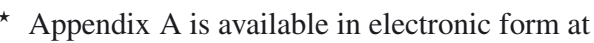
http://www. aanda.org
}

IRAS 16293-2422 has long been considered one of the "template" sources for astrochemistry. Being the deeply embedded (Class 0) low-mass protostar with the richest line spectrum, it has been the subject of many targeted (sub)millimeter wave spectroscopic studies (e.g., Blake et al. 1994; van Dishoeck et al. 1995; Ceccarelli et al. 1998, 2000; Cazaux et al. 2003; Caux et al. 2011) as well as specialized modeling efforts attempting to establish its chemical composition - in particular, variation in its molecular abundances as function of radius (e.g., Ceccarelli et al. 2000; Schöier et al. 2002). The detections of complex organics toward this source (e.g., Cazaux et al. 2003; Bottinelli et al. 2004; Kuan et al. 2004; Bisschop et al. 2008) have sparked new interest in the physical processes that can lead to the evaporation of icy grain mantles on small scales of protostars - and thereby also the chemical processes determining their molecular compositions.

However, IRAS 16293-2422 has also illustrated some of the inherent difficulties in relating the larger scale line emission picked up by single-dish telescopes to the source structures on few hundred AU scales, e.g., revealed by millimeter interferometric observations. After the identification of IRAS 16293-2422 as a binary through high resolution centimeter 
and millimeter wavelength continuum observations (Wootten 1989; Mundy et al. 1992), it has been the target of many studies trying to relate the structure of the two main components to their line emission and place them in an evolutionary context. The southeastern of the two components, "IRAS 16293A", appears resolved in continuum observations, breaking into a number of different components at subarcsecond scales (Chandler et al. 2005; Pech et al. 2010). The northwestern component, "IRAS 16293B", in contrast appears unresolved on these scales. In terms of line emission the two sources also show significant differences: both show detection of complex organic molecules for example (Bottinelli et al. 2004; Kuan et al. 2004; Remijan \& Hollis 2006; Bisschop et al. 2008) - but the relative line strengths and widths vary between the two sources. Whereas it is generally agreed that the IRAS 16293A component is protostellar in nature - it has been suggested that the IRAS 16293B component either represented a more evolved (T Tauri) star (e.g., Stark et al. 2004; Takakuwa et al. 2007) or alternatively a very young object, possibly before starting accretion/mass loss (Chandler et al. 2005).

In this paper we present a large survey of the line emission in the $230 \mathrm{GHz}$ and $345 \mathrm{GHz}$ atmospheric windows of IRAS 16293-2422 from the SMA. The paper is laid out as follows: Sect. 2 describes the details of the observations and Sect. 3 presents an overview of the line emission in global terms. Section 4 discusses a few of the key aspects that can be derived from just visual inspection of the molecular line emission maps and Sect. 5 summarizes the main conclusions of the paper.

\section{Observations}

IRAS 16293-2422 was observed in a number of spectral settings between 2004 and 2007 using the SMA, (Ho et al. 2004). We here focus on four sets of observations covering different spectral setups at 220 and $340 \mathrm{GHz}$. The log of the observations, beam sizes and noise levels are summarized in Table 1. Previous papers by Yeh et al. (2008) and Bisschop et al. (2008) presented part of these data from 2005 Feb. 18, focusing on the CO outflow emission and selected complex organic molecules, respectively.

The data were taken with the SMA in its compact or compact-North configuration resulting in average beam sizes of $\approx 2-4^{\prime \prime}(250-500 \mathrm{AU}$ at a typical distance to Ophiuchus of $125 \mathrm{pc}$ ). For three of the four datasets a pointing center at $\alpha=16.32^{\mathrm{m}} \cdot 22.91^{\mathrm{s}}$., $\delta=-24.28^{\prime} 35^{\prime \prime} .5$ [J2000] was used. For the last dataset (2007 March 22) the pointing center was $\alpha=16^{\mathrm{h}} 32^{\mathrm{m}} \cdot 22.72^{\mathrm{s}}$., $\delta=-24^{\mathrm{d}} \cdot 28^{\prime} 34^{\prime \prime} 3$ [J2000]. The positions for the two main continuum peaks seen in these images (Fig. 1) are at $\alpha=16^{\mathrm{h}} 32^{\mathrm{m}} 22.87^{\mathrm{s}} ., \delta=-24^{\mathrm{d}} 28^{\prime} 36^{\prime \prime} .4$ [J2000] (IRAS16293A or "A") and $\alpha=16.32^{\mathrm{m}} \cdot 22.62^{\mathrm{s}}, \delta=-24.28^{\prime} 32^{\prime \prime} 4$ [J2000] (IRAS16293B or "B") with an agreement between the fitted positions of about $0.2^{\prime \prime}$. The field of view of the SMA observations cover a region of 30-50" (3750-6250 AU; diameter) at $345-230 \mathrm{GHz}$.

Two of the four datasets (the $220 / 230 \mathrm{GHz}$ and $337 / 347 \mathrm{GHz}$ datasets from 2005 February 18 and 2007 March 22, respectively) were taken as part of dual receiver observations with the high frequency receiver tuned to lines at $690 \mathrm{GHz}$. For these datasets the excellent weather conditions required for the $690 \mathrm{GHz}$ observations also result in significantly improved rms noise levels in the lower frequency data discussed here. The correlator was configured with uniform spectral coverage over the (at the time) $\approx 2 \mathrm{GHz}$ bandwidth in each sideband of the SMA receivers. Each $2 \mathrm{GHz}$ sideband was covered by 24 chunks of the correlator with a width of $128 \mathrm{MHz}$ each - and each

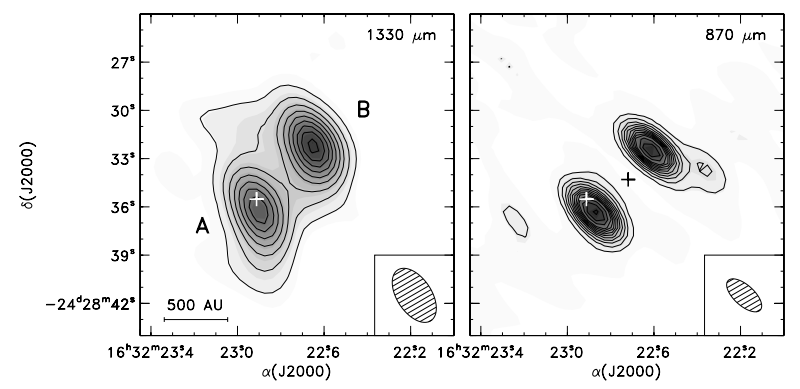

Fig. 1. Continuum images of IRAS 16293-2422 at $1.3 \mathrm{~mm}$ (left) and $0.87 \mathrm{~mm}$ (right). In the left panel the contours are given in steps of $0.1 \mathrm{Jy}$ beam $^{-1}$ to $1.0 \mathrm{Jy}_{\text {beam }}^{-1}$ and from there in steps of $0.2 \mathrm{Jy} \mathrm{beam}^{-1}$ and in the right in steps of $0.2 \mathrm{Jy} \mathrm{beam}^{-1}$ to $2.0 \mathrm{Jy} \mathrm{beam}^{-1}$ and from there in steps of $0.4 \mathrm{Jy} \mathrm{beam}^{-1}$ (in the continuum data the noise level is determined by the interferometer dynamic range). The white plussigns indicate the pointing centers of the observations, except those from 2007 March 22 for which the pointing center is indicated by the black plus-sign in the right panel.

chunk split into 256 channels (128 channels for the dual receiver observations).

The data were calibrated using the standard recipes - including calibration of the complex gains by observations of the nearby quasar J1743-038 and flux and passband calibration by observations of planets (Uranus, in particular). The initial data reduction was performed using the MIR package (Qi 2008) and continuum subtracted line maps were created using the Miriad package (Sault et al. 1995) with which further analysis was also done.

\section{Analysis}

In this paper we focus on the morphology of the line emission from the IRAS 16293-2422 data and refer to other papers in the literature for a more in-depth discussion of continuum emission toward the sources. We make the data publicly available for anyone interested in a more in-depth analysis of specific molecules: the SMA raw data are available through CfA Radio Telescope Data Center ${ }^{1}$ and the spectra toward the two continuum peaks in FITS format through a dedicated website ${ }^{2}$ (the full reduced datacubes are available on a collaborative basis).

Figures 2-9 show the composite spectra toward the continuum positions of IRAS 16293A and IRAS 16293B. Key differences for the line emission in the two sources also noted in previous papers are clearly illustrated: typically the IRAS 16293A component show broader and stronger lines, for example, clearly illustrated in the methanol $\mathrm{CH}_{3} \mathrm{OH} J_{k}=77_{k}-6_{k}$ branch at $338.4 \mathrm{GHz}$. On the other hand, IRAS 16293B shows the presence of some sets of lines not seen in IRAS 16293A, e.g., in the frequency range from $346.9-347.3 \mathrm{GHz}$ harboring a number of transitions of acetaldehyde, $\mathrm{CH}_{3} \mathrm{CHO}$.

A few lines show very complex profiles likely due to combinations of optical depth effects and spatial resolving out due to the interferometer's lack of short-spacings: with the shortest projected baselines of about $8 \mathrm{~m}$ length (Table 1) the SMA observations for example recover less than $50 \%$ of any emission with a Gaussian distribution with a FWHM of $10-15^{\prime \prime}$ (i.e., molecules with a similar surface brightness distribution as the envelope traced by single-dish continuum observations; Schöier et al. 2002) and an even smaller fraction for molecules more

\footnotetext{
1 http://cfa-www .harvard.edu/rtdc

2 http://www.nbi.dk/ jeskj/sma-iras16293.html
} 
J. K. Jørgensen et al.: A large SMA molecular line survey of IRAS 16293-2422
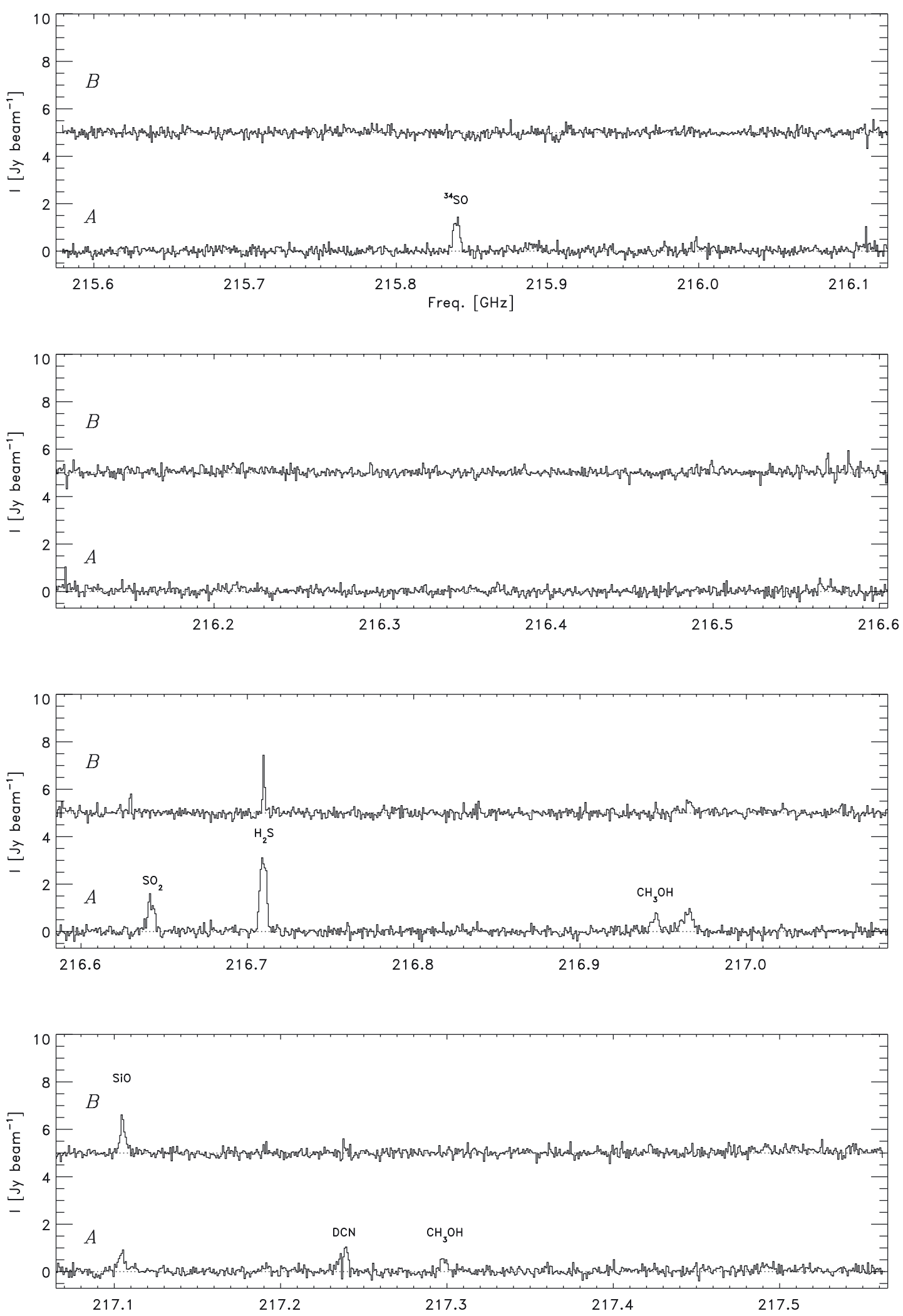

Fig. 2. Composite spectrum in the range $215.5-217.5 \mathrm{GHz}$ for the central beam $\left(5.5^{\prime \prime} \times 3.2^{\prime \prime}\right.$; line 1 of Table 1$)$ toward the source IRAS $16293 \mathrm{~A}$ (at 0 on the $Y$-axis) and IRAS 16293B (offset in the $Y$-axis direction). Transitions of some of the prominent species have been identified.

homogeneously distributed (e.g., less strongly weighted by temperature than the dust continuum emission). This is clearly seen for the $\mathrm{CO}$ isotopologues $-{ }^{12} \mathrm{CO}$ at $230.538 \mathrm{GHz}$ and ${ }^{13} \mathrm{CO}$ at $220.398 \mathrm{GHz}$, as examples - but the "absorption" features seen toward IRAS 16293B for, e.g., $\mathrm{N}_{2} \mathrm{D}^{+}$at $231.321 \mathrm{GHz}$ and $\mathrm{CN}$ at $226.875 \mathrm{GHz}$, also reflect this. In particular, the absence of $\mathrm{CN}$ emission in the maps is a clear example of the effects of the interferometer resolving out more extended emission: in pointed JCMT single-dish observations of $\mathrm{CN}$ at $226.875 \mathrm{GHz}$ van Dishoeck et al. (1995) found lines with 

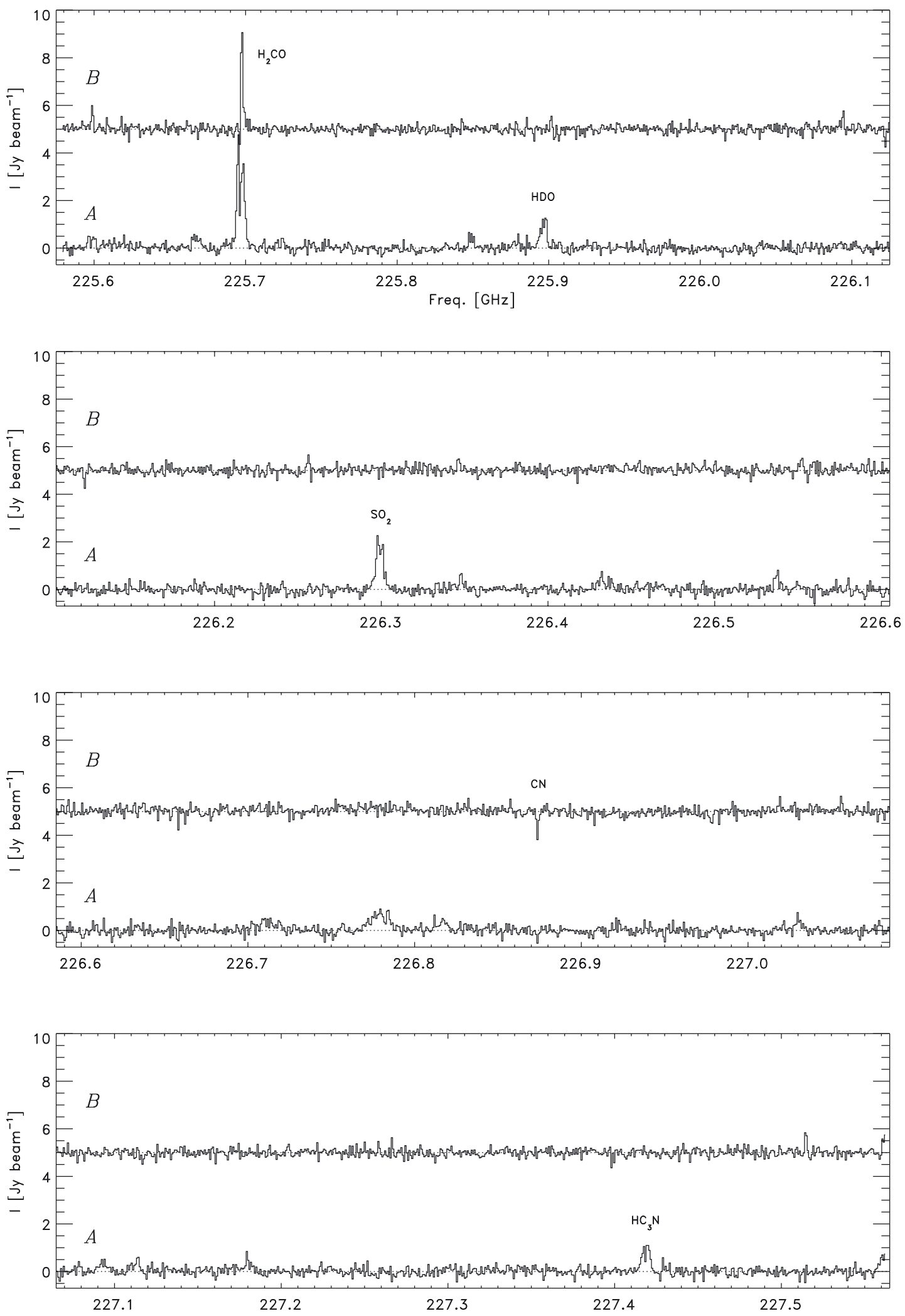

Fig. 3. As in Fig. 2 for the range $225.5-227.5 \mathrm{GHz}$ (beam size $5.5^{\prime \prime} \times 3.2^{\prime \prime}$; line 1 of Table 1 ).

intensities of $0.6-0.8 \mathrm{~km} \mathrm{~s}^{-1}\left(10-15 \mathrm{Jy}^{\text {beam }}{ }^{-1} \mathrm{~km} \mathrm{~s}^{-1}\right)$, contrasting the absence of $\mathrm{CN}$ emission in the SMA maps presented here. As pointed out by van Dishoeck et al., the narrow widths of the $\mathrm{CN}$ lines suggests a picture where this species is probing only the outer envelope and ambient core. This would indeed be on spatial scales resolved out by the SMA observations.
The interferometer's spatial filtering makes it difficult to use the interferometric data for quantitative estimates of, e.g., exact column densities or other physical parameters without a careful treatment of the amount of resolved-out emission, for example by combining the interferometric data with short-spacing maps from single-dish telescopes or more detailed models of the 
J. K. Jørgensen et al.: A large SMA molecular line survey of IRAS 16293-2422
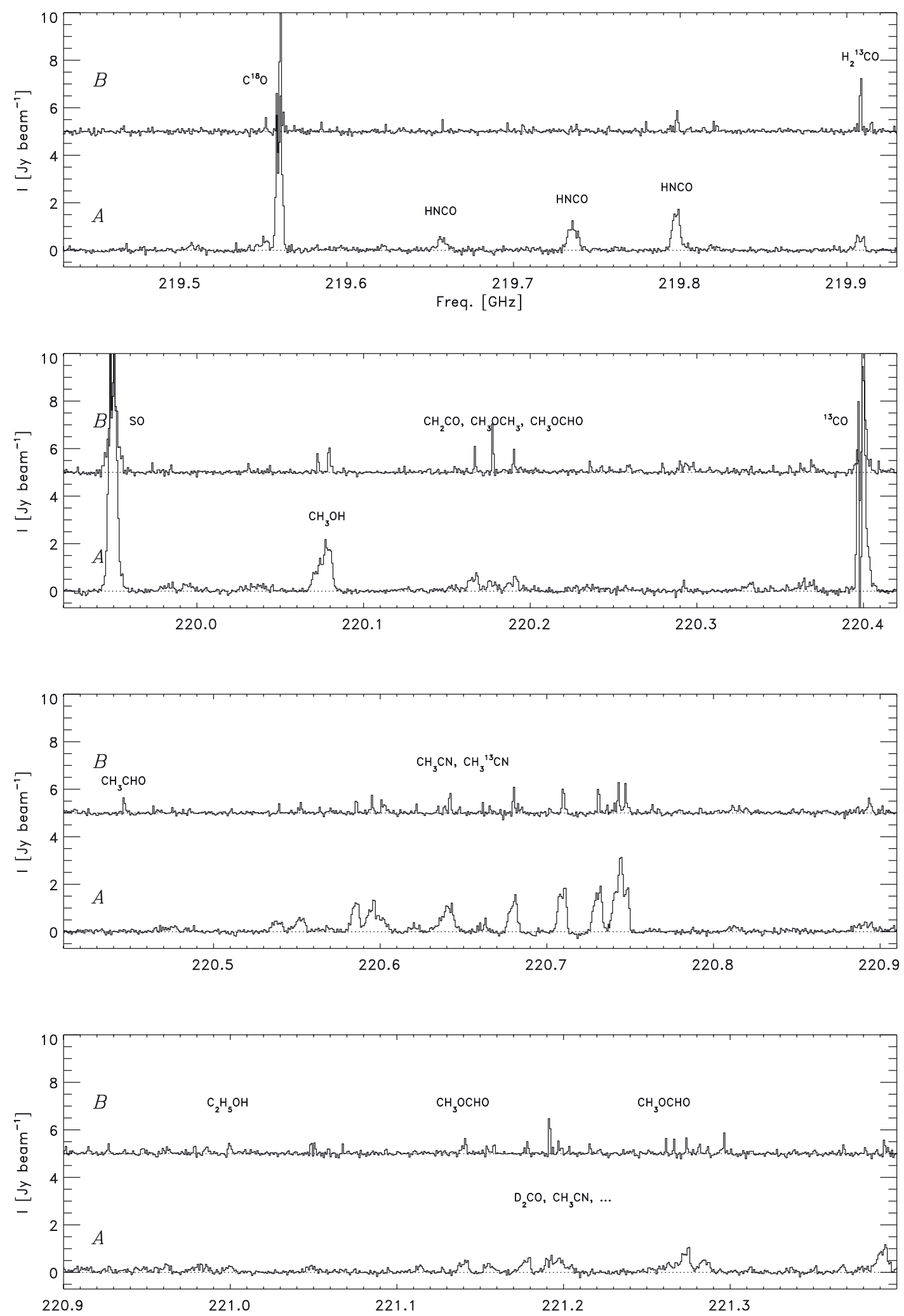

Fig. 4. As in Fig. 2 for the range $219.4-221.4 \mathrm{GHz}$ (beam size $4.0^{\prime \prime} \times 2.4^{\prime \prime}$; line 2 of Table 1 ).

source structure (see, e.g., Schöier et al. 2004; and Takakuwa et al. 2007). Still, the interferometric maps reveal the most prominent structures in the surface brightness distributions from the molecular lines - for example where the largest column densities of the different species occur - and therefore allow for a qualitative interpretation of the relations and differences between the imaged molecular species.
Lines present in the spectra toward each of the two continuum peak positions were identified using the CDMS (Müller et al. 2001, 2005) and JPL (Pickett et al. 1998) spectroscopic catalogs: the catalog entries were downloaded for the molecular species expected toward the two protostars, and compared to the observed spectra. Line identifications were made by eye taking into account the excitation energy levels and intrinsic line 

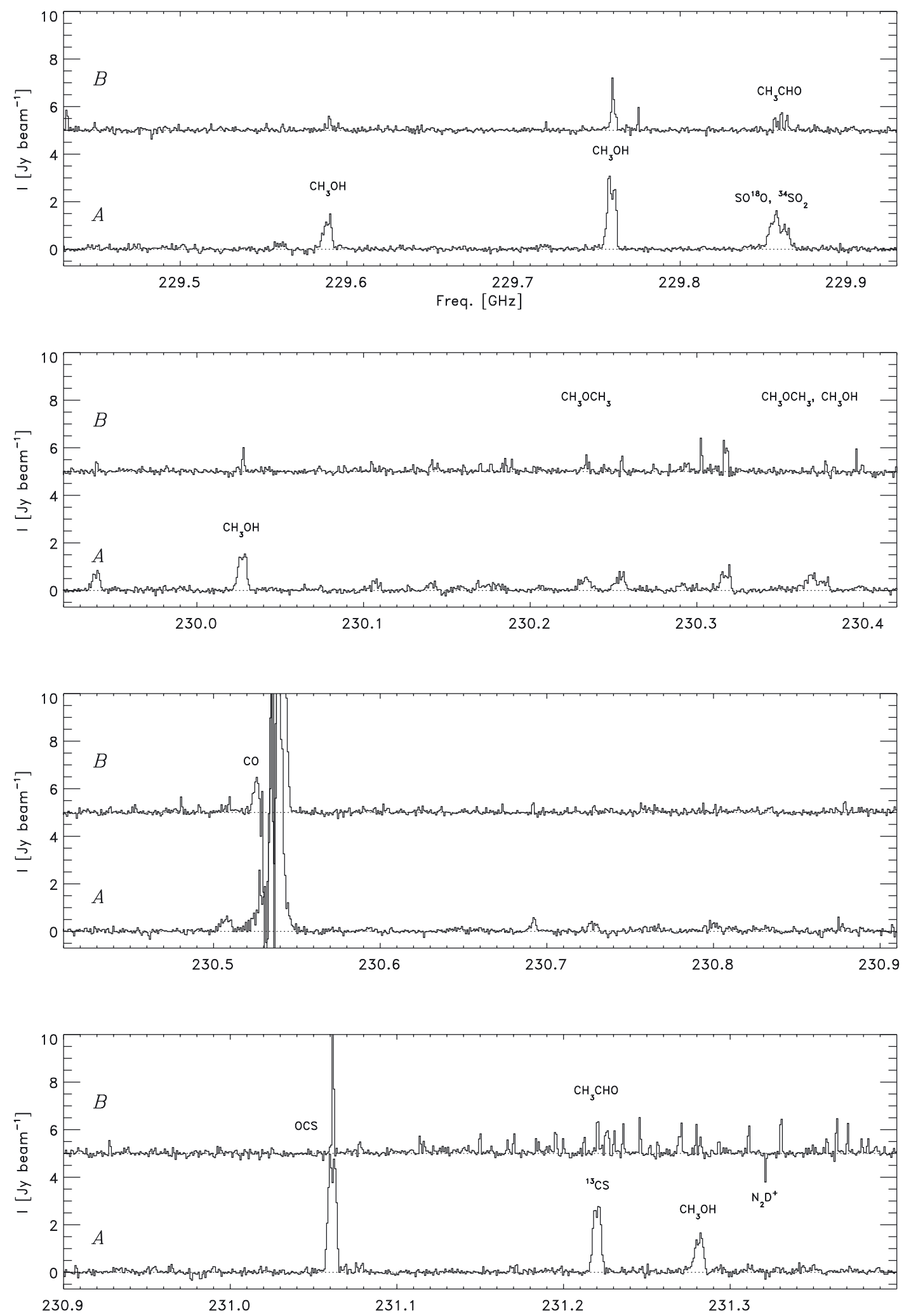

Fig. 5. As in Fig. 2 for the range $229.4-231.4 \mathrm{GHz}$ (beam size $4.0^{\prime \prime} \times 2.4^{\prime \prime}$; line 2 of Table 1 ).

strengths when evaluating the detection of a given transition. This process was done iteratively: that is, for detected species lower excited or stronger lines unassigned in the first round were searched for, e.g., looking at possible line blends with stronger lines for other species. Unassigned lines were checked against both catalogs and if a sufficient number of lines of a given molecule was detected, it was included in the search list.
In this manner a total of 515 transitions (996 including tabulated hyperfine components) from 54 molecular species (including isotopologues) were identified. About $10 \%$ of the features in the spectra remain unassigned. Table 2 summarizes the detected molecules, the number of lines and the energy ranges for the detected species - while Table A.1 compiles all the identified lines. 
J. K. Jørgensen et al.: A large SMA molecular line survey of IRAS 16293-2422
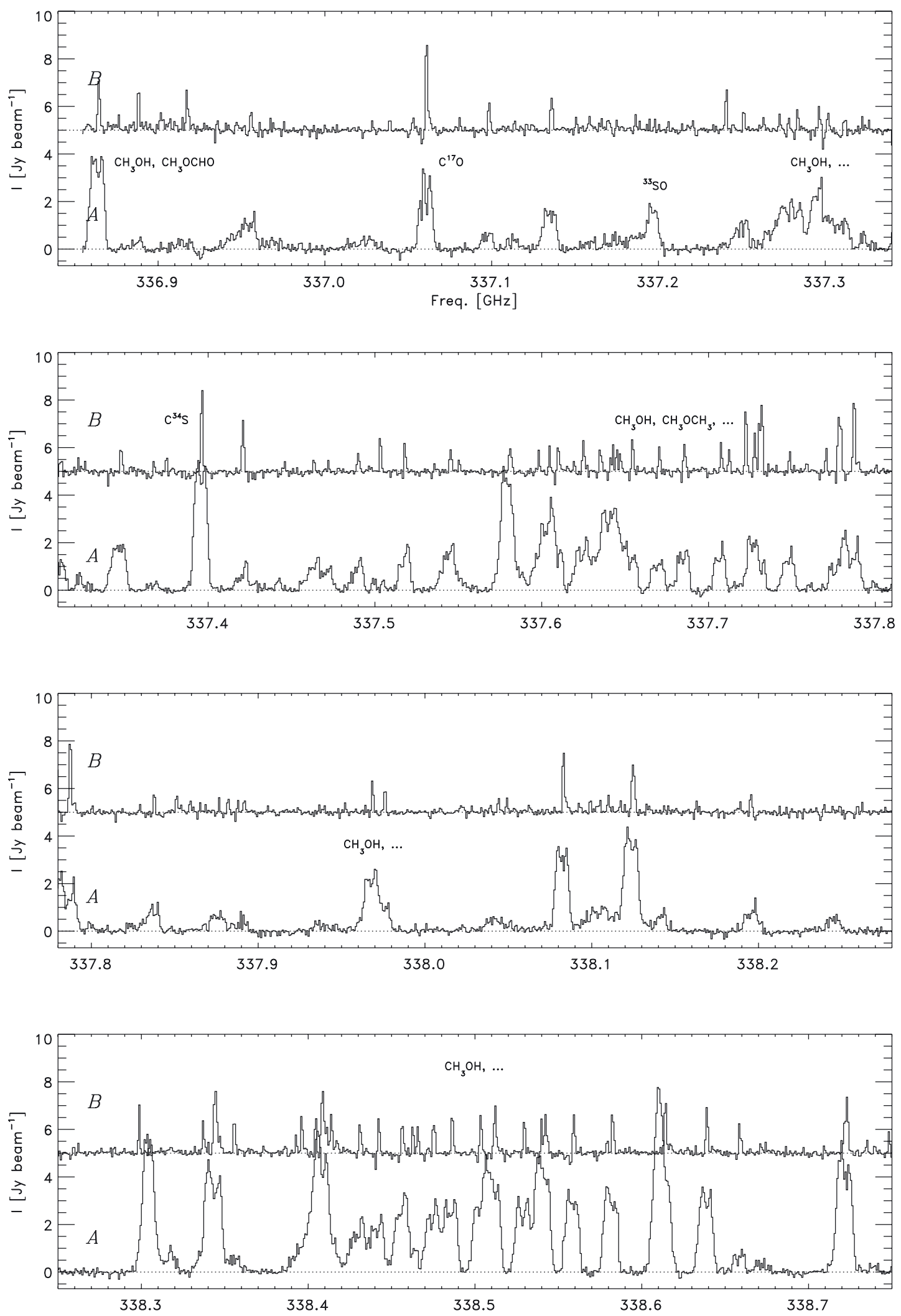

Fig. 6. As in Fig. 2 for the range 336.85-338.85 GHz (beam size $2.5^{\prime \prime} \times 1.6^{\prime \prime}$; line 3 of Table 1).

Figure 10 shows the cumulative distribution of the upper energy levels, $E_{\mathrm{u}}$, for the detected molecules - compared to the full catalog entries for the same species over the measured frequency ranges. The figure clearly illustrates the upper limit for the temperatures of the detected species - with approximately $90 \%$ of the detected molecular lines having $E_{\mathrm{u}}$ lower than $550 \mathrm{~K}$, compared to $50 \%$ of the catalog entries having $E_{\mathrm{u}}$ lower than this temperature.

For each detected line, the first and second moments (centroid velocity and dispersion) were estimated toward the positions of the two components by numerical integrations of the spectra over velocity intervals of $\pm 5 \mathrm{~km} \mathrm{~s}^{-1}$ around the expected 

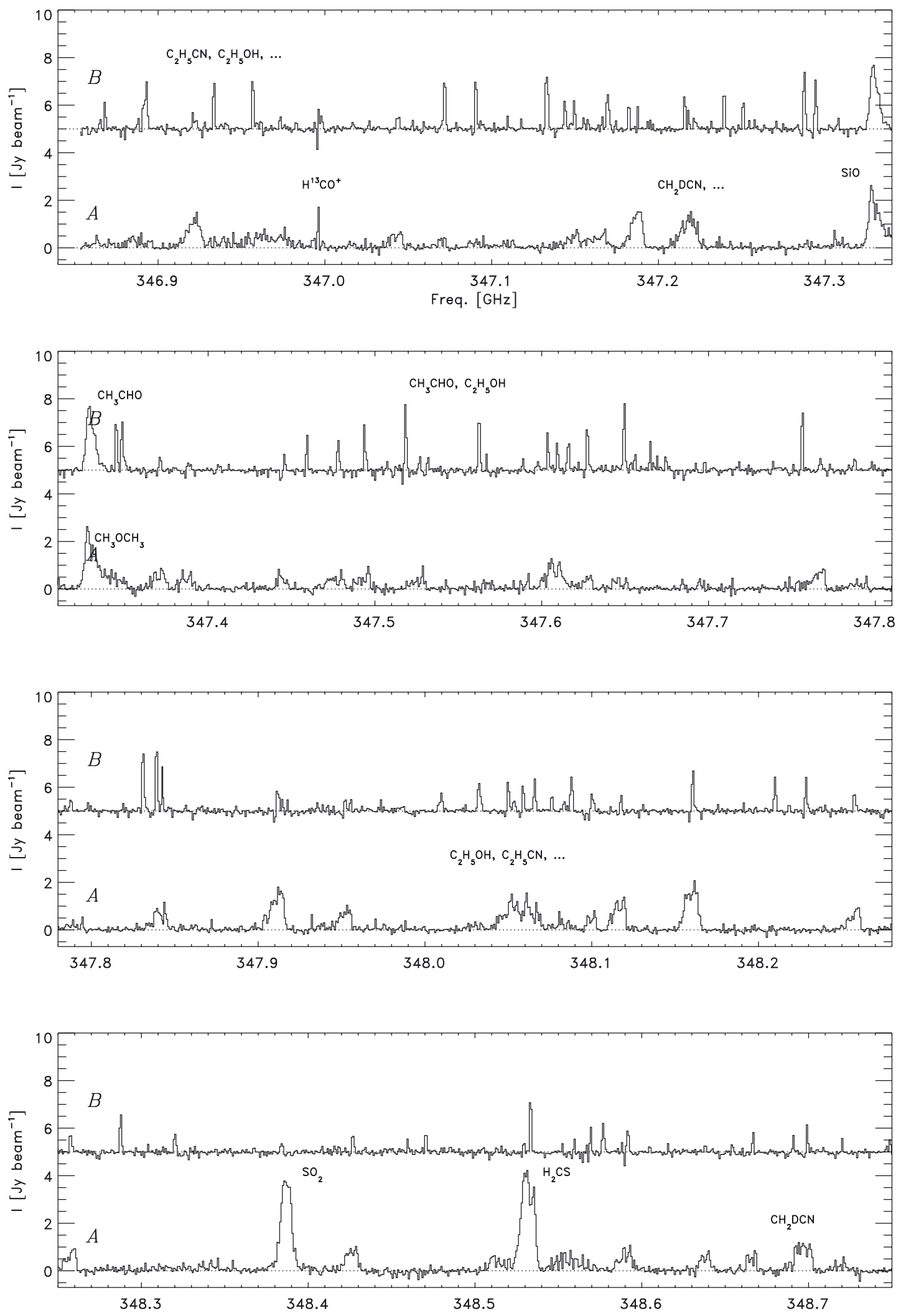

Fig. 7. As in Fig. 2 for the range 346.85-348.85 GHz (beam size $2.5^{\prime \prime} \times 1.6^{\prime \prime}$; line 3 of Table 1).

systemic velocity of each line at $\approx 3 \mathrm{~km} \mathrm{~s}^{-1}$. Figure 11 summarizes the distribution of these velocities. As expected from the above comments and previous findings in literature, the lines toward the IRAS 16293A continuum peak are on average wider and slightly more red-shifted than toward the IRAS 16293B peak (the peaks of the distributions in Fig. 11 shifted toward higher velocities). However, as illustrated by the figure, the distributions of both centroid velocities and dispersions are broader toward IRAS 16293B than IRAS 16293A. This suggests that the emission toward IRAS $16293 \mathrm{~B}$ can be divided into a set of lines localized for this source with another set of lines probing the more general environment of both sources in common. It is possible 

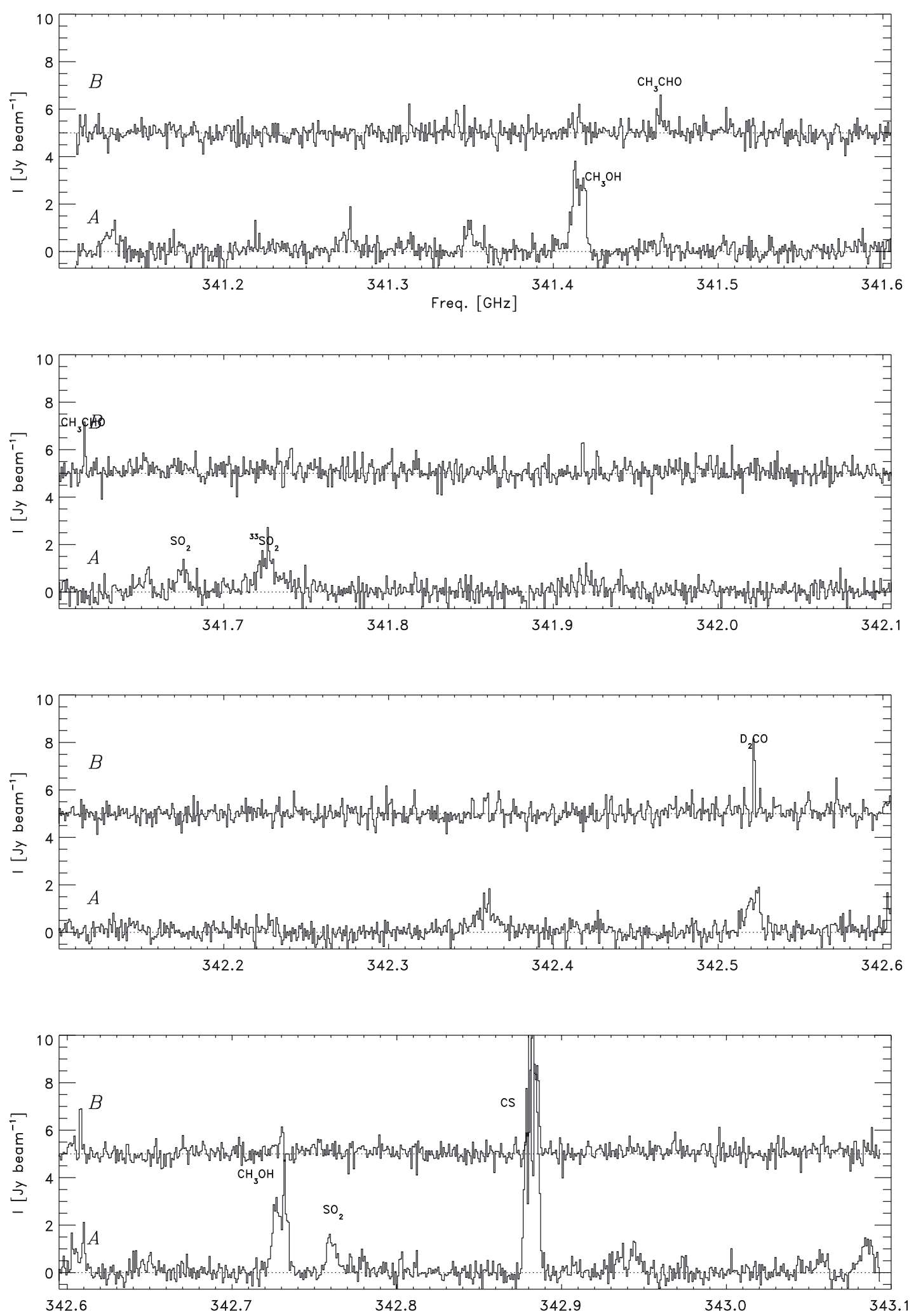

Fig. 8. As in Fig. 2 for the range 341.1-343.3 GHz (beam size 3.5" $\times 1.9^{\prime \prime}$; line 4 of Table 1).

that uncertainties in the determined line rest frequencies contribute to some of the scatter in this plot. However, since a large number of the lines are detected in both sources, it is unlikely that these uncertainties introduce the systematic shift and broadening of the lines between the two sources.

For each molecular species the emission from detected, isolated lines were integrated over $V_{\text {sys }} \pm \Delta V$ where $V_{\text {sys }}$ is the average centroid velocity for the IRAS 16293A component and $\Delta V$ the average line width. Compilations of the maps from the inner $24^{\prime \prime} \times 24^{\prime \prime}$ are shown in Figs. 12-15. In these plots, maps from different transitions for the same molecule have been added together weighted by their noise. For molecules with transitions in multiple frequency bands, data from one band only were used to keep the spatial resolution similar (see Table A.1). For 

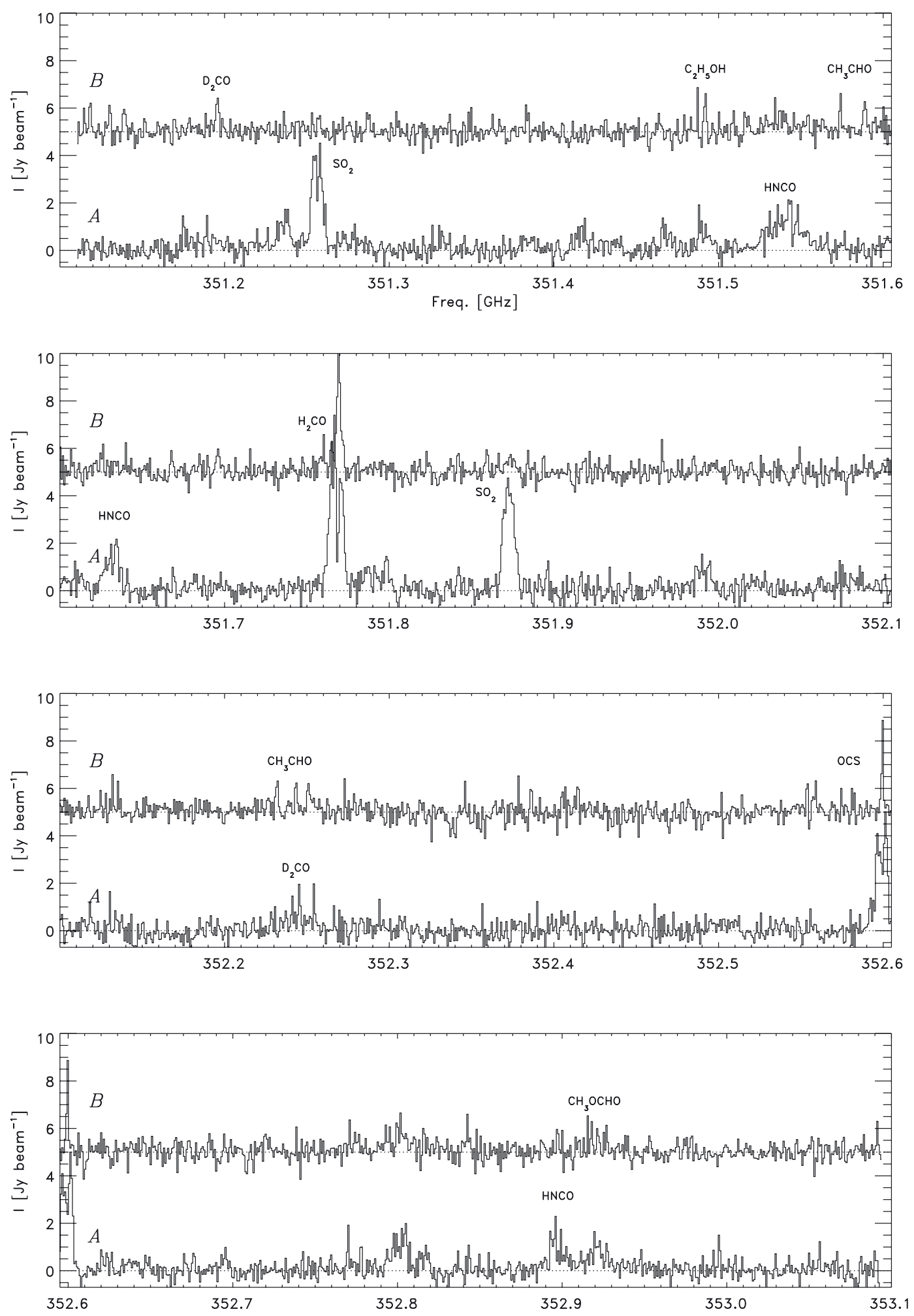

Fig. 9. As in Fig. 2 for the range 351.1-353.1 GHz (beam size 3.5" $\times 1.9^{\prime \prime}$; line 4 of Table 1).

molecules with a large number of detected lines with high $\mathrm{S} / \mathrm{N}$ spanning a range of energy levels, the integrations were subdivided into integrations over lines in different energy ranges.

\section{Results and discussion}

In this section we discuss the general features of the detected emission before going into a few more specific topics in detail.
Generally the integrated line emission maps of IRAS 162932422 can be divided into groups:

1. Maps with significant extended emission encompassing both sources but without clear peaks or with peaks offset from the continuum sources. Examples: $\mathrm{CO}, \mathrm{SiO}$ and $\mathrm{H}_{2} \mathrm{CO} 5_{1,5}-4_{1,4}$.

2. Maps with significant extended emission peaking on one or both continuum sources. Examples: ${ }^{13} \mathrm{CO}, \mathrm{C}^{18} \mathrm{O}, \mathrm{C}^{17} \mathrm{O}, \mathrm{CS}$ and isotopologues, $\mathrm{SO}, \mathrm{H}_{2} \mathrm{CO} / \mathrm{H}_{2}^{13} \mathrm{CO} 3_{1,2}-2_{1,1}, \mathrm{H}_{2} \mathrm{C}^{18} \mathrm{O}$. 
Table 1. Log of observations.

\begin{tabular}{lccccc}
\hline \hline $\begin{array}{l}\text { Frequency range } \\
{[\mathrm{GHz}]}\end{array}$ & Observed date & Beam size $^{a}$ & $\begin{array}{c}\text { Spectral resolution } \\
{\left[\mathrm{km} \mathrm{s}^{-1}\right]}\end{array}$ & $\begin{array}{c}\text { Sensitivity } \\
{\left[\mathrm{Jy} \mathrm{beam}^{-1} \text { chan }^{-1}\right]}\end{array}$ & $\begin{array}{c}\text { Projected baselines }^{b} \\
{[\mathrm{k} \lambda]}\end{array}$ \\
\hline $215.6-217.6 / 225.6-227.6$ & $2004-07-23$ & $5.5^{\prime \prime} \times 3.2^{\prime \prime}$ & 0.56 & 0.24 & $6-91$ \\
$219.4-221.4 / 229.4-231.4$ & $2005-02-18$ & $4.0^{\prime \prime} \times 2.4^{\prime \prime}$ & 1.1 & 0.062 & $7-54$ \\
$336.8-338.7 / 346.7-348.7$ & $2007-03-22$ & $2.5^{\prime \prime} \times 1.6^{\prime \prime}$ & 0.72 & 0.11 & $10-141$ \\
$341.2-343.1 / 351.1-353.1$ & $2005-08-14$ & $3.5^{\prime \prime} \times 1.9^{\prime \prime}$ & 0.36 & 0.60 & $11-82$ \\
\hline
\end{tabular}

Notes. ${ }^{(a)}$ With natural weighting. ${ }^{(b)}$ Range of projected interferometer baselines observed for given dataset measured in $\mathrm{k} \lambda$.

Table 2. Detected molecules.

\begin{tabular}{|c|c|c|c|c|c|c|c|c|}
\hline Molecules & $n_{\text {lines }}$ & $E_{\mathrm{u}}[\mathrm{K}]$ & Molecules & $n_{\text {lines }}$ & $E_{\mathrm{u}}[\mathrm{K}]$ & Molecules & $n_{\text {lines }}$ & $E_{\mathrm{u}}[\mathrm{K}]$ \\
\hline \multicolumn{9}{|c|}{$\mathrm{CO}, \mathrm{HCO}^{+}$and N-bearing species } \\
\hline $\mathrm{CO}$ & 1 & 16.6 & ${ }^{13} \mathrm{CO}$ & 1 & 15.9 & $\mathrm{C}^{18} \mathrm{O}$ & 1 & 15.8 \\
\hline $\mathrm{C}^{17} \mathrm{O}$ & 1 & 32.4 & $\mathrm{H}^{13} \mathrm{CO}^{+}$ & 1 & 41.6 & $\mathrm{HC}_{3} \mathrm{~N}$ & 1 & 141.9 \\
\hline $\mathrm{H}_{2} \mathrm{CN}$ & 4 & $21.1-175.4$ & $\mathrm{CH}_{3} \mathrm{CN}$ & 20 & $68.9-1291.5$ & $\mathrm{CH}_{3}{ }^{13} \mathrm{CN}$ & 8 & $68.8-646.6$ \\
\hline $\mathrm{C}_{2} \mathrm{H}_{5} \mathrm{CN}$ & 34 & $79.1-681.3$ & $\mathrm{HNCO}$ & 12 & $58.0-835.7$ & $\mathrm{HNC}^{18} \mathrm{O}$ & 1 & 195.5 \\
\hline \multicolumn{9}{|c|}{ O-bearing species } \\
\hline $\mathrm{H}_{2} \mathrm{CO}$ & 3 & $33.4-174.0$ & $\mathrm{H}_{2}{ }^{13} \mathrm{CO}$ & 1 & 32.9 & $\mathrm{H}_{2} \mathrm{C}^{18} \mathrm{O}$ & 5 & $97.4-239.6$ \\
\hline $\mathrm{CH}_{3} \mathrm{OH}$ & 62 & $39.8-802.2$ & ${ }^{13} \mathrm{CH}_{3} \mathrm{OH}$ & 5 & $87.1-302.5$ & $\mathrm{C}_{2} \mathrm{H}_{5} \mathrm{OH}$ & 37 & $74.4-1289.1$ \\
\hline $\mathrm{HCOOH}$ & 1 & 332.7 & $\mathrm{CH}_{2} \mathrm{CO}$ & 1 & 76.5 & $\mathrm{CH}_{3} \mathrm{CHO}$ & 101 & $22.9-864.6$ \\
\hline $\mathrm{CH}_{3} \mathrm{OCH}_{3}$ & 26 & $48.0-952.8$ & $\mathrm{CH}_{3} \mathrm{OCHO}-\mathrm{A}$ & 35 & $81.4-604.3$ & $\mathrm{CH}_{3} \mathrm{OCHO}-\mathrm{E}$ & 43 & $56.9-629.8$ \\
\hline$\left(\mathrm{CH}_{3}\right)_{2} \mathrm{CO}$ & 28 & 29.9-700.8 & & & & & & \\
\hline \multicolumn{9}{|c|}{ S-bearing species } \\
\hline CS & 1 & 65.8 & $\mathrm{C}^{34} \mathrm{~S}$ & 1 & 64.8 & ${ }^{13} \mathrm{CS}$ & 1 & 33.3 \\
\hline $\mathrm{H}_{2} \mathrm{~S}$ & 1 & 84.0 & $\mathrm{H}_{2} \mathrm{CS}$ & 2 & $102.4-105.2$ & $\mathrm{H}_{2} \mathrm{C}^{34} \mathrm{~S}$ & 1 & 141.8 \\
\hline $\mathrm{HCS}^{+}$ & 1 & 73.7 & OCS & 2 & $110.9-253.9$ & $\mathrm{O}^{13} \mathrm{CS}$ & 2 & $110.5-253.1$ \\
\hline SO & 1 & 35.0 & ${ }^{33} \mathrm{SO}$ & 5 & $25.4-80.5$ & ${ }^{34} \mathrm{SO}$ & 2 & $25.3-34.4$ \\
\hline $\mathrm{SO}_{2}$ & 10 & $35.9-678.5$ & ${ }^{33} \mathrm{SO}_{2}$ & 5 & $52.4-118.5$ & ${ }^{34} \mathrm{SO}_{2}$ & 5 & $18.7-247.8$ \\
\hline $\mathrm{SO}^{18} \mathrm{O}$ & 3 & $49.0-522.1$ & $\mathrm{SO}^{17} \mathrm{O}$ & 2 & $102.8-103.3$ & & & \\
\hline \multicolumn{9}{|c|}{$\mathrm{SiO}$ and deuterated species } \\
\hline $\mathrm{SiO}$ & 2 & $31.3-75.0$ & $\mathrm{~N}_{2} \mathrm{D}^{+}$ & 1 & 22.2 & $\mathrm{DCO}^{+}$ & 1 & 20.7 \\
\hline DCN & 1 & 20.9 & HDCS & 1 & 51.5 & $\mathrm{D}_{2} \mathrm{CS}$ & 3 & $105.8-207.5$ \\
\hline $\mathrm{DCS}^{+}$ & 1 & 36.3 & $\mathrm{D}_{2} \mathrm{CO}$ & 6 & $32.0-285.5$ & $\mathrm{D}_{2}{ }^{13} \mathrm{CO}$ & 1 & 57.2 \\
\hline $\mathrm{CH}_{2} \mathrm{DCN}$ & 9 & $24.1-309.7$ & HCOOD & 2 & $34.3-386.6$ & HDO & 1 & 167.6 \\
\hline
\end{tabular}

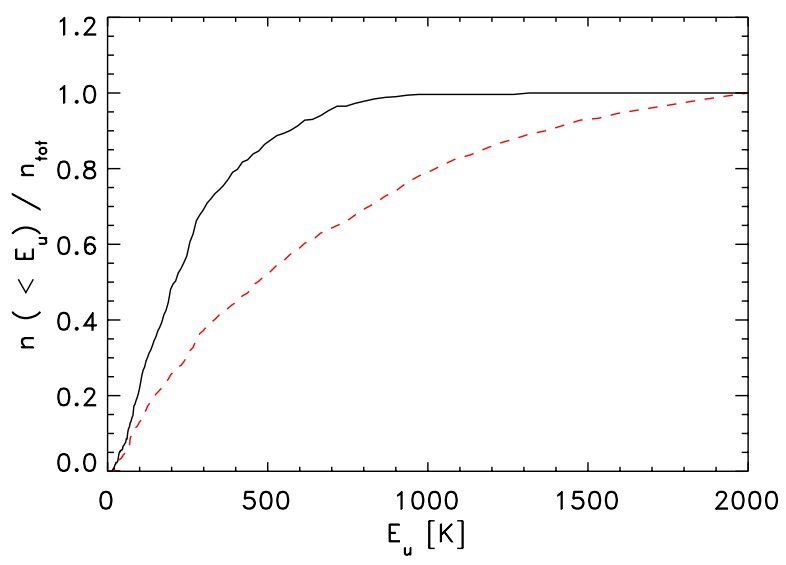

Fig. 10. Cumulative distribution of the upper energy levels for the detected transitions (solid line) and all transitions in the search frequency range for the detected molecules (dashed line).

3. Maps with localized peaks at the continuum sources, with IRAS 16293A being significantly stronger than IRAS 16293B (the latter in a few cases even absent). Examples: nitrogen- and sulfur-bearing species (including $\mathrm{HC}_{3} \mathrm{~N}, \mathrm{CH}_{3} \mathrm{CN}, \mathrm{HNCO}$, isotopologues of $\mathrm{SO}, \mathrm{SO}_{2}, \mathrm{OCS}$ among others), most deuterium-bearing species, $\mathrm{CH}_{3} \mathrm{OH}$ and its ${ }^{13} \mathrm{C}$ isotopologue.
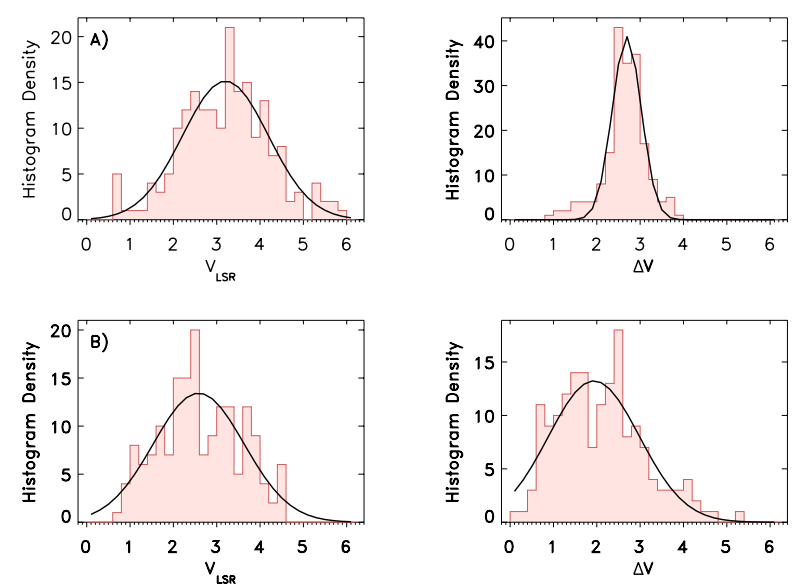

Fig. 11. Distribution of centroid velocities and widths (dispersions) in the left and right panels, respectively for emission lines detected toward the A source (upper panels) and B source (lower panels). Gaussian fits to the distributions are over-plotted ( $V_{\mathrm{LSR}}$ of 3.2 and $2.7 \mathrm{~km} \mathrm{~s}^{-1}$ and $\Delta V$ of 2.6 and 1.9 for $\mathrm{A}$ and $\mathrm{B}$ respectively). The $V_{\mathrm{LSR}}$ and $\Delta V$ distributions for the two sources are significantly different according to a standard $\mathrm{T}$ test for distributions with unequal variances.

4. Maps with localized peaks at the continuum sources, with the two peaks being approximately similar in strength. Examples: $\mathrm{CH}_{3} \mathrm{OCH}_{3}, \mathrm{CH}_{3} \mathrm{OCHO}, \mathrm{D}_{2} \mathrm{CO}$. 


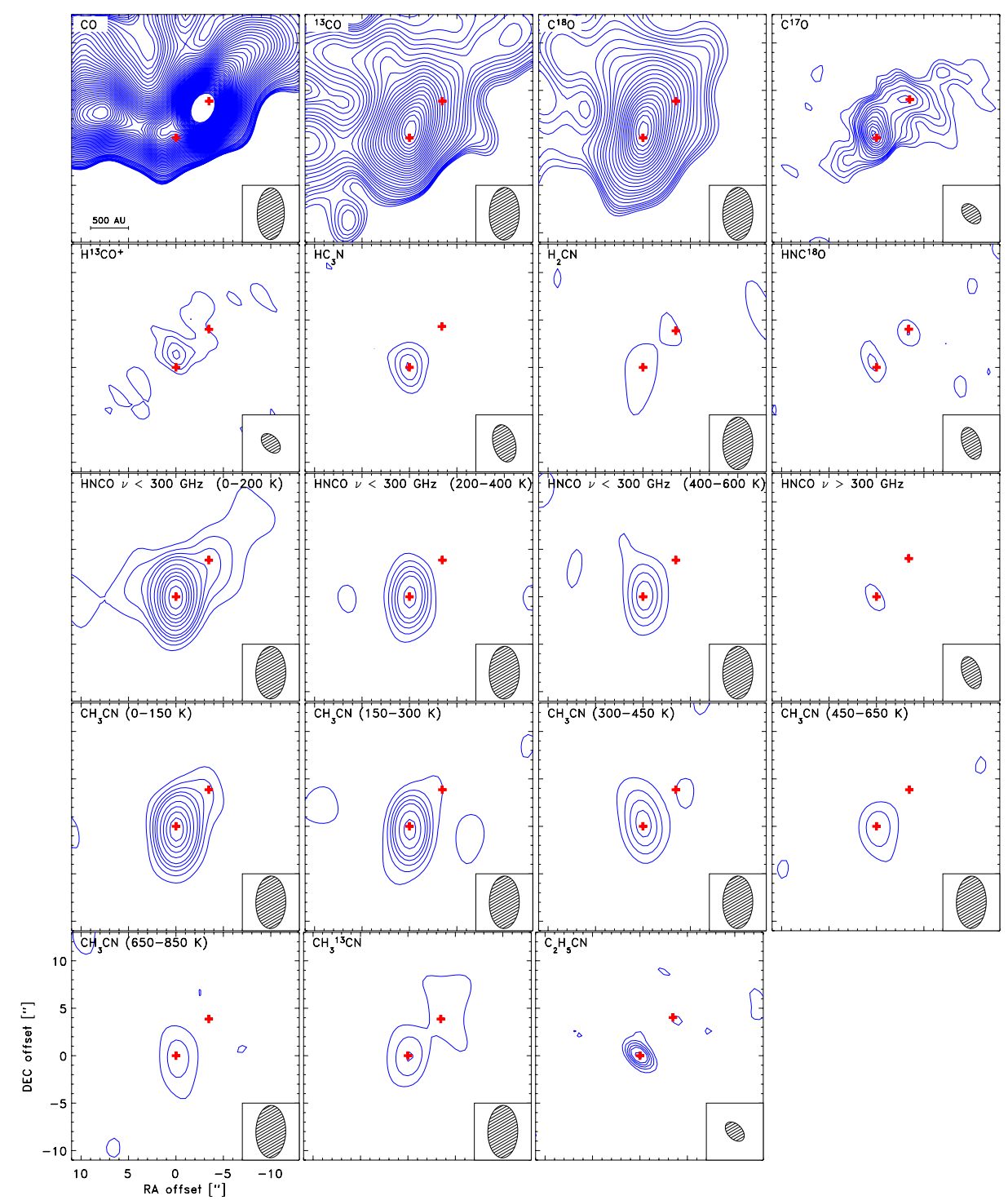

Fig. 12. Emission for $\mathrm{CO}, \mathrm{HCO}^{+}$and the N-bearing organic molecules. For each molecule, except where noted otherwise, the emission has been integrated over all identified lines in one selected frequency band - isolated by at least $10 \mathrm{MHz}$ from other species (see Table A.1 for specific lines). The integration is performed over the width of the "A" component (i.e., from 0 to $6 \mathrm{~km} \mathrm{~s}^{-1}$ ) and contours are shown in steps of $3 \sigma$ to $15 \sigma$ and in steps of $6 \sigma$ thereafter, where $\sigma$ is the rms noise level for the integrated line intensity; the rms per channel is given in Table 1. A scale-bar is shown in the upper left panel. The beam size at the frequency of the selected transitions for the given molecule is shown in the lower right corner of each panel.

5. Maps with localized peaks at the continuum sources, with IRAS 16293B source being stronger than IRAS 16293A. Examples: $\mathrm{CH}_{3} \mathrm{CHO}, \mathrm{CH}_{2} \mathrm{CO}$.

6. Maps with extended faint emission not strongly correlated with the continuum peaks. Examples: $\mathrm{N}_{2} \mathrm{D}^{+}, \mathrm{H}^{13} \mathrm{CO}^{+}$, $\mathrm{DCO}^{+}$.

These maps underline the complicated structure of the protostellar system: the overlap between the emission in, e.g., the extended dense gas tracers suggest that the two sources are embedded in one larger-scale connected envelope, whose column density peaks close to IRAS 16293A. A fainter local maximum in column density is present toward IRAS 16293B, however. The absence of this secondary peak in, e.g., the maps of ${ }^{13} \mathrm{CO}$ and $\mathrm{C}^{18} \mathrm{O}$ (Fig. 16, upper panels) suggest that these species are becoming optically thick on scales close to the spatial scales probed by the interferometric observations. A particular clear example of that is seen in the emission from $3_{1,2}-2_{1,1}$ transitions of $\mathrm{H}_{2} \mathrm{CO}$ and $\mathrm{H}_{2}^{13} \mathrm{CO}$ : for those two species an inversion is seen with the main $\mathrm{H}_{2}^{12} \mathrm{CO}$ isotopologue being stronger toward IRAS $16293 \mathrm{~A}$ while the fainter $\mathrm{H}_{2}^{13} \mathrm{CO}$ isotopologue is stronger toward IRAS 16293B (Fig. 16, lower panels). The two transitions also appear close to identical in strength in the maps - further indicating a high optical thickness of the main isotopologue and significant resolved-out emission. Optical depth effects and general surface brightness sensitivity may also explain the differences between for example the main isotologue of $\mathrm{SO}$ and the fainter species $\left({ }^{33} \mathrm{SO},{ }^{34} \mathrm{SO}\right)$ : the latter may also be extended similar to the main isotopologue, but with too low surface brightnesses to be picked up by the SMA observations. A few species show very strongly differentiated emission between the two sources. The sulfur-species $\left(\mathrm{SO}_{2}\right.$ in particular) are strongly concentrated toward IRAS 16293A while a few of the complex organics $\left(\mathrm{CH}_{3} \mathrm{CHO}\right.$ in particular) appear most prominently toward IRAS 16293B. As the lines of the different species are not significantly different in excitation temperatures, these 


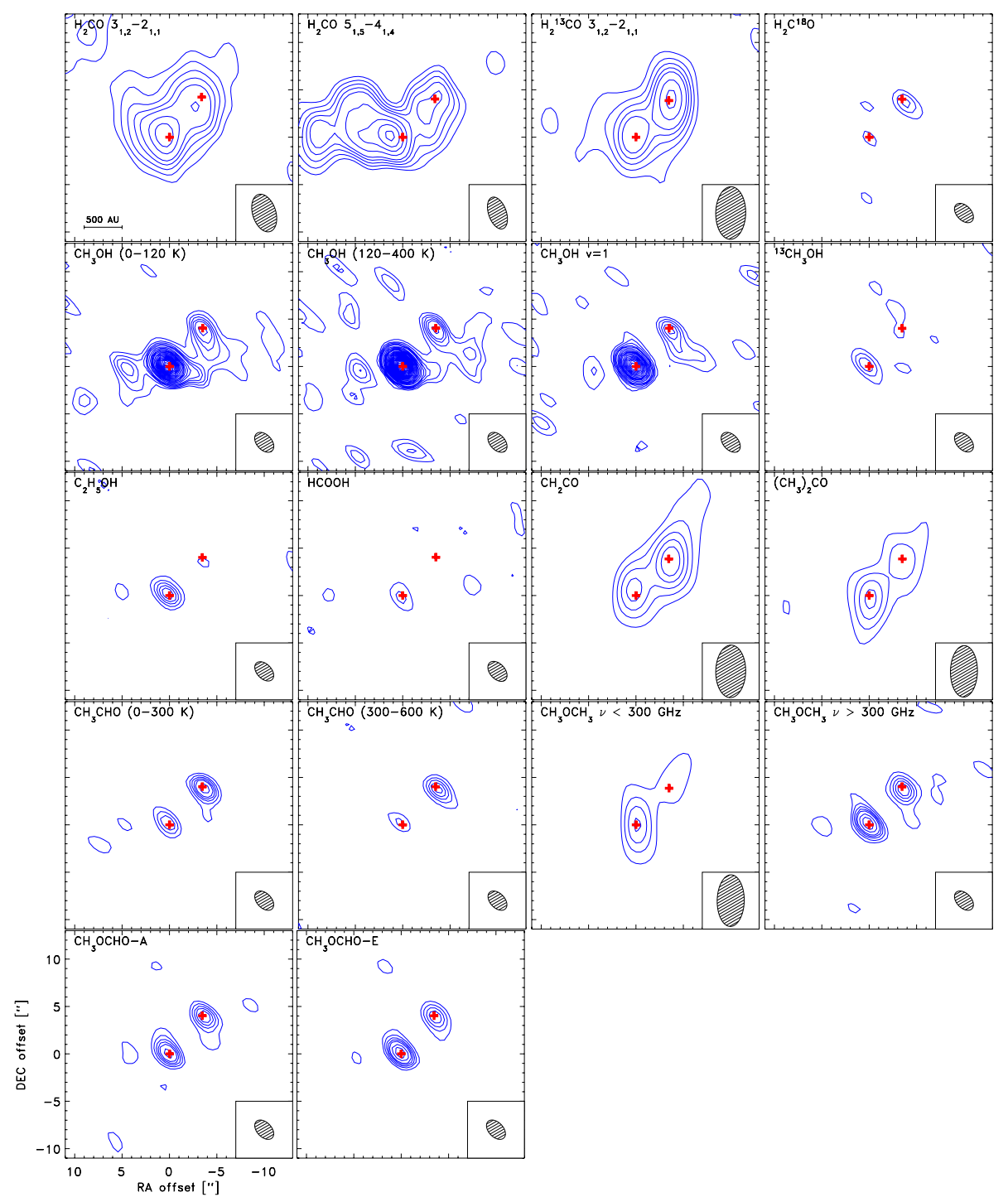

Fig. 13. As in Fig. 12 for the O-bearing organic molecules.

differences in their relative prominences point to different chemical structures of the two components in IRAS 16293-2422 possibly reflecting differences in their physical evolution.

\subsection{Cold envelope chemistry}

Although a natural focus in the submillimeter interferometric observations is on the higher excited lines, warmer gas and the small-scale structure close to protostars themselves, the high resolution offered by the interferometric observations provides interesting insights into the chemistry in the colder envelope on large scales. The survey includes a number of species that predominantly are present in the cold 20-30 K gas and/or very sensitive to changes in chemistry occurring at these temperatures.

One clear example is offered by a comparison between $\mathrm{C}^{18} \mathrm{O}$, $\mathrm{DCO}^{+}$and $\mathrm{N}_{2} \mathrm{D}^{+}$(Fig. 17). The emission from these three species are all mainly associated with IRAS 16293A, and all show significant emission extending over $5-10^{\prime \prime}$ scales. $\mathrm{C}^{18} \mathrm{O}$ is the species located closest to the continuum peak. $\mathrm{DCO}^{+}$is also present there, but shows its maximum offset by $3-4^{\prime \prime}$. The $\mathrm{N}_{2} \mathrm{D}^{+}$transition in contrast does not show any emission at the continuum $/ \mathrm{C}^{18} \mathrm{O}$ peaks, but is offset in the same direction of
$\mathrm{DCO}^{+}$with its peak shifted even further. Of course, the "absorption feature" of $\mathrm{N}_{2} \mathrm{D}^{+}$toward IRAS $16293 \mathrm{~B}$ indicates that this species is also present along line of sights toward the central protostars, but simply resolved-out. It is likely that something similar is the case for $\mathrm{DCO}^{+}$as well. Still, the maps reveal the differences between the brightest spots in the emission in each of the molecular species, reflecting that their underlying spatial distributions also differ.

Figure 17 shows the temperature from self-consistent dust radiative transfer models of IRAS 16293-2422 (Schöier et al. 2002; Jørgensen et al. 2005a). In those papers, the structure of IRAS 16293-2422 is modeled as a single spherical protostellar dust envelope heated by a central source of luminosity. Using the spectral energy distribution and submillimeter continuum maps to constrain the envelope density structure, the models then calculate the temperature distribution as function of radius self-consistently. For this plot, we locate the envelope at the position of IRAS 16293A and assign half the total luminosity to this source. It is seen that the differentiation between $\mathrm{CO}, \mathrm{DCO}^{+}$ and $\mathrm{N}_{2} \mathrm{D}^{+}$is taking place at scales corresponding to the radii of $20-30 \mathrm{~K}$ in the envelope. The comparison to these spherical models is naturally a simplification because of the binarity of the system: the dust and gas in the northern-western part envelope 


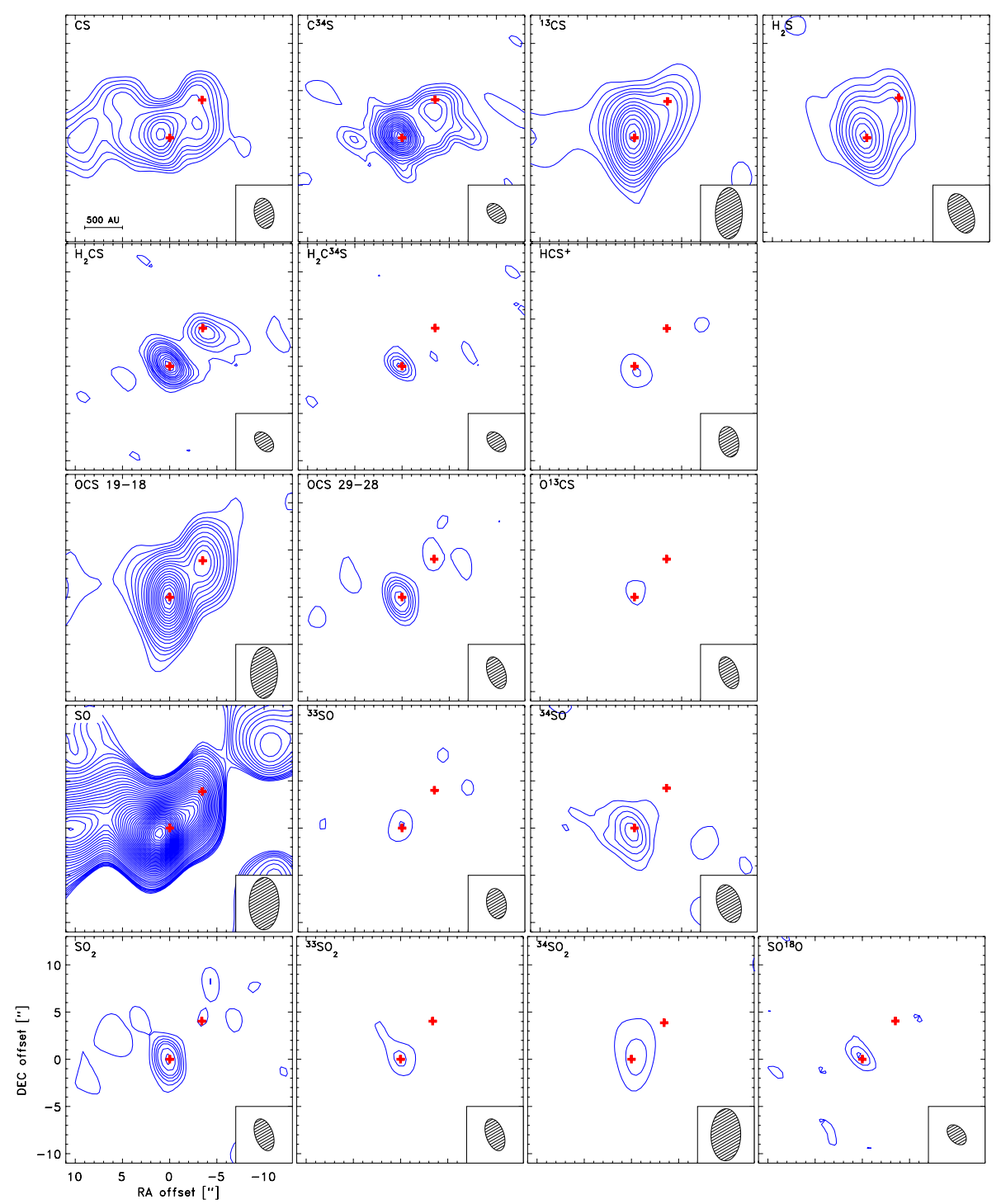

Fig. 14. As in Fig. 12 for the S-bearing molecules.

is likely affected by the presence of IRAS 16293B, as also suggested by the absence of the line emission there.

The differentiation between $\mathrm{C}^{18} \mathrm{O}, \mathrm{DCO}^{+}$and $\mathrm{N}_{2} \mathrm{D}^{+}$can be understood in the context of the gas-phase chemistry of the cold envelope gas (Fig. 18): CO has been shown to be freezing out significantly at low temperatures in the outer regions of protostellar envelopes, desorbing off the dust grains once the temperature increases to $\approx 30 \mathrm{~K}$ (e.g., Jørgensen et al. 2002, 2005b). This gives a primary peak of the $\mathrm{C}^{18} \mathrm{O}$ emission associated with the compact continuum emission marking the location of the protostar itself as seen in Fig. 17. At larger radii and low temperatures, the freeze-out of $\mathrm{CO}$ gives a boost to $\mathrm{DCO}^{+}$and $\mathrm{N}_{2} \mathrm{D}^{+}: \mathrm{DCO}^{+}$is tied to the $\mathrm{CO}$ abundance through the reaction $\mathrm{H}_{2} \mathrm{D}^{+}+\mathrm{CO} \rightarrow \mathrm{DCO}^{+}$. This takes place most efficiently at temperatures lower than $30 \mathrm{~K}$ where the amounts of $\mathrm{H}_{2} \mathrm{D}^{+}$increases due to the small energy difference in the reaction:

$\mathrm{H}_{3}^{+}+\mathrm{HD} \rightarrow \mathrm{H}_{2} \mathrm{D}^{+}+\mathrm{H}_{2}$

(Roberts \& Millar 2000). At temperatures higher than $30 \mathrm{~K}$ in contrast, $\mathrm{H}_{2} \mathrm{D}^{+}$is rapidly transformed into $\mathrm{H}_{3}^{+}$through reactions with $\mathrm{H}_{2}$ and then further incorporated into $\mathrm{HCO}^{+}$through reactions with $\mathrm{CO}$. This effect is similar for $\mathrm{N}_{2} \mathrm{D}^{+}-$except that it is even further enhanced by the fact that any $\mathrm{CO}$ present in the gas will work very efficiently in destroying $\mathrm{N}_{2} \mathrm{D}^{+}$, thus limiting it even further $\left(\mathrm{N}_{2} \mathrm{H}^{+}\right.$is also enhanced in the colder, $\mathrm{CO}$ depleted, gas - because of the lack of its primary destruction agent; see, e.g., Jørgensen et al. 2004). One would therefore expect a sequence in the presence of these three species with $\mathrm{CO}$ being present most closely to the center, $\mathrm{DCO}^{+}$following this at slightly lower temperatures and $\mathrm{N}_{2} \mathrm{D}^{+}$at the lowest temperatures (Fig. 18). This scenario is in qualitative agreement with what is seen in the SMA data with the species peaking at the distances expected from the temperature of the protostellar envelope given its temperature profile in a simple spherical model (Fig. 17).

\subsection{The importance of the outflows in IRAS 16293-2422}

The outflow activity in IRAS 16293-2422 has been the topic of many discussions in literature - both in terms of the larger scales probed by single-dish observations and on smaller scales trying to identify what outflows are driven by each of the components. CO line emission toward IRAS 16293-2422 show a characteristic quadrupolar structure (Walker et al. 1988), which could reflect its binary nature. Stark et al. (2004) suggested that this quadrupolar morphology could be interpreted as being a superposition of an older outflow in the East-West direction driven by 


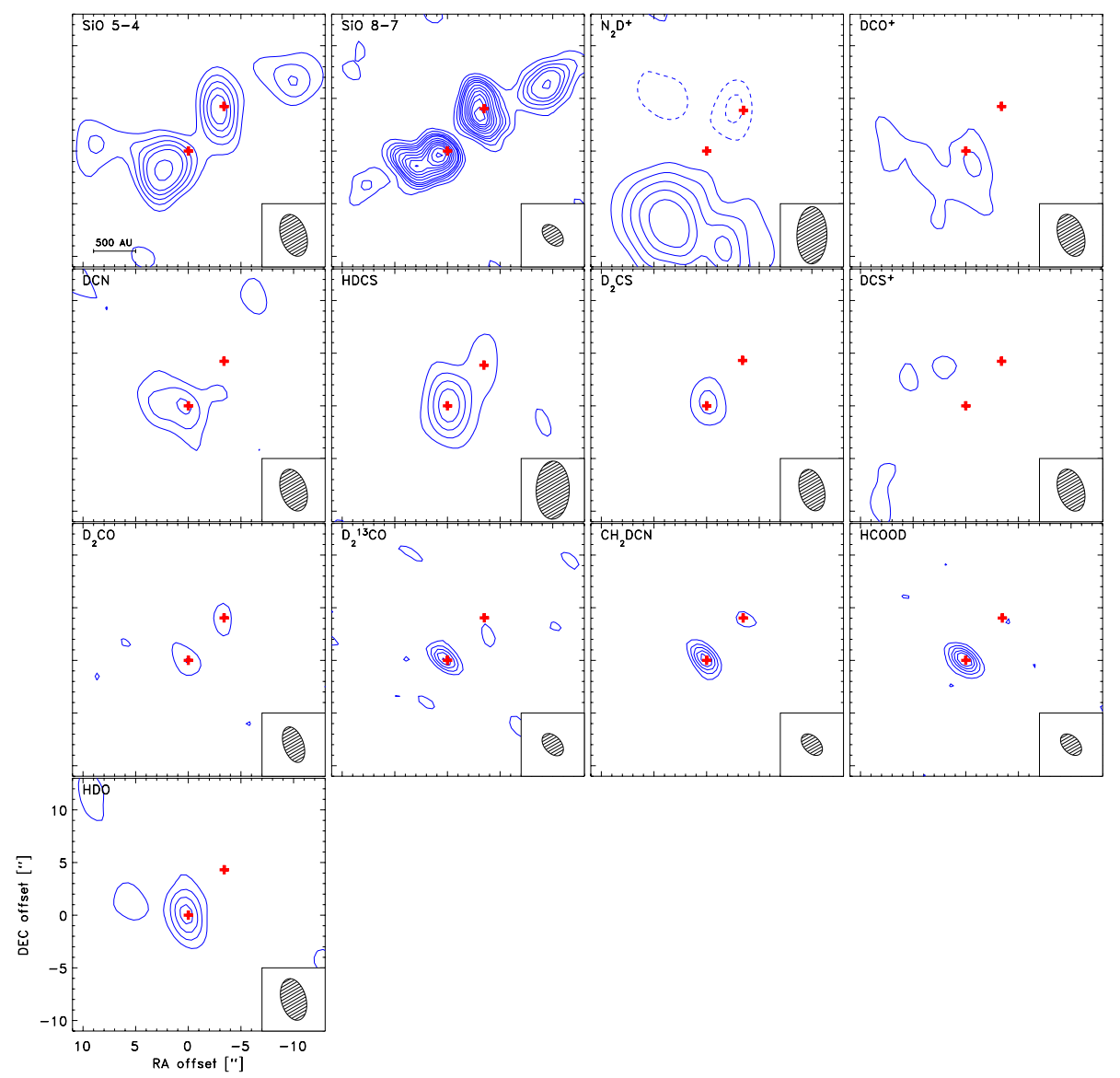

Fig. 15. As in Fig. 12 for $\mathrm{SiO}$ and the deuterated molecules. For the $\mathrm{N}_{2} \mathrm{D}^{+}$panel the observed "absorption" feature is illustrated by the dashed contours corresponding to negative contour levels.

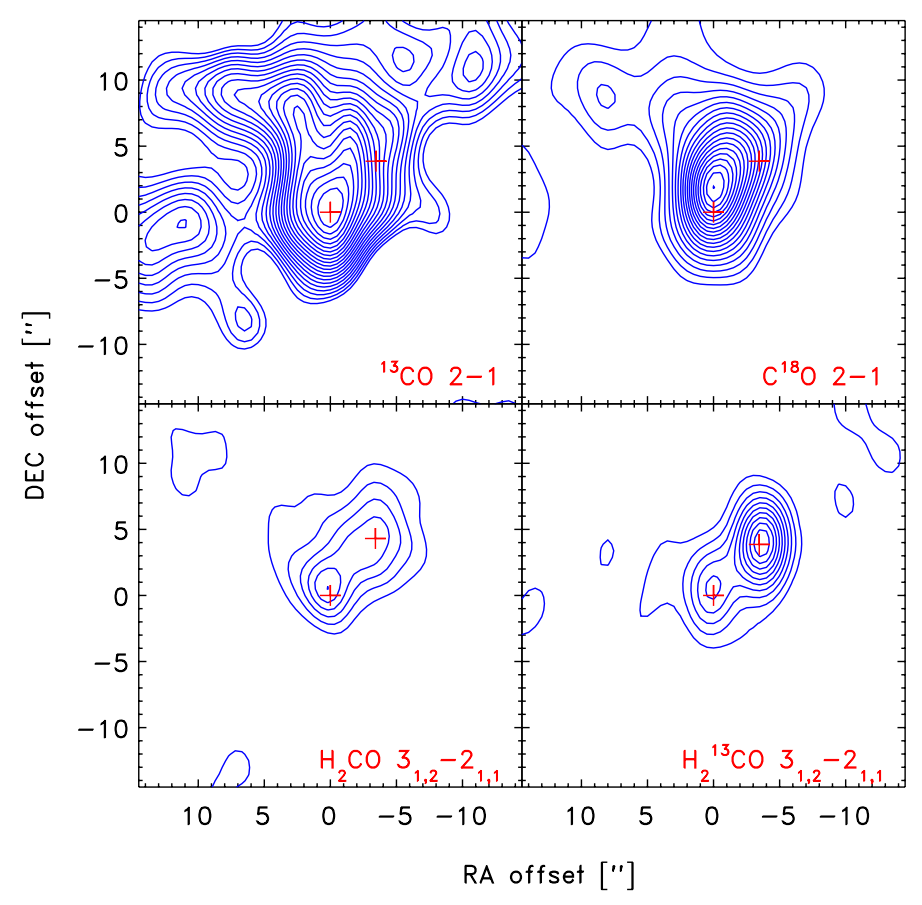

Fig. 16. Comparison between ${ }^{13} \mathrm{CO} 2-1$ (upper left), $\mathrm{C}^{18} \mathrm{O} 2-1$ (upper right), $\mathrm{H}_{2} \mathrm{CO} 3_{1,2}-2_{1,1}$ (lower left) and $\mathrm{H}_{2}^{13} \mathrm{CO} 3_{1,2}-2_{1,1}$ (lower right). For all species the emission is integrated from 1 to $5 \mathrm{~km} \mathrm{~s}^{-1}$. The contours are shown in steps of $9 \mathrm{Jy} \mathrm{beam}^{-1} \mathrm{~km} \mathrm{~s}^{-1}$ for the $\mathrm{CO}$ isotopologues and $3 \mathrm{Jy} \mathrm{beam}^{-1} \mathrm{~km} \mathrm{~s}^{-1}$ for the $\mathrm{H}_{2} \mathrm{CO}$ isotopologues.
IRAS 16293B and a younger outflow in the Northeast/Southwest direction driven by IRAS 16293A. This led these authors to suggest that the IRAS 16293B in fact was the older of these two sources - possibly a low luminosity T Tauri star. This view has, however, been challenged by high resolution $\mathrm{CO}$ observations showing that the East-West outflow is unambiguously associated with IRAS 16293A (e.g., Yeh et al. 2008). On the smallest scales in the system, it remains an important question if the outflows play a role in regulating the temperature and density structure: through the high angular resolution $\mathrm{CO} 2-1$ and 3-2 maps Yeh et al. (2008) for example showed the existence of two bright spots in their outflow maps offset by about $1^{\prime \prime}$ from the two protostars and toward IRAS16293A in particular, Chandler et al. (2005) showed that excitation transitions of a number of other species were offset likely due to the impact of this outflow (in particular, their Fig. 21).

Besides $\mathrm{CO}$ often used tracers of outflow emission are the transitions of $\mathrm{SiO}$ (in particular, $J=2-1,5-4$ and 8-7) thought to be the result of silicon in atomic form sputtering off dust grains and reacting with $\mathrm{OH}$ in the gas-phase producing $\mathrm{SiO}$ in the process (e.g., Schilke et al. 1997). The larger scale environment of IRAS 16293-2422 has been mapped in the line of SiO 2-1 with single-dish telescopes (Hirano et al. 2001; Castets et al. 2001) and used for discussions of the relation between the $\mathrm{SiO}$ emission and the protostellar outflows.

Ceccarelli et al. (2000) discussed multi-transition single-dish observations of the $\mathrm{SiO}$ emission at the location of the central protostellar binary and analyzed the emission in the context of models of a spherical collapsing envelope. They demonstrated 


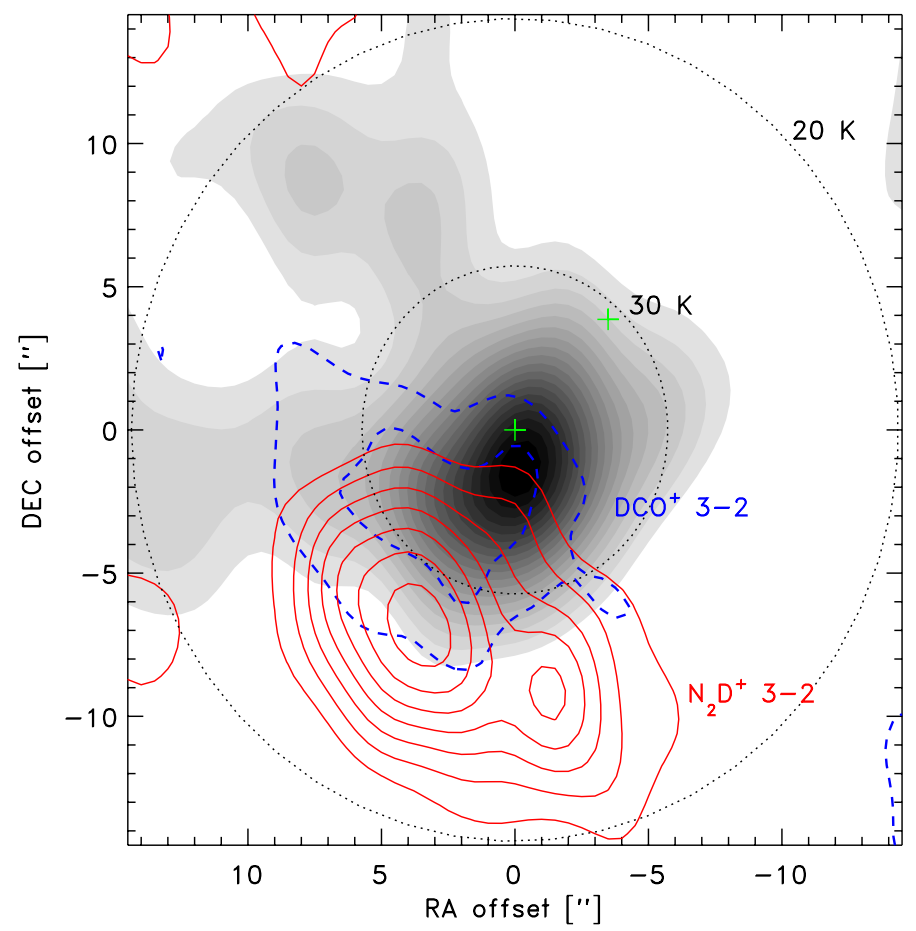

Fig. 17. Comparison between the $\mathrm{C}^{18} \mathrm{O} 2-1$ (grey-scale), $\mathrm{DCO}^{+} 3-2$ (dashed blue contours) and $\mathrm{N}_{2} \mathrm{D}^{+} 3-2$ toward the core. The lines are integrated from velocities of 3-7 $\mathrm{km} \mathrm{s}^{-1}\left(\mathrm{C}^{18} \mathrm{O}\right.$ and $\left.\mathrm{N}_{2} \mathrm{D}^{+}\right)$and $4-6 \mathrm{~km} \mathrm{~s}^{-1}$ $\left(\mathrm{DCO}^{+}\right)$. The dotted circles indicate the projected radii, where the dust temperature from radiative transfer calculations (Schöier et al. 2002; Jørgensen et al. 2005a) has dropped to $30 \mathrm{~K}$ and $20 \mathrm{~K}$, respectively assuming that the IRAS 16293A component is the sole source of luminosity and that the envelope is centered on this source.

that the $\mathrm{SiO}$ emission could be explained within this model if the $\mathrm{SiO}$ abundance increased from a low ("molecular cloud") value of $4 \times 10^{-12}$ to a "warm" value of $1.5 \times 10^{-8}$. They noted that in this model, the bulk of the observed $\mathrm{SiO} 5-4$ emission arises at a distance less than $150 \mathrm{AU}$ from the central source where the infall velocity is large, about $2.8 \mathrm{~km} \mathrm{~s}^{-1}$ in their model, consistent with the large line width seen in the single-dish observations.

The observations presented here show that this model does not provide an adequate description of the emission morphology of these $\mathrm{SiO}$ transitions. In fact, both the $J=5-4$ and 8-7 transitions show emission significantly extended on scales comparable to typical single-dish beams extending over the two protostellar sources with localized peaks close to the two protostars. In IRAS 16293A, the $\mathrm{SiO}$ emission peaks slightly east of the central protostar close to the location of the bright $\mathrm{CO}$ spot reported by Yeh et al. (2008), whereas the emission toward IRAS 16293B is slightly extended around the position of the central protostar and the CO bright spot associated with that source - but not uniquely associated with either. Generally, very few low-mass protostars show significant $\mathrm{SiO}$ line emission (e.g., Jørgensen et al. 2007), so the strong detection toward IRAS 16293-2422 (e.g., Blake et al. 1994) is notable in itself. SiO is thought to be produced by sputtering of silicon of dust grains in shocks, reacting with $\mathrm{OH}$ once in the gas-phase. This would suggest that the shock activity is prominent both in the vicinity of IRAS 16293A and IRAS 16293B - despite the absence of a clear CO outflow driven by the latter. It is therefore likely that the outflow driven shock is affecting the physics and chemistry of the gas in the immediate vicinity of IRAS 16293B. Higher resolution observations of the kinematics of the gas at this position are needed to

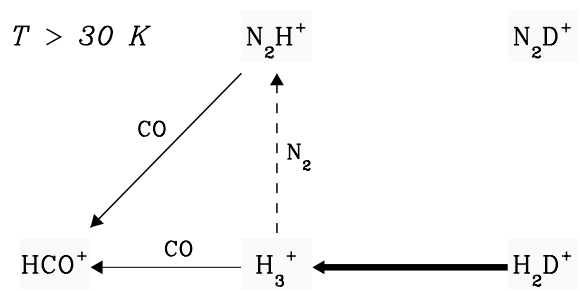

$\mathrm{DCO}^{+}$
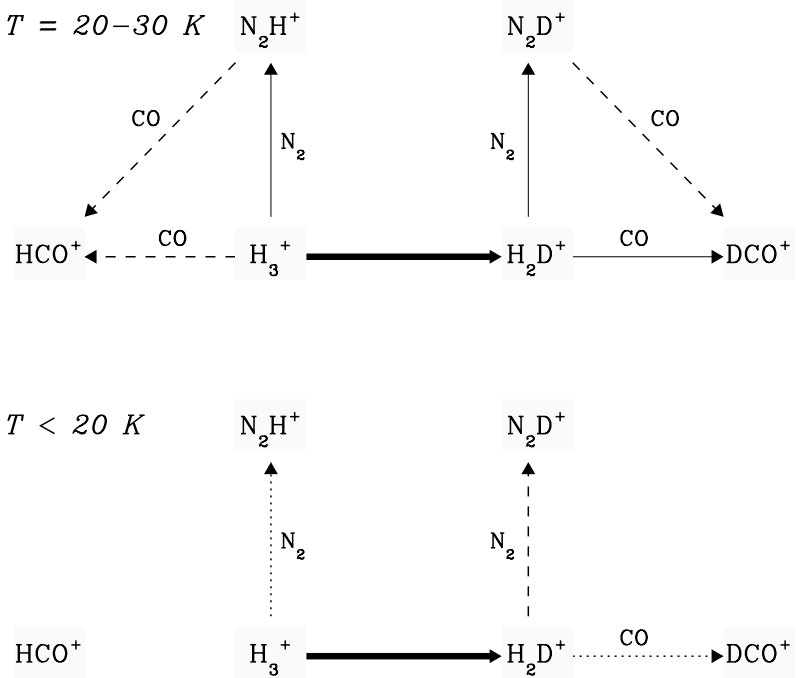

Fig. 18. Schematic chemical network for $\mathrm{HCO}^{+}, \mathrm{DCO}^{+}, \mathrm{N}_{2} \mathrm{D}^{+}$and $\mathrm{N}_{2} \mathrm{H}^{+}$in different regions of protostellar envelopes: at high temperatures $(T>30 \mathrm{~K}) \mathrm{CO}$ is in the gas-phase and $\mathrm{H}_{3}^{+}$is dominating over $\mathrm{H}_{2} \mathrm{D}^{+}$(the reaction in Eq. (1) proceeds to the left) enhancing $\mathrm{HCO}^{+}$and destroying $\mathrm{N}_{2} \mathrm{H}^{+}$. At intermediate temperatures $(T=20-30 \mathrm{~K}) \mathrm{CO}$ depletion and $\mathrm{H}_{2} \mathrm{D}^{+}$production starts to kick-in (the reaction in Eq. (1) proceeds to the right), enhancing $\mathrm{N}_{2} \mathrm{H}^{+}$(less destruction through $\mathrm{CO}$ ) and the deuterated species $\left(\mathrm{DCO}^{+}\right.$in particular, through reactions between $\mathrm{H}_{3}^{+}$and $\mathrm{CO}$ ). At low temperatures $\mathrm{CO}$ depletion is very significant and $\mathrm{N}_{2} \mathrm{D}^{+}$is enhanced relative to the other species.

clarify the importance of these shocks compared to the radiation by the embedded protostar.

\subsubsection{HDO emission}

Clearly the outflows in the IRAS 16293-2422 have an impact on the emission on large scales. Some care therefore needs to be taken in interpreting (unresolved) single-dish observations of the system - in particular, for discussing molecules tracing small-scale structures. A few examples, of species probing gas affected by the outflow emission are $\mathrm{CS}, \mathrm{CH}_{3} \mathrm{OH}$ and HDO. The two former species are known to be tracers of dense envelope gas affected by outflow emission in protostellar systems (e.g., Jørgensen et al. 2005c), but the latter is particular noteworthy: the SMA data encompass the HDO $3_{12}-2_{21}$ transition at $225.896 \mathrm{GHz}$, a relatively high excitation transition of HDO, which potentially could reveal the presence and distribution of (deuterated) water in this low-mass protostar.

Figure 20 compares the integrated HDO emission to that of SiO 5-4. The maps show two major peaks of the HDO line. One is associated with I16293A and one offset at about (5", $\left.0^{\prime \prime}\right)$. A third peak is seen at even larger distances - but channel maps (Fig. 21) suggests that this is an extension of the secondary peak. Figure 21 shows the channel maps of the HDO transition 


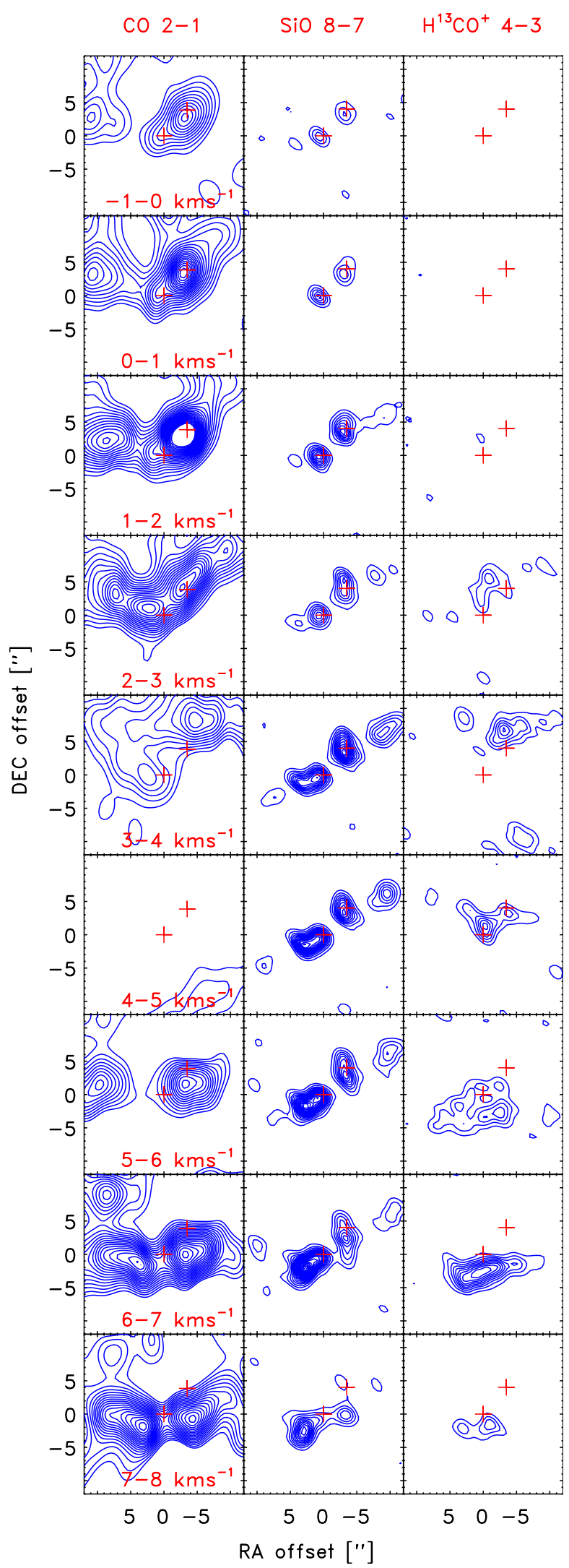

Fig. 19. Channel maps for $\mathrm{CO} 2-1$ (left column), SiO 8-7 (middle column) and $\mathrm{H}^{13} \mathrm{CO}^{+} 4-3$ (right column). Contours are given in steps of $20 \sigma$ for $\mathrm{CO} 2-1$ and $3 \sigma$ for $\mathrm{SiO} 8-7$ and $\mathrm{H}^{13} \mathrm{CO}^{+} 4-3$.

and Fig. 22 spectra toward these three positions. The emission at continuum peak is seen most prominently at the systemic

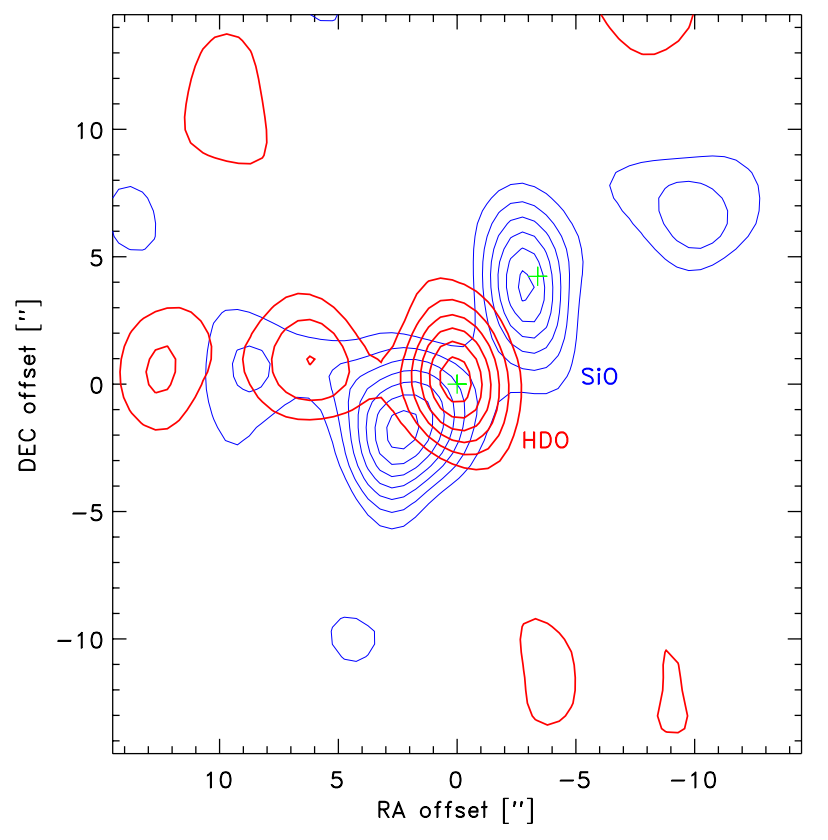

Fig. 20. HDO (225.9 GHz; red) and $\mathrm{SiO}(217.1 \mathrm{GHz}$; blue) maps compared. Both datasets were integrated over the velocity range from -1 to $6 \mathrm{~km} \mathrm{~s}^{-1}$. The contours are given in steps of $3 \sigma$.

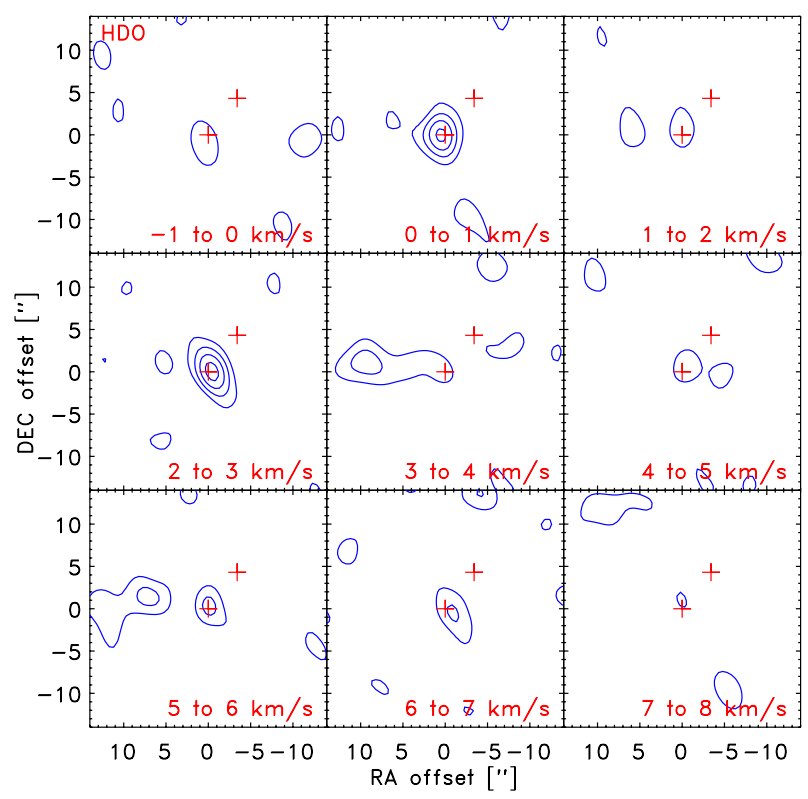

Fig. 21. Channel maps (averaged over 2 channels $/ 1.1 \mathrm{~km} \mathrm{~s}^{-1}$ ) of HDO (velocities given in upper right corner of each panel). The HDO data have had a taper of $3^{\prime \prime}$ applied.

velocity, $V_{\mathrm{LSR}}$, of the majority of the lines in the data at about $4 \mathrm{~km} \mathrm{~s}^{-1}$. The second peak east of the IRAS 16293A continuum position is redshifted relative to this but still extending around the systemic velocity. The morphology of the HDO emission appear related although not directly correlated to that of $\mathrm{SiO}$ : generally the HDO emission peaks appear in "valleys" of the red-shifted lobe of the $\mathrm{SiO}$ outflow emission (Fig. 20).

\section{Summary}

This paper has presented a large SMA imaging survey of the line emission from molecular species toward the deeply embedded, Class 0, protostellar binary IRAS 16293-2422 down 


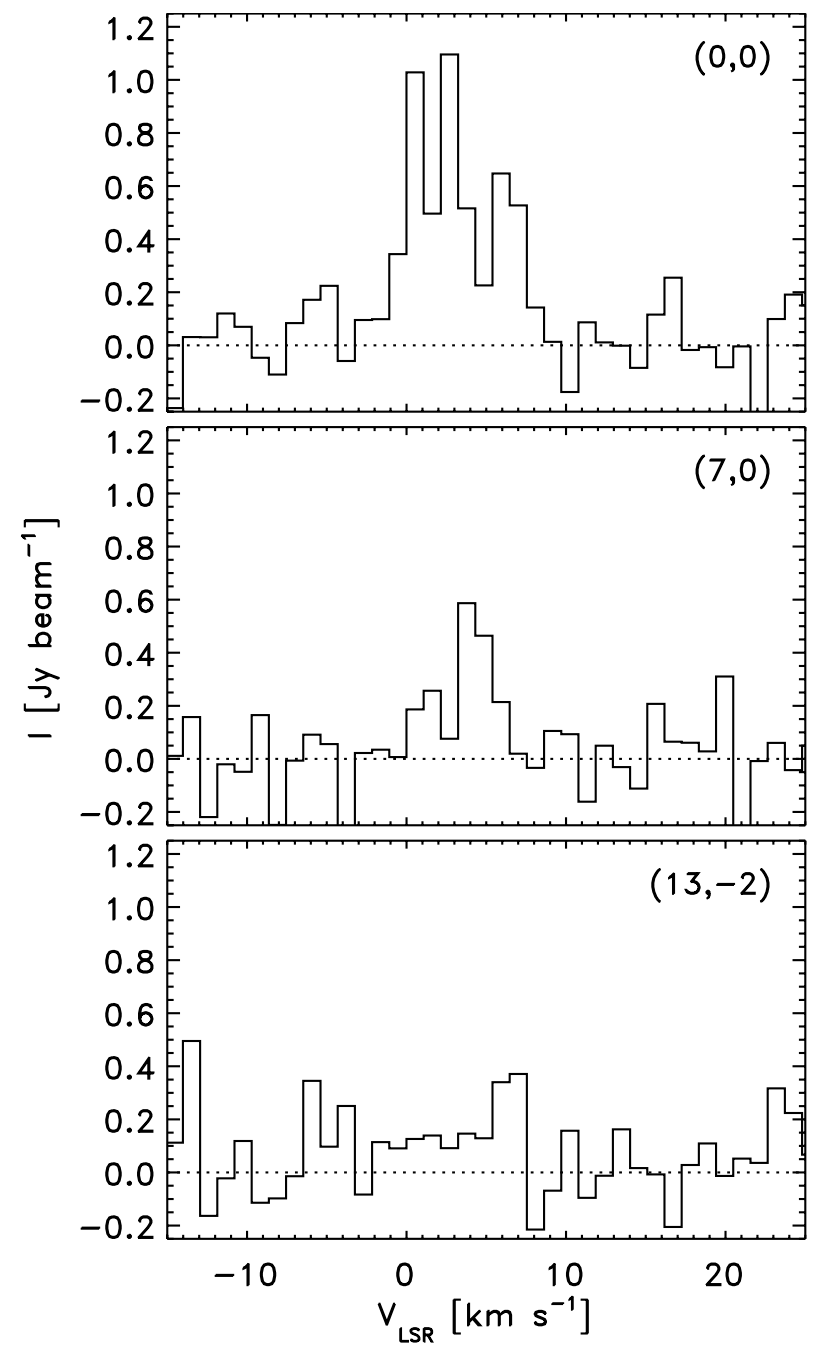

Fig. 22. Representative spectra of HDO in the central beams from maps with a 3 " taper applied (see also Fig. 21) toward the continuum peak of IRAS 16293A, the secondary peak and a position further offset toward the east where the emission is extended the offsets relative to the position of IRAS 16293A in arcseconds given in the upper right corner of each panel.

to $1.5-3^{\prime \prime}$ (190-380 AU) resolution scales. We have identified the molecular line emission toward each of the two components in the protostellar binary and discuss some general features of the emission.

- 515 transitions of 54 species (including isotopologues) are identified. $90 \%$ of the identified transitions have upper level energies lower than $550 \mathrm{~K}$. A richness of both non-organic and organic molecules (of varying complexity) are seen toward both binary components.

- Significantly narrower lines are observed toward IRAS 16293 B than IRAS $16293 \mathrm{~A}$ in the system $\left(1.9 \mathrm{~km} \mathrm{~s}^{-1}\right.$ for IRAS 16293B vs. $2.6 \mathrm{~km} \mathrm{~s}^{-1}$ for IRAS 16293A) and the lines toward IRAS $16293 \mathrm{~B}$ are found to be blue-shifted by about $0.5 \mathrm{~km} \mathrm{~s}^{-1}$ compared to IRAS $16293 \mathrm{~A}$ as well.

- The molecular species show significantly different strengths relatively at the two components. IRAS 16293A in general has the stronger emission and shows many nitrogen and sulfur-bearing species weak or absent toward IRAS 16293B. The latter in contrast harbors a number of stronger transitions from oxygen-bearing complex organics - in particular, $\mathrm{CH}_{3} \mathrm{CHO}$, which is very faint toward IRAS $16293 \mathrm{~A}$ (see also
Bisschop et al. 2008). There is no evidence for significantly different excitation conditions in the two sources, however.

- Outflowing motions are clearly witnessed by the maps of CO (see also Yeh et al. 2008) and SiO. The latter shows extended emission toward IRAS 16293A but notably very compact emission near IRAS 16293B suggesting the presence of shocks in the immediate vicinity of this source.

- A few specific examples are discussed. More extended emission from $\mathrm{N}_{2} \mathrm{D}^{+}, \mathrm{DCO}^{+}$and $\mathrm{CO}$ shows differences that can be attributed to cold gas-phase chemistry on large scales in the outer parts of the protostellar core. The emission from deuterated water (HDO) is only present toward IRAS 16293A with evidence for some water coming off dust grains in regions impacted by the protostellar outflow traced by $\mathrm{SiO}$.

The data presented in this paper illustrate the potential of (and need for) high angular resolution imaging when discussing the physics and chemistry of nearby embedded low-mass protostars based on submillimeter wavelength observations - and caution against over-interpretations based on lower resolution data in complex systems such as IRAS 16293-2422. On the other hand, the wealth of information in these and similar studies provide many independent, strong constraints and could be used to shed light on some of the unanswered questions concerning the physical and chemical structure and evolution of low-mass protostars. Once the Atacama Large Millimeter Array (ALMA) is fully operational with its large spectral bandwidth (up to $8 \mathrm{GHz}$ in each of two sidebands) and collecting area, similar types of observations will be routinely done and thus provide a significant boost to studies of the molecular astrophysics in star-forming regions. The data presented in this paper will guide higher sensitivity and resolution observations with ALMA, but also contain a wealth of information in their own right. We therefore welcome everyone to make use of these data and make them publicly available.

Acknowledgements. We would like to thank the anonymous referee for a number of good suggestions helping to improve the presentation of this survey. This paper is based on data from the Submillimeter Array: the Submillimeter Array is a joint project between the Smithsonian Astrophysical Observatory and the Academia Sinica Institute of Astronomy and Astrophysics and is funded by the Smithsonian Institution and the Academia Sinica. It is a pleasure to thank everybody involved with the Submillimeter Array for the continued development of this observatory. The research of J.K.J. was supported by a Junior Group Leader Fellowship from the Lundbeck foundation. Research at Centre for Star and Planet Formation is funded by the Danish National Research Foundation and the University of Copenhagen's programme of excellence. Quang Nguyen Luong's research at Bonn University was supported by a M.Sc. fellowship from Bonn International Graduate School of Physics and Astronomy (BIGS) and Argelander Institut für Astronomie.

\section{References}

Bisschop, S. E., Jørgensen, J. K., Bourke, T. L., Bottinelli, S., \& van Dishoeck, E. F. 2008, A\&A, 488, 959

Blake, G. A., van Dishoek, E. F., Jansen, D. J., Groesbeck, T. D., \& Mundy, L. G. 1994, ApJ, 428, 680

Bottinelli, S., Ceccarelli, C., Neri, R., et al. 2004, ApJ, 617, L69

Castets, A., Ceccarelli, C., Loinard, L., Caux, E., \& Lefloch, B. 2001, A\&A, 375, 40

Caux, E., Kahane, C., Castets, A., et al. 2011, A\&A, 532, A23

Cazaux, S., Tielens, A. G. G. M., Ceccarelli, C., et al. 2003, ApJ, 593, L51

Ceccarelli, C., Caux, E., White, G. J., et al. 1998, A\&A, 331, 372

Ceccarelli, C., Castets, A., Caux, E., et al. 2000, A\&A, 355, 1129

Ceccarelli, C., Caselli, P., Herbst, E., Tielens, A. G. G. M., \& Caux, E. 2007, in Protostars and Planets V, ed. B. Reipurth, D. Jewitt, \& K. Keil, 47

Chandler, C. J., Brogan, C. L., Shirley, Y. L., \& Loinard, L. 2005, ApJ, 632, 371

Herbst, E., \& van Dishoeck, E. F. 2009, ARA\&A, 47, 427

Hirano, N., Mikami, H., Umemoto, T., Yamamoto, S., \& Taniguchi, Y. 2001, ApJ, 547, 899

Ho, P. T. P., Moran, J. M., \& Lo, K. Y. 2004, ApJ, 616, L1 
Jørgensen, J. K., Schöier, F. L., \& van Dishoeck, E. F. 2002, A\&A, 389, 908 Jørgensen, J. K., Schöier, F. L., \& van Dishoeck, E. F. 2004, A\&A, 416, 603 Jørgensen, J. K., Lahuis, F., Schöier, F. L., et al. 2005a, ApJ, 631, L77

Jørgensen, J. K., Schöier, F. L., \& van Dishoeck, E. F. 2005b, A\&A, 435, 177 Jørgensen, J. K., Schöier, F. L., \& van Dishoeck, E. F. 2005c, A\&A, 437, 501 Jørgensen, J. K., Bourke, T. L., Myers, P. C., et al. 2007, ApJ, 659, 479

Kuan, Y., Huang, H., Charnley, S. B., et al. 2004, ApJ, 616, L27

Müller, H. S. P., Thorwirth, S., Roth, D. A., \& Winnewisser, G. 2001, A\&A, 370, L49

Müller, H. S. P., Schlöder, F., Stutzki, J., \& Winnewisser, G. 2005, J. Mol. Struct. 742,215

Mundy, L. G., Wootten, A., Wilking, B. A., Blake, G. A., \& Sargent, A. I. 1992, ApJ, 385, 306

Pech, G., Loinard, L., Chandler, C. J., et al. 2010, ApJ, 712, 1403

Pickett, H. M., Poynter, I. R. L., Cohen, E. A., et al. 1998, J. Quant. Spec. Radiat. Transf., 60, 883

Qi, C. 2008, The MIR Cookbook, The Submillimeter Array/HarvardSmithsonian Center for Astrophysics, http://cfa-www.harvard.edu/ $\sim \mathrm{cqi} / \mathrm{mircook}$. html
Remijan, A. J., \& Hollis, J. M. 2006, ApJ, 640, 842

Roberts, H., \& Millar, T. J. 2000, A\&A, 361, 388

Sault, R. J., Teuben, P. J., \& Wright, M. C. H. 1995, in Astronomical Data Analysis Software and Systems IV, ed. R. A. Shaw, H. E. Payne, \& J. J. E. Hayes, PASP Conf. Ser., 77, 433

Schilke, P., Walmsley, C. M., Pineau des Forets, G., \& Flower, D. R. 1997, A\&A, 321,293

Schöier, F. L., Jørgensen, J. K., van Dishoeck, E. F., \& Blake, G. A. 2002, A\&A, 390, 1001

Schöier, F. L., Jørgensen, J. K., van Dishoeck, E. F., \& Blake, G. A. 2004, A\&A, 418,185

Stark, R., Sandell, G., Beck, S. C., et al. 2004, ApJ, 608, 341

Takakuwa, S., Ohashi, N., Bourke, T. L., et al. 2007, ApJ, 662, 431

van Dishoeck, E. F. \& Blake, G. A. 1998, ARA\&A, 36, 317

van Dishoeck, E. F., Blake, G. A., Jansen, D. J., \& Groesbeck, T. D. 1995, ApJ, 447, 760

Walker, C. K., Lada, C. J., Young, E. T., \& Margulis, M. 1988, ApJ, 332, 335

Wootten, A. 1989, ApJ, 337, 858

Yeh, S. C. C., Hirano, N., Bourke, T. L., et al. 2008, ApJ, 675, 454 


\section{Appendix A: Compilation of all identified emission lines}

Table A.1. Compilation of all identified emission lines.

\begin{tabular}{|c|c|c|c|c|c|c|}
\hline Frequency & Molecule & Transition & $\log \left(\mu^{2} S\right)^{a}$ & $E_{\mathrm{u}}[\mathrm{K}]^{b}$ & Flag $^{c}$ & $\mathrm{Plot}^{d}$ \\
\hline 215.8399200 & ${ }^{34} \mathrm{SO}$ & $5_{6}-4_{5}$ & 1.15 & 34.38 & $\mathrm{~A}$ & + \\
\hline 216.1097290 & $\mathrm{CH}_{3} \mathrm{OCHO}-\mathrm{E}$ & $19_{2,18}-18_{2,17}$ & 1.69 & 109.34 & B & - \\
\hline 216.1125822 & $\mathrm{DCO}^{+}$ & $3-2$ & 1.66 & 20.74 & $\mathrm{~A}$ & + \\
\hline 216.1154858 & $\mathrm{CH}_{3} \mathrm{OCHO}-\mathrm{A}$ & $19_{2,18}-18_{2,17}$ & 1.69 & 109.32 & B & - \\
\hline 216.2065780 & $\mathrm{DCS}^{+}$ & $6-5$ & 1.36 & 36.32 & $\mathrm{~A}$ & + \\
\hline 216.2947260 & $\mathrm{CH}_{3} \mathrm{CHO}$ & $11_{1,10,5}-10_{1,9,5}$ & 2.14 & 269.62 & B & - \\
\hline 216.5686510 & $\mathrm{H}_{2} \mathrm{CO}$ & $9_{1,8}-9_{1,9}$ & 0.54 & 173.99 & 1 & + \\
\hline 216.5819360 & $\mathrm{CH}_{3} \mathrm{CHO}$ & $11_{1,10,2}-10_{1,9,2}$ & 2.14 & 64.87 & $\mathrm{~B}$ & - \\
\hline 216.6302210 & $\mathrm{CH}_{3} \mathrm{CHO}$ & $11_{1,10,0}-10_{1,9,0}$ & 2.14 & 64.81 & B & - \\
\hline 216.6433035 & $\mathrm{SO}_{2}$ & $22_{2,20}-22_{1,21}$ & 1.55 & 248.44 & A & - \\
\hline 216.7104365 & $\mathrm{H}_{2} \mathrm{~S}$ & $2_{2,0}-2_{1,1}$ & 0.31 & 83.98 & 1 & + \\
\hline 216.8388463 & $\mathrm{CH}_{3} \mathrm{OCHO}-\mathrm{A}$ & $18_{2,16}-17_{2,15}$ & 1.66 & 105.67 & 1 & - \\
\hline 216.9456000 & $\mathrm{CH}_{3} \mathrm{OH}$ & $5_{1,4}-4_{2,2}(A+)$ & 0.05 & 55.87 & 1 & - \\
\hline 216.9655183 & $\mathrm{CH}_{3} \mathrm{OCHO}-\mathrm{E}$ & $20_{2,19}-19_{1,19}$ & $2.09 *$ & 90.67 & 1 & -1 \\
\hline 216.9666519 & $\mathrm{CH}_{3} \mathrm{OCHO}-\mathrm{A}$ & $20_{0,20}-19_{1,19}$ & $2.09 *$ & 90.65 & 1 & -1 \\
\hline 217.1049800 & $\mathrm{SiO}$ & $5-4$ & 1.68 & 31.26 & 1 & + \\
\hline 217.2370538 & $\mathrm{CH}_{3} \mathrm{OCH}_{3}$ & $34_{7,28,2}-33_{8,25,2}$ & $2.07 *$ & 590.64 & 1 & -1 \\
\hline 217.2385378 & DCN & $3-2$ & 1.91 & 20.85 & 1 & + \\
\hline 217.2992020 & $\mathrm{CH}_{3} \mathrm{OH}$ & $6_{1,5}-7_{2,6}, v=1(-E)$ & 0.67 & 373.92 & 1 & - \\
\hline 219.4681426 & $\mathrm{CH}_{3} \mathrm{OCH}_{3}$ & $28_{5,24,2}-27_{6,21,2}$ & $2.00 *$ & 384.79 & 1 & + \\
\hline 219.5055900 & $\mathrm{C}_{2} \mathrm{H}_{5} \mathrm{CN}$ & $24_{2,22}-23_{2,21}$ & 2.55 & 135.62 & A & -1 \\
\hline 219.5063307 & $\mathrm{H}_{2} \mathrm{CN}$ & $9_{1,8,19,8}-9_{1,9,19,8}$ & -4.92 & 175.40 & $\mathrm{~A}$ & -1 \\
\hline 219.5470997 & $\mathrm{HNCO}$ & $10_{4,6,9}-9_{4,5,9}$ & $2.11 *$ & 729.27 & A & - \\
\hline 219.5529227 & $\mathrm{HN}^{13} \mathrm{CO}$ & $10_{4,6,9}-9_{4,5,9}$ & $2.11 *$ & 727.58 & 1 & - \\
\hline 219.5603541 & $\mathrm{C}^{18} \mathrm{O}$ & $2-1$ & -1.61 & 15.81 & 1 & + \\
\hline 219.6218327 & $\mathrm{C}_{2} \mathrm{H}_{5} \mathrm{CN}$ & $54_{6,48}-53_{7,47}$ & 1.13 & 681.29 & 1 & - \\
\hline 219.6238599 & $\mathrm{H}_{2} \mathrm{CN}$ & $3_{0,3,2,5}-2_{0,2,0,5}$ & -4.86 & 21.12 & A & - \\
\hline 219.6567105 & $\mathrm{HNCO}$ & $10_{3,8,9}-9_{3,7,9}$ & $2.15^{*}$ & 426.37 & 1 & + \\
\hline 219.7056522 & $\mathrm{C}_{2} \mathrm{H}_{5} \mathrm{OH}$ & $43_{2,42,0}-42_{3,40,1}$ & 1.06 & 822.87 & B & - \\
\hline 219.7355213 & HNCO & $10_{2,9,9}-9_{2,8,9}$ & $2.17 *$ & 210.01 & 1 & + \\
\hline 219.7983198 & $\mathrm{HNCO}$ & $10_{0,10,9}-90,9,9$ & $1.89 *$ & 36.92 & 1 & + \\
\hline 219.8196052 & $\left(\mathrm{CH}_{3}\right)_{2} \mathrm{CO}$ & $21_{12,10,0}-20_{13,7,0}$ & 1.35 & 183.25 & 1 & + \\
\hline 219.9085250 & $\mathrm{H}_{2}{ }^{13} \mathrm{CO}$ & $3_{1,2}-2_{1,1}$ & 1.64 & 32.94 & 1 & + \\
\hline 219.9494420 & SO & $5_{6}-45$ & 1.15 & 34.98 & 1 & + \\
\hline 219.9839950 & $\mathrm{CH}_{3} \mathrm{OH}$ & $25_{3,22}-24_{4,20}(A+)$ & 0.92 & 802.16 & 1 & - \\
\hline 219.9939390 & $\mathrm{CH}_{3} \mathrm{OH}$ & $23_{5,19}-22_{6,17}(A+)$ & 0.82 & 775.88 & 1 & - \\
\hline 219.9969407 & $\left(\mathrm{CH}_{3}\right)_{2} \mathrm{CO}$ & $32_{7,25,0}-32_{7,26,1}$ & $3.33^{*}$ & 317.44 & A & - \\
\hline 220.0784900 & $\mathrm{CH}_{3} \mathrm{OH}$ & $8_{0,8}-7_{1,6}(A+)$ & 0.54 & 96.61 & 1 & - \\
\hline 220.1651979 & $\left(\mathrm{CH}_{3}\right)_{2} \mathrm{CO}$ & $19_{16,4,0}-19_{13,6,1}$ & 0.34 & 168.30 & A & -1 \\
\hline 220.1668155 & $\mathrm{CH}_{3} \mathrm{OCHO}-\mathrm{E}$ & $17_{2,15}-16_{4,12}$ & 1.63 & 103.15 & 1 & - \\
\hline 220.1687526 & $\left(\mathrm{CH}_{3}\right)_{2} \mathrm{CO}$ & $32_{7,25,0}-32_{7,26,0}$ & $3.03 *$ & 317.43 & A & -1 \\
\hline 220.1781956 & $\mathrm{CH}_{2} \mathrm{CO}$ & $11_{1,11}-10_{1,10}$ & 1.82 & 76.48 & 1 & + \\
\hline 220.1843344 & $\mathrm{CH}_{3} \mathrm{OCH}_{3}$ & $32_{15,17,0}-33_{14,2}$ & $1.98 *$ & 774.86 & 1 & - \\
\hline 220.1902269 & $\mathrm{CH}_{3} \mathrm{OCHO}-\mathrm{A}$ & $17_{4,13}-16_{4,12}$ & 1.63 & 103.14 & 1 & - \\
\hline 220.2350419 & $\mathrm{CH}_{3} \mathrm{CN}$ & $12_{11,0,12}-11_{11,0,11}$ & $2.25 *$ & 910.24 & $\mathrm{~B}$ & + \\
\hline 220.2961130 & $\mathrm{CH}_{3}{ }^{13} \mathrm{CN}$ & $12_{9,12}-11_{9,11}$ & $2.98 *$ & 625.50 & $\mathrm{~B}$ & + \\
\hline 220.3461944 & $\mathrm{H}_{2} \mathrm{CN}$ & $9_{1,8,5,10}-9_{1,9,5,10}$ & -4.82 & 175.37 & A & + \\
\hline 220.3597073 & $\left(\mathrm{CH}_{3}\right)_{2} \mathrm{CO}$ & $22_{1,22,1}-21_{1,21,1}$ & $3.95 *$ & 102.83 & 1 & + \\
\hline 220.3640282 & $\left(\mathrm{CH}_{3}\right)_{2} \mathrm{CO}$ & $22_{1,22,0}-21_{1,21,0}$ & $3.95 *$ & 102.74 & 1 & - \\
\hline 220.3676372 & $\left(\mathrm{CH}_{3}\right)_{2} \mathrm{CO}$ & $11_{11,1,1}-10_{10,1,2}$ & 2.54 & 62.89 & 1 & -1 \\
\hline 220.3677269 & $\mathrm{CH}_{3}{ }^{13} \mathrm{CN}$ & $12_{8,12}-11_{8,11}$ & $2.79 *$ & 504.37 & 1 & -1 \\
\hline 220.3986842 & ${ }^{13} \mathrm{CO}$ & $2-1$ & -1.31 & 15.87 & 1 & + \\
\hline 220.4013740 & $\mathrm{CH}_{3} \mathrm{OH}$ & $10_{5,5}-11_{4,8}(A-)$ & 0.28 & 251.64 & 1 & - \\
\hline 220.4464450 & $\mathrm{CH}_{3} \mathrm{CHO}$ & $13_{3,10,2}-13_{2,11,2}$ & 1.15 & 104.67 & $\mathrm{~B}$ & - \\
\hline 220.4667117 & $\mathrm{H}_{2} \mathrm{CN}$ & $3_{2,2,23,1}-2,1,21,1$ & -4.57 & 68.66 & A & + \\
\hline 220.4758142 & $\mathrm{CH}_{3} \mathrm{CN}$ & $12_{8,0,12}-11_{8,0,11}$ & $2.79 *$ & 504.40 & 1 & + \\
\hline 220.4858600 & $\mathrm{CH}_{3}{ }^{13} \mathrm{CN}$ & $12_{6,12}-11_{6,11}$ & $3.22 *$ & 304.69 & 1 & + \\
\hline 220.5393300 & $\mathrm{CH}_{3} \mathrm{CN}$ & $12_{7,0,12}-11_{7,0,11}$ & $2.86^{*}$ & 397.45 & 1 & + \\
\hline 220.5511144 & $\left(\mathrm{CH}_{3}\right)_{2} \mathrm{CO}$ & $12_{8,5,0}-11_{7,5,1}$ & 0.21 & 63.84 & 1 & + \\
\hline 220.5703792 & $\mathrm{CH}_{3}{ }^{13} \mathrm{CN}$ & $12_{4,12}-11_{4,11}$ & $2.99 *$ & 161.94 & 1 & + \\
\hline 220.5851975 & HNCO & $10_{1,9,9}-9_{1,8,9}$ & $1.88 *$ & 80.33 & 1 & + \\
\hline 220.5944295 & $\mathrm{CH}_{3} \mathrm{CN}$ & $12_{6,0,12}-11_{6,0,12}$ & $3.22 *$ & 304.72 & 1 & - \\
\hline
\end{tabular}


Table A.1. continued.

\begin{tabular}{|c|c|c|c|c|c|c|}
\hline Frequency & Molecule & Transition & $\log \left(\mu^{2} \mathbf{S}\right)^{a}$ & $\overline{E_{\mathrm{u}}[\mathrm{K}]^{b}}$ & Flag $^{c}$ & $\mathrm{Plot}^{d}$ \\
\hline 220.5999883 & $\mathrm{CH}_{3}{ }^{13} \mathrm{CN}$ & $12_{3,12}-11_{3,11}$ & $3.32 *$ & 111.95 & 1 & -1 \\
\hline 220.6019270 & $\mathrm{C}_{2} \mathrm{H}_{5} \mathrm{OH}$ & $13_{1,13,2}-12_{0,12,2}$ & 1.18 & 74.44 & 1 & -1 \\
\hline 220.6211464 & $\mathrm{CH}_{3}{ }^{13} \mathrm{CN}$ & $12_{2,12}-11_{2,11}$ & $3.03 *$ & 76.23 & 1 & + \\
\hline 220.6338478 & $\mathrm{CH}_{3}{ }^{13} \mathrm{CN}$ & $12_{1,12}-11_{1,11}$ & $2.88 *$ & 54.80 & 1 & - \\
\hline 220.6380781 & $\mathrm{CH}_{3}{ }^{13} \mathrm{CN}$ & $12_{0,11}-11_{0,10}$ & $3.04 *$ & 47.65 & 1 & - \\
\hline 220.6411217 & $\mathrm{CH}_{3} \mathrm{CN}$ & $12_{5,0,12}-11_{5,0,11}$ & $2.96^{*}$ & 226.22 & 1 & - \\
\hline 220.6609152 & $\mathrm{C}_{2} \mathrm{H}_{5} \mathrm{CN}$ & $25_{2,24}-24_{2,23}$ & 2.57 & 143.02 & B & - \\
\hline 220.6648874 & $\left(\mathrm{CH}_{3}\right)_{2} \mathrm{CO}$ & $11_{11,1,0}-10_{10,1,1}$ & 3.14 & 62.92 & 1 & - \\
\hline 220.6793199 & $\mathrm{CH}_{3} \mathrm{CN}$ & $12_{4,0,12}-11_{4,0,12}$ & $2.99 *$ & 161.96 & 1 & + \\
\hline 220.7090798 & $\mathrm{CH}_{3} \mathrm{CN}$ & $12_{3,0,12}-11_{3,0,12}$ & $3.32 *$ & 111.97 & 1 & -1 \\
\hline 220.7104700 & $\mathrm{CH}_{3} \mathrm{OCHO}-\mathrm{E}$ & $24_{2,22}-24_{1,24}$ & $0.34 *$ & 147.64 & 1 & -1 \\
\hline 220.7302701 & $\mathrm{CH}_{3} \mathrm{CN}$ & $12_{2,0,12}-11_{2,0,12}$ & $3.03 *$ & 76.25 & 1 & + \\
\hline 220.7429903 & $\mathrm{CH}_{3} \mathrm{CN}$ & $12_{1,0,12}-11_{1,0,12}$ & $3.04 *$ & 54.82 & 1 & - \\
\hline 220.7472403 & $\mathrm{CH}_{3} \mathrm{CN}$ & $12_{0,0,12}-11_{0,0,12}$ & $3.04 *$ & 47.68 & 1 & - \\
\hline 220.8106418 & $\mathrm{CH}_{3} \mathrm{OCHO}-\mathrm{A}$ & $24_{1,23}-24_{0,24}$ & 0.14 & 168.81 & 1 & -1 \\
\hline 220.8117404 & $\mathrm{CH}_{3} \mathrm{OCHO}-\mathrm{E}$ & $18_{3,15}-17_{4,14}$ & 0.65 & 105.87 & 1 & - \\
\hline 220.8140200 & $\mathrm{CH}_{3} \mathrm{OCHO}-\mathrm{E}$ & $28_{5,23}-28_{4,25}$ & 0.62 & 247.74 & 1 & -1 \\
\hline 220.8151931 & $\mathrm{CH}_{3} \mathrm{OCHO}-\mathrm{A}$ & $18_{3,16}-17_{2,15}$ & 0.65 & 105.86 & 1 & -1 \\
\hline 220.8476425 & $\mathrm{CH}_{3} \mathrm{OCH}_{3}$ & $24_{4,20,0}-23_{5,19,0}$ & $1.84 *$ & 276.29 & $\mathrm{~B}$ & + \\
\hline 220.8889464 & $\mathrm{CH}_{3} \mathrm{OCHO}-\mathrm{A}$ & $18_{17,1}-17_{17,0}$ & $1.01 *$ & 271.32 & 1 & - \\
\hline 220.8932375 & $\mathrm{CH}_{3} \mathrm{OCH}_{3}$ & $23_{4,20,2}-23_{3,21,2}$ & $2.37 *$ & 253.23 & B & - \\
\hline 220.9261742 & $\mathrm{CH}_{3} \mathrm{OCHO}-\mathrm{A}$ & $18_{16,2}-17_{16,1}$ & $1.30 *$ & 249.44 & 1 & - \\
\hline 220.9351812 & $\mathrm{CH}_{3} \mathrm{OCHO}-\mathrm{E}$ & $18_{16,2}-17_{16,1}$ & 1.00 & 270.64 & 1 & - \\
\hline 220.9468249 & $\mathrm{CH}_{3} \mathrm{OCHO}-\mathrm{A}$ & $37_{9,29}-37_{8,30}$ & 1.02 & 473.29 & 1 & -1 \\
\hline 220.9475069 & $\mathrm{CH}_{3} \mathrm{OCHO}-\mathrm{E}$ & $18_{16,3}-17_{16,2}$ & 1.00 & 270.63 & 1 & -1 \\
\hline 220.9615825 & $\mathrm{C}_{2} \mathrm{H}_{5} \mathrm{CN}$ & $46_{6,40}-46_{5,41}$ & 1.63 & 505.97 & 1 & -1 \\
\hline 220.9625105 & $\left(\mathrm{CH}_{3}\right)_{2} \mathrm{CO}$ & $11_{11,1,0}-10_{10,0,0}$ & $3.14 *$ & 41.74 & 1 & -1 \\
\hline 220.9778206 & $\mathrm{CH}_{3} \mathrm{OCHO}-\mathrm{A}$ & $18_{15,3}-17_{15,2}$ & $1.47 *$ & 228.89 & 1 & -1 \\
\hline 220.9785217 & $\mathrm{CH}_{3} \mathrm{CN}$ & $12_{9,1,12}-11_{9,1,11}$ & $2.49 *$ & 1291.48 & 1 & -1 \\
\hline 220.9834922 & $\mathrm{CH}_{3} \mathrm{OCHO}-\mathrm{E}$ & $18_{15,3}-17_{15,2}$ & 1.17 & 250.09 & 1 & - \\
\hline 220.9872199 & ${ }^{33} \mathrm{SO}_{2}$ & $14_{3,11,13}-14_{2,12,13}$ & $1.97 *$ & 97.31 & 1 & - \\
\hline 220.9983979 & $\mathrm{CH}_{3} \mathrm{OCHO}-\mathrm{E}$ & $18_{15,4}-17_{15,3}$ & 1.17 & 250.08 & 1 & -1 \\
\hline 220.9988850 & $\mathrm{C}_{2} \mathrm{H}_{5} \mathrm{OH}$ & $13_{0,13,1}-12_{0,12,1}$ & 1.32 & 135.54 & 1 & -1 \\
\hline 221.0476595 & $\mathrm{CH}_{3} \mathrm{OCHO}-\mathrm{A}$ & $18_{14,4}-17_{14,3}$ & $1.58 *$ & 209.65 & 1 & - \\
\hline 221.0498464 & $\mathrm{CH}_{3} \mathrm{OCHO}-\mathrm{E}$ & $18_{14,4}-17_{14,3}$ & 1.28 & 230.87 & 1 & -1 \\
\hline 221.0516320 & $\mathrm{C}_{2} \mathrm{H}_{5} \mathrm{OH}$ & $29_{7,22,0}-29_{6,24,1}$ & 1.23 & 478.72 & 1 & -1 \\
\hline 221.0669592 & $\mathrm{CH}_{3} \mathrm{OCHO}-\mathrm{E}$ & $18_{14,5}-17_{14,4}$ & 1.28 & 230.85 & B & - \\
\hline 221.1148971 & ${ }^{34} \mathrm{SO}_{2}$ & $22_{2,20}-22_{1,21}$ & 1.53 & 247.83 & A & + \\
\hline 221.1396461 & $\mathrm{CH}_{3} \mathrm{OCHO}-\mathrm{E}$ & $18_{13,5}-17_{13,4}$ & 1.36 & 212.97 & 1 & -1 \\
\hline 221.1410146 & $\mathrm{CH}_{3} \mathrm{OCHO}-\mathrm{A}$ & $18_{13,5}-17_{13,4}$ & $1.66^{*}$ & 191.74 & 1 & -1 \\
\hline 221.1543046 & $\mathrm{C}_{2} \mathrm{H}_{5} \mathrm{OH}$ & $29_{17,12,0}-30_{16,14,1}$ & $0.57 *$ & 750.57 & 1 & - \\
\hline 221.1585432 & $\mathrm{CH}_{3} \mathrm{OCHO}-\mathrm{E}$ & $18_{13,6}-17_{13,5}$ & 1.36 & 212.95 & 1 & - \\
\hline 221.1770778 & HDCS & $7_{1,6}-6_{1,5}$ & 1.27 & 51.45 & 1 & + \\
\hline 221.1916648 & $\mathrm{D}_{2} \mathrm{CO}$ & $4_{1,4}-33_{1,3}$ & 1.31 & 31.96 & 1 & - \\
\hline 221.1966270 & $\mathrm{CH}_{3} \mathrm{CN}$ & $12_{6,1,12}-11_{6,1,12}$ & $2.89 *$ & 909.71 & 1 & -1 \\
\hline 221.1978221 & $\mathrm{CH}_{3} \mathrm{OCH}_{3}$ & $27_{5,22,0}-27_{4,23,0}$ & $2.61 *$ & 359.34 & 1 & 1 \\
\hline 221.1991513 & $\mathrm{CH}_{3} \mathrm{CN}$ & $12_{-1,2,12}-11_{1,2,12}$ & $3.01 *$ & 566.77 & 1 & -1 \\
\hline 221.2020390 & $\mathrm{C}_{2} \mathrm{H}_{5} \mathrm{CN}$ & $42_{2,40}-42_{2,41}$ & 0.53 & 396.30 & 1 & - \\
\hline 221.2158030 & $\mathrm{CH}_{3} \mathrm{CHO}$ & $11_{2,10,7}-10_{2,9,7}$ & 2.09 & 450.75 & B & - \\
\hline 221.2606831 & $\mathrm{CH}_{3} \mathrm{OCHO}-\mathrm{E}$ & $18_{12,6}-17_{12,5}$ & 1.42 & 196.40 & 1 & - \\
\hline 221.2656015 & $\mathrm{CH}_{3} \mathrm{OCHO}-\mathrm{A}$ & $18_{12,6}-17_{12,5}$ & $1.73 *$ & 175.16 & 1 & - \\
\hline 221.2727950 & $\mathrm{CH}_{2} \mathrm{CN}$ & $11_{3,9,12}-10_{3,8,11}$ & $-2.64 *$ & 161.17 & 1 & - \\
\hline 221.2748271 & $\mathrm{CH}_{2} \mathrm{CN}$ & $11_{2,10,11}-10_{2,9,10}$ & -2.39 & 116.52 & 1 & - \\
\hline 221.2809035 & $\mathrm{CH}_{3} \mathrm{OCHO}-\mathrm{E}$ & $18_{12,7}-17_{12,6}$ & 1.42 & 196.39 & 1 & - \\
\hline 221.2852410 & ${ }^{13} \mathrm{CH}_{3} \mathrm{OH}$ & $8_{1,8}-7_{0,7}(A-)$ & 0.70 & 87.12 & 1 & - \\
\hline 221.2938400 & $\mathrm{CH}_{3} \mathrm{OCHO}-\mathrm{E}$ & $28_{6,23}-28_{5,24}$ & 0.62 & 247.76 & 1 & -1 \\
\hline 221.2958080 & $\mathrm{CH}_{3} \mathrm{CHO}$ & $13_{3,10,0}-13_{2,11,0}$ & 1.22 & 104.69 & 1 & -1 \\
\hline 221.3119500 & $\mathrm{CH}_{3} \mathrm{CN}$ & $12_{6,2,12}-11_{6,2,12}$ & $2.89 *$ & 749.85 & 1 & + \\
\hline 221.3382190 & $\mathrm{CH}_{3} \mathrm{CN}$ & $12_{3,1,12}-11_{3,1,12}$ & $2.98 *$ & 677.15 & 1 & + \\
\hline 221.3503700 & $\mathrm{CH}_{3} \mathrm{CN}$ & $12_{5,2,12}-11_{5,2,12}$ & $2.93 *$ & 684.78 & 1 & + \\
\hline 221.3676691 & $\mathrm{CH}_{3} \mathrm{CN}$ & $12_{2,1,12}-11_{2,1,12}$ & $3.30 *$ & 628.15 & 1 & + \\
\hline 221.3807396 & $\mathrm{CH}_{3} \mathrm{CN}$ & $12_{4,2,12}-11_{4,2,12}$ & $3.26^{*}$ & 633.92 & 1 & - \\
\hline
\end{tabular}


Table A.1. continued.

\begin{tabular}{|c|c|c|c|c|c|c|}
\hline Frequency & Molecule & Transition & $\log \left(\mu^{2} \mathrm{~S}\right)^{a}$ & $E_{\mathrm{u}}[\mathrm{K}]^{b}$ & Flag $^{c}$ & $\mathrm{Plot}^{d}$ \\
\hline 221.3873001 & $\mathrm{CH}_{3} \mathrm{CN}$ & $12_{1,1,12}-11_{1,1,12}$ & $3.01 *$ & 593.42 & 1 & - \\
\hline 221.3941500 & $\mathrm{CH}_{3} \mathrm{CN}$ & $12_{0,2,12}-11_{0,2,12}$ & $3.01 *$ & 572.98 & 1 & - \\
\hline 225.5990847 & $\mathrm{CH}_{3} \mathrm{OCH}_{3}$ & $12_{1,12,2}-11_{0,11,2}$ & $2.34 *$ & 48.13 & 1 & - \\
\hline 225.6977750 & $\mathrm{H}_{2} \mathrm{CO}$ & $3_{1,2}-2_{1,1}$ & 1.64 & 33.45 & 1 & + \\
\hline 225.8967200 & HDO & $3_{1,2}-2,1$ & -0.16 & 167.56 & 1 & + \\
\hline 226.2563101 & $\mathrm{CH}_{3} \mathrm{CHO}$ & $13_{0,13,0}-12_{1,12,0}$ & 1.31 & 83.05 & B & - \\
\hline 226.3000267 & $\mathrm{SO}_{2}$ & $14_{3,11}-14_{2,12}$ & 1.36 & 118.98 & A & - \\
\hline 226.3469275 & $\mathrm{CH}_{3} \mathrm{OCH}_{3}$ & $14_{1,13,0}-13_{2,12,0}$ & $2.00 *$ & 77.14 & 1 & - \\
\hline 226.5383379 & $\left(\mathrm{CH}_{3}\right)_{2} \mathrm{CO}$ & $8_{8,1,1}-7_{5,3,2}$ & -0.49 & 34.10 & A & - \\
\hline 226.7846543 & $\left(\mathrm{CH}_{3}\right)_{2} \mathrm{CO}$ & $20_{3,17,1}-19_{4,16,1}$ & $3.34 *$ & 104.67 & A & - \\
\hline 226.8126092 & $\left(\mathrm{CH}_{3}\right)_{2} \mathrm{CO}$ & $12_{9,3,0}-11_{8,4,1}$ & 2.74 & 66.19 & A & - \\
\hline 226.8577140 & $\mathrm{CH}_{3} \mathrm{CHO}$ & $11_{3,8,2}-11_{2,9,2}$ & 0.99 & 81.48 & B & - \\
\hline 227.0194892 & $\mathrm{CH}_{3} \mathrm{OCHO}-\mathrm{E}$ & $19_{4,16}-18_{4,15}$ & 1.69 & 116.57 & 1 & - \\
\hline 227.0280673 & $\mathrm{CH}_{3} \mathrm{OCHO}-\mathrm{A}$ & $19_{2,17}-18_{2,16}$ & 1.69 & 116.56 & 1 & - \\
\hline 227.0318807 & ${ }^{34} \mathrm{SO}_{2}$ & $12_{39}-12_{210}$ & 1.27 & 93.08 & 1 & - \\
\hline 227.0946010 & $\mathrm{CH}_{3} \mathrm{OH}$ & $21_{1,20}-21_{0,21}(A+)$ & 1.06 & 557.06 & 1 & - \\
\hline 227.1141731 & $\mathrm{D}_{2} \mathrm{CS}$ & $8_{5,3}-7_{5,2}$ & $1.43^{*}$ & 185.69 & 1 & + \\
\hline 227.1799845 & $\mathrm{D}_{2} \mathrm{CS}$ & $8_{4,4}-7_{4,3}$ & $1.82 *$ & 128.69 & 1 & + \\
\hline 227.4189050 & $\mathrm{HC}_{3} \mathrm{~N}$ & $25-24$ & 2.54 & 141.89 & A & + \\
\hline 227.5143590 & $\mathrm{CH}_{3} \mathrm{CHO}$ & $11_{3,8,0}-11_{2,9,0}$ & 1.13 & 81.49 & B & - \\
\hline 227.5613486 & $\mathrm{CH}_{3} \mathrm{OCHO}-\mathrm{E}$ & $21_{2,20}-20_{1,20}$ & $2.11 *$ & 100.58 & 1 & -1 \\
\hline 227.5622413 & $\mathrm{CH}_{3} \mathrm{OCHO}-\mathrm{A}$ & $21_{0,21}-20_{1,20}$ & $2.08 *$ & 100.56 & 1 & -1 \\
\hline 229.4320840 & $\mathrm{CH}_{3} \mathrm{CHO}$ & $11_{1,11,1}-10_{0,10,2}$ & 1.23 & 61.54 & B & - \\
\hline 229.5591486 & $\mathrm{C}_{2} \mathrm{H}_{5} \mathrm{OH}$ & $14_{0,14,1}-13_{1,13,1}$ & -1.15 & 146.39 & A & - \\
\hline 229.5890730 & $\mathrm{CH}_{3} \mathrm{OH}$ & $15_{4,11}-16_{3,13}(A+)$ & 0.66 & 374.43 & 1 & -1 \\
\hline 229.5904100 & $\mathrm{CH}_{3} \mathrm{OCHO}-\mathrm{E}$ & $19_{3,16}-18_{4,15}$ & 0.70 & 116.69 & 1 & - \\
\hline 229.5950200 & $\mathrm{CH}_{3} \mathrm{OCHO}-\mathrm{A}$ & $19_{3,17}-18_{2,16}$ & 0.70 & 116.68 & 1 & - \\
\hline 229.7587600 & $\mathrm{CH}_{3} \mathrm{OH}$ & $8_{1,8}-7_{0,7}(A-)$ & 0.70 & 89.10 & 1 & - \\
\hline 229.7750710 & $\mathrm{CH}_{3} \mathrm{CHO}$ & $11_{1,11,0}-10_{0,10,0}$ & 1.23 & 61.46 & B & - \\
\hline 229.8548654 & $\mathrm{SO}^{18} \mathrm{O}$ & $14_{0,14}-13_{1,13}$ & 1.44 & 88.85 & A & - \\
\hline 229.8576282 & ${ }^{34} \mathrm{SO}_{2}$ & $4_{2,2}-3_{1,3}$ & 0.66 & 18.67 & 1 & - \\
\hline 229.8609140 & $\mathrm{CH}_{3} \mathrm{CHO}$ & $10_{3,7,0}-10_{2,8,0}$ & 1.08 & 71.29 & B & - \\
\hline 229.8641900 & $\mathrm{CH}_{3} \mathrm{OH}$ & $19_{5,15}-20_{4,16}(+E)$ & 0.76 & 578.59 & 1 & - \\
\hline 229.9391800 & $\mathrm{CH}_{3} \mathrm{OH}$ & $19_{5,14}-20_{4,17}(-E)$ & 0.76 & 578.59 & 1 & - \\
\hline 230.0270600 & $\mathrm{CH}_{3} \mathrm{OH}$ & $3_{2,2}-4_{1,4}(A-)$ & -0.13 & 39.83 & 1 & - \\
\hline 230.1055541 & $\mathrm{CH}_{3} \mathrm{CHO}$ & $26_{3,23,2}-25_{4,22,1}$ & 1.02 & 348.36 & 1 & -1 \\
\hline 230.1066085 & $\mathrm{CH}_{3} \mathrm{CHO}$ & $12_{2,10,5}-12_{1,12,4}$ & 0.20 & 287.68 & 1 & - \\
\hline 230.1084450 & $\mathrm{C}_{2} \mathrm{H}_{5} \mathrm{OH}$ & $43_{5,38,0}-43_{4,39,0}$ & -0.63 & 885.64 & 1 & -1 \\
\hline 230.1413735 & $\mathrm{CH}_{3} \mathrm{OCH}_{3}$ & $25_{4,22,2}-25_{3,22,2}$ & $2.40 *$ & 297.12 & 1 & - \\
\hline 230.1446090 & $\mathrm{CH}_{3} \mathrm{CHO}$ & $13_{0,13,3}-12_{1,12,3}$ & 1.27 & 289.71 & B & - \\
\hline 230.1595183 & $\mathrm{CH}_{3} \mathrm{OCHO}-\mathrm{E}$ & $35_{10,26}-35_{0,35}$ & 0.41 & 418.81 & 1 & - \\
\hline 230.1777310 & $\left(\mathrm{CH}_{3}\right)_{2} \mathrm{CO}$ & $23_{0,23,0}-22_{0,22,1}$ & $3.86^{*}$ & 112.86 & 1 & - \\
\hline 230.1828134 & $\left(\mathrm{CH}_{3}\right)_{2} \mathrm{CO}$ & $28_{2,26,0}-28_{2,27,1}$ & $2.81 *$ & 197.70 & 1 & - \\
\hline 230.2314190 & $\mathrm{SO}^{17} \mathrm{O}$ & $13_{3,10}-13_{2,11}$ & 2.09 & 103.28 & 1 & - \\
\hline 230.2337575 & $\mathrm{CH}_{3} \mathrm{OCH}_{3}$ & $17_{2,15,0}-16_{3,14,0}$ & $1.96^{*}$ & 125.55 & 1 & - \\
\hline 230.2728523 & $\mathrm{CH}_{3} \mathrm{CHO}$ & $9_{5,4,2}-10_{4,7,1}$ & 0.24 & 98.01 & B & - \\
\hline 230.2927250 & $\mathrm{CH}_{3} \mathrm{OH}$ & $22_{2,20}-21_{3,19}(A+)$ & 0.00 & 609.54 & 1 & -1 \\
\hline 230.2938579 & $\mathrm{CH}_{3} \mathrm{OCHO}-\mathrm{A}$ & $22_{9,13}-22_{8,14}$ & 0.71 & 203.35 & 1 & - \\
\hline 230.3018800 & $\mathrm{CH}_{3} \mathrm{CHO}$ & $12_{2,11,0}-11_{2,10,0}$ & 2.17 & 81.04 & B & - \\
\hline 230.3157400 & $\mathrm{CH}_{3} \mathrm{CHO}$ & $12_{2,11,1}-11_{2,10,1}$ & 2.17 & 81.05 & B & -1 \\
\hline 230.3175270 & $\mathrm{O}^{13} \mathrm{CS}$ & $19-18$ & 0.99 & 110.54 & 1 & -1 \\
\hline 230.3681785 & $\mathrm{CH}_{3} \mathrm{OCH}_{3}$ & $28_{5,23,3}-27_{6,22,3}$ & $1.90 *$ & 384.23 & 1 & -1 \\
\hline 230.3681990 & $\mathrm{CH}_{3} \mathrm{OH}$ & $22_{4,18}-21_{5,17}(A+)$ & 0.82 & 682.73 & 1 & -1 \\
\hline 230.3764780 & $\mathrm{CH}_{3} \mathrm{OCHO}-\mathrm{A}$ & $22_{9,14}-22_{8,15}$ & 0.71 & 203.35 & 1 & -1 \\
\hline 230.3780799 & $\mathrm{C}_{2} \mathrm{H}_{5} \mathrm{OH}$ & $11_{5,6,1}-11_{4,7,1}$ & -1.28 & 147.18 & 1 & -1 \\
\hline 230.3951700 & $\mathrm{CH}_{3} \mathrm{CHO}$ & $12_{2,11,3}-11_{2,10,3}$ & 2.17 & 286.40 & B & - \\
\hline 230.4531157 & $\mathrm{CH}_{3} \mathrm{CHO}$ & $8_{3,6,1}-8_{2,6,2}$ & 0.32 & 53.60 & B & - \\
\hline 230.5075159 & $\mathrm{CH}_{3} \mathrm{OCH}_{3}$ & $26_{4,23,0}-25_{5,20,0}$ & $1.95 *$ & 320.83 & 1 & + \\
\hline 230.5380000 & $\mathrm{CO}$ & $2-1$ & -1.62 & 16.60 & 1 & + \\
\hline 230.6010400 & $\mathrm{CH}_{3} \mathrm{CHO}$ & $5_{2,4,1}-4_{1,3,2}$ & 0.44 & 22.91 & B & - \\
\hline 230.6725540 & $\mathrm{C}_{2} \mathrm{H}_{5} \mathrm{OH}$ & $13_{2,11,0}-12_{2,10,0}$ & 1.31 & 138.62 & B & - \\
\hline 230.6915910 & $\mathrm{D}_{2} \mathrm{CO}$ & $13_{2,11}-13_{2,12}$ & 0.71 & 285.49 & 1 & - \\
\hline 230.8108827 & $\mathrm{SO}^{17} \mathrm{O}$ & $14_{2,13}-14_{1,14}$ & 1.92 & 102.83 & 1 & + \\
\hline 230.9271460 & $\mathrm{CH}_{3} \mathrm{CHO}$ & $12_{6,6,5}-11_{6,5,5}$ & 2.06 & 359.36 & B & - \\
\hline
\end{tabular}


Table A.1. continued.

\begin{tabular}{|c|c|c|c|c|c|c|}
\hline Frequency & Molecule & Transition & $\log \left(\mu^{2} S\right)^{a}$ & $\overline{E_{\mathrm{u}}[\mathrm{K}]^{b}}$ & Flag $^{c}$ & $\mathrm{Plot}^{d}$ \\
\hline 230.9363200 & $\mathrm{CH}_{3} \mathrm{OCHO}-\mathrm{E}$ & $29_{5,24}-29_{4,26}$ & 0.62 & 264.14 & 1 & - \\
\hline 231.0609934 & OCS & $19-18$ & 0.99 & 110.90 & 1 & + \\
\hline 231.1142580 & $\mathrm{CH}_{3} \mathrm{CHO}$ & $9_{3,6,2}-9_{2,7,2}$ & 0.88 & 62.03 & $\mathrm{~B}$ & - \\
\hline 231.1165900 & $\mathrm{CH}_{3} \mathrm{CHO}$ & $12_{8,4,3}-11_{8,3,3}$ & $2.23 *$ & 399.27 & B & - \\
\hline 231.1494163 & $\mathrm{CH}_{3} \mathrm{CHO}$ & $12_{11,1,2}-11_{11,0,2}$ & 1.39 & 344.56 & B & -1 \\
\hline 231.1502100 & $\mathrm{CH}_{3} \mathrm{CHO}$ & $12_{4,8,5}-11_{4,7,5}$ & 2.13 & 314.33 & B & -1 \\
\hline 231.1728105 & $\left(\mathrm{CH}_{3}\right)_{2} \mathrm{CO}$ & $12_{10,2,0}-11_{9,3,1}$ & 1.45 & 68.58 & A & + \\
\hline 231.1835600 & $\mathrm{CH}_{3} \mathrm{CHO}$ & $12_{9,3,2}-11_{9,2,2}$ & 1.82 & 254.62 & B & -1 \\
\hline 231.1854280 & $\mathrm{CH}_{3} \mathrm{CHO}$ & $12_{10,3,1}-11_{10,2,1}$ & 1.67 & 297.30 & B & -1 \\
\hline 231.1953200 & $\mathrm{CH}_{3} \mathrm{CHO}$ & $12_{8,4,2}-11_{8,3,2}$ & 1.93 & 216.40 & B & -1 \\
\hline 231.1953200 & $\mathrm{CH}_{3} \mathrm{CHO}$ & $12_{9,4,1}-11_{9,3,1}$ & 1.82 & 254.61 & B & -1 \\
\hline 231.1992628 & $\mathrm{CH}_{3} \mathrm{OCHO}-\mathrm{A}$ & $21_{9,12}-21_{8,13}$ & 0.68 & 190.29 & 1 & -1 \\
\hline 231.2000431 & $\mathrm{CH}_{3} \mathrm{CHO}$ & $12_{8,4,5}-11_{8,3,5}$ & 1.93 & 420.75 & B & - \\
\hline 231.2001400 & $\mathrm{CH}_{3} \mathrm{OCHO}-\mathrm{E}$ & $21_{9,12}-21_{8,13}$ & 0.68 & 190.29 & 1 & -1 \\
\hline 231.2126600 & $\mathrm{CH}_{3} \mathrm{CHO}$ & $12_{10,2,0}-11_{10,1,0}$ & $1.97 *$ & 275.06 & B & - \\
\hline 231.2206852 & ${ }^{13} \mathrm{CS}$ & $5_{0}-4_{0}$ & 1.58 & 33.29 & 1 & + \\
\hline 231.2254500 & $\mathrm{CH}_{3} \mathrm{CHO}$ & $12_{7,5,2}-11_{7,4,2}$ & 2.00 & 182.64 & B & -1 \\
\hline 231.2269550 & $\mathrm{CH}_{3} \mathrm{CHO}$ & $12_{9,3,0}-11_{9,2,0}$ & $2.12 *$ & 232.33 & B & -1 \\
\hline 231.2336498 & $\mathrm{CH}_{3} \mathrm{CHO}$ & $12_{8,5,1}-11_{8,4,1}$ & $2.40 *$ & 194.11 & B & - \\
\hline 231.2449800 & $\mathrm{CH}_{3} \mathrm{CHO}$ & $12_{7,5,0}-11_{7,4,0}$ & $2.30 *$ & 160.38 & B & - \\
\hline 231.2557700 & $\mathrm{CH}_{3} \mathrm{CHO}$ & $12_{5,7,5}-11_{5,6,5}$ & 2.10 & 334.37 & B & - \\
\hline 231.2676400 & $\mathrm{CH}_{3} \mathrm{CHO}$ & $12_{7,6,1}-11_{7,5,1}$ & 2.00 & 182.53 & B & - \\
\hline 231.2729582 & $\mathrm{CH}_{3} \mathrm{CHO}$ & $12_{6,7,0}-11_{6,6,0}$ & $2.53 *$ & 131.15 & B & - \\
\hline 231.2811000 & $\mathrm{CH}_{3} \mathrm{OH}$ & $10_{2,9}-9_{3,6}(-E)$ & 0.43 & 165.34 & 1 & - \\
\hline 231.3104600 & $\mathrm{CH}_{3} \mathrm{CHO}$ & $12_{6,7,1}-11_{6,6,1}$ & 2.06 & 153.26 & B & -1 \\
\hline 231.3104889 & $\mathrm{CH}_{3} \mathrm{CHO}$ & $7_{3,5,1}-7_{2,5,2}$ & 0.05 & 46.19 & $\mathrm{~B}$ & - \\
\hline 231.3122995 & $\mathrm{C}_{2} \mathrm{H}_{5} \mathrm{CN}$ & $27_{0,27}-26_{1,26}$ & 1.54 & 157.70 & A & - \\
\hline 231.3132402 & $\mathrm{C}_{2} \mathrm{H}_{5} \mathrm{CN}$ & $24_{2,23}-23_{1,22}$ & 1.26 & 132.43 & A & -1 \\
\hline 231.3218566 & $\mathrm{~N}_{2} \mathrm{D}^{+}$ & $3-2$ & 2.49 & 22.20 & 1 & + \\
\hline 231.3297000 & $\mathrm{CH}_{3} \mathrm{CHO}$ & $12_{58,0}-11_{570}$ & $2.40 *$ & 106.41 & B & - \\
\hline 231.3572900 & $\mathrm{CH}_{3} \mathrm{CHO}$ & $12_{3,9,5}-11_{3,8,5}$ & 2.15 & 299.05 & $\mathrm{~B}$ & - \\
\hline 231.3665150 & $\mathrm{CH}_{3} \mathrm{CHO}$ & $12_{5,7,2}-11_{5,6,2}$ & $2.40 *$ & 106.32 & $\mathrm{~B}$ & - \\
\hline 231.3820710 & $\mathrm{CH}_{3} \mathrm{CHO}$ & $12_{5,8,4}-11_{5,7,4}$ & 2.10 & 333.58 & $\mathrm{~B}$ & - \\
\hline 231.3892035 & $\left(\mathrm{CH}_{3}\right)_{2} \mathrm{CO}$ & $9_{3,7,0}-8_{0,8,1}$ & 0.97 & 29.85 & $\mathrm{~A}$ & + \\
\hline 336.8651100 & $\mathrm{CH}_{3} \mathrm{OH}$ & $12_{1,11}-12_{0,12}(-E)$ & 1.36 & 197.07 & 1 & + \\
\hline 336.8892125 & $\mathrm{CH}_{3} \mathrm{OCHO}-\mathrm{E}$ & $26_{0,26}-25_{0,25}$ & 1.82 & 235.46 & 1 & + \\
\hline 336.9180949 & $\mathrm{CH}_{3} \mathrm{OCHO}-\mathrm{A}$ & $26_{6,20}-25_{6,19}$ & 1.82 & 235.46 & 1 & + \\
\hline 336.9421799 & $\left(\mathrm{CH}_{3}\right)_{2} \mathrm{CO}$ & $24_{11,13,0}-23_{12,12,0}$ & 2.73 & 230.39 & 1 & - \\
\hline 336.9476895 & $\left(\mathrm{CH}_{3}\right)_{2} \mathrm{CO}$ & $33_{1,32,1}-32_{2,31,2}$ & $3.63 *$ & 252.63 & 1 & - \\
\hline 336.9532380 & $\mathrm{C}_{2} \mathrm{H}_{5} \mathrm{CN}$ & $51_{8,43}-51_{7,44}$ & 1.63 & 641.69 & 1 & - \\
\hline 337.0266138 & $\mathrm{SO}^{18} \mathrm{O}$ & $27_{9,18}-28_{8,21}$ & $1.26^{*}$ & 489.73 & A & + \\
\hline 337.0547330 & $\mathrm{CH}_{3} \mathrm{CHO}$ & $18_{8,10,8}-17_{8,9,8}$ & 2.29 & 692.10 & B & - \\
\hline 337.0611207 & $\mathrm{C}^{17} \mathrm{O}$ & $3_{1}-2_{1}$ & $-0.66 *$ & 0.00 & 1 & - \\
\hline 337.0810820 & $\mathrm{CH}_{3} \mathrm{CHO}$ & $18_{1,18,6}-17_{1,17,6}$ & 2.34 & 526.12 & B & - \\
\hline 337.1358730 & $\mathrm{CH}_{3} \mathrm{OH}$ & $3_{3,0}-4_{2,2}(A+)$ & -0.61 & 61.64 & 1 & -1 \\
\hline 337.1363180 & $\mathrm{CH}_{3} \mathrm{OCHO}-\mathrm{E}$ & $36_{3,34}-36_{1,36}$ & $0.65^{*}$ & 331.03 & 1 & -1 \\
\hline 337.1844552 & $\mathrm{CH}_{3} \mathrm{OCH}_{3}$ & $31_{3,28,3}-31_{0,31,3}$ & $1.94 *$ & 415.16 & 1 & - \\
\hline 337.1872764 & $\mathrm{CH}_{3} \mathrm{CHO}$ & $24_{2,22,3}-23_{3,21,3}$ & 1.11 & 496.77 & $\mathrm{~B}$ & -1 \\
\hline 337.1889589 & $\mathrm{CH}_{3} \mathrm{OCH}_{3}$ & $31_{3,28,0}-31_{0,31,0}$ & $1.94 *$ & 415.16 & 1 & -1 \\
\hline 337.1984253 & ${ }^{33} \mathrm{SO}$ & $8_{7,6}-7_{6,5}$ & $1.80 *$ & 48.17 & 1 & - \\
\hline 337.2417130 & $\mathrm{CH}_{3} \mathrm{CHO}$ & $12_{2}-11_{11}$ & 0.99 & 81.05 & B & - \\
\hline 337.2496124 & ${ }^{33} \mathrm{SO}$ & $8_{7,6}-7_{6,6}$ & $0.22 *$ & 48.16 & 1 & - \\
\hline 337.2784481 & $\left(\mathrm{CH}_{3}\right)_{2} \mathrm{CO}$ & $41_{25,16,0}-40_{28,13,1}$ & 1.14 & 700.82 & 1 & - \\
\hline 337.2862444 & $\left(\mathrm{CH}_{3}\right)_{2} \mathrm{CO}$ & $36_{32,5,0}-35_{33,3,1}$ & 1.36 & 606.30 & 1 & - \\
\hline 337.2970681 & $\mathrm{CH}_{3} \mathrm{OCH}_{3}$ & $43_{8,36,0}-42_{9,33,0}$ & $2.08 *$ & 920.41 & 1 & -1 \\
\hline 337.2974390 & $\mathrm{CH}_{3} \mathrm{OH}$ & $7_{1,7}-6_{1,6}, v=1(+E)$ & 0.74 & 390.01 & 1 & -1 \\
\hline 337.3010067 & $\mathrm{CH}_{3} \mathrm{OCHO}-\mathrm{A}$ & $36_{1,35}-36_{1,36}$ & $0.65^{*}$ & 331.00 & 1 & -1 \\
\hline 337.3025736 & $\mathrm{NH}_{2} \mathrm{CHO}$ & $19_{2,18,19}-19_{1,19,19}$ & $1.12 *$ & 171.60 & 1 & -1 \\
\hline 337.3047696 & ${ }^{33} \mathrm{SO}$ & $8_{7,7}-7_{6,8}$ & -2.32 & 80.53 & 1 & - \\
\hline 337.3230950 & $\mathrm{C}_{2} \mathrm{H}_{5} \mathrm{OH}$ & $20_{7,14,2}-20_{6,15,2}$ & 1.29 & 238.01 & 1 & - \\
\hline 337.3475840 & $\mathrm{C}_{2} \mathrm{H}_{5} \mathrm{CN}$ & $38_{3,36}-37_{3,35}$ & 2.75 & 327.85 & 1 & - \\
\hline 337.3678544 & $\mathrm{CH}_{2} \mathrm{DCN}$ & $2_{2,1}-2_{1,2}$ & -1.60 & 24.07 & 1 & - \\
\hline 337.3744549 & $\mathrm{CH}_{3} \mathrm{CHO}$ & $26_{4,23,0}-26_{3,24,0}$ & 1.52 & 361.51 & $\mathrm{~B}$ & - \\
\hline
\end{tabular}


Table A.1. continued.

\begin{tabular}{|c|c|c|c|c|c|c|}
\hline Frequency & Molecule & Transition & $\log \left(\mu^{2} \mathbf{S}\right)^{a}$ & $E_{\mathrm{u}}[\mathrm{K}]^{b}$ & Flag $^{c}$ & $\mathrm{Plot}^{d}$ \\
\hline 337.3964590 & $\mathrm{C}^{34} \mathrm{~S}$ & $7_{0}-6_{0}$ & 1.43 & 64.77 & 1 & + \\
\hline 337.4213396 & $\mathrm{CH}_{3} \mathrm{OCH}_{3}$ & $21_{2,19,0}-20_{3,18,0}$ & $2.18 *$ & 187.75 & 1 & + \\
\hline 337.4435631 & $\mathrm{HCOOH}$ & $15_{8,8}-14_{8,7}$ & $1.62 *$ & 300.36 & 1 & + \\
\hline 337.4636710 & $\mathrm{CH}_{3} \mathrm{OH}$ & $7_{6,1}-6_{6,0}, v=1(+E)$ & $0.48 *$ & 500.61 & 1 & - \\
\hline 337.4666253 & $\mathrm{C}_{2} \mathrm{H}_{5} \mathrm{CN}$ & $13_{6,8}-14_{4,11}$ & -2.41 & 79.14 & A & - \\
\hline 337.4747690 & $\mathrm{H}_{2} \mathrm{C}^{34} \mathrm{~S}$ & $10_{2,9}-9_{2,8}$ & 1.42 & 141.82 & A & + \\
\hline 337.4899220 & $\mathrm{CH}_{3} \mathrm{CHO}$ & $28_{3,26,0}-28_{1,27,0}$ & 0.31 & 396.09 & B & -1 \\
\hline 337.4905230 & $\mathrm{CH}_{3} \mathrm{OH}$ & $7_{6,2}-6_{6,1}, v=1(A-)$ & 0.16 & 558.23 & 1 & -1 \\
\hline 337.5034508 & $\mathrm{CH}_{3} \mathrm{OCHO}-\mathrm{A}$ & $27_{8,20}-26_{8,19}$ & 1.82 & 267.09 & 1 & + \\
\hline 337.5190670 & $\mathrm{CH}_{3} \mathrm{OH}$ & $7_{3,5}-6_{3,4}, v=1(A+)$ & 0.66 & 482.22 & 1 & + \\
\hline 337.5460480 & $\mathrm{CH}_{3} \mathrm{OH}$ & $7_{5,3}-6_{5,2}, v=1(+E)$ & $0.74 *$ & 452.95 & 1 & - \\
\hline 337.5516472 & $\mathrm{D}_{2}{ }^{13} \mathrm{CO}$ & $6_{0,6}-5_{0,5}$ & 1.82 & 57.25 & 1 & + \\
\hline 337.5816630 & $\mathrm{CH}_{3} \mathrm{OH}$ & $7_{4,4}-6_{4,3}, v=1(A+)$ & 0.58 & 428.19 & 1 & + \\
\hline 337.5986450 & $\mathrm{D}_{2} \mathrm{CS}$ & $12_{0,12}-11_{0,11}$ & 1.82 & 105.77 & 1 & - \\
\hline 337.6052550 & $\mathrm{CH}_{3} \mathrm{OH}$ & $7_{2,5}-6_{2,4}, v=1(A-)$ & 0.72 & 429.42 & 1 & - \\
\hline 337.6105800 & $\mathrm{CH}_{3} \mathrm{OH}$ & $7_{6,1}-6_{6,0}, v=1(A+)$ & 0.16 & 657.10 & 1 & -1 \\
\hline 337.6106240 & $\mathrm{CH}_{3} \mathrm{OH}$ & $7_{3,4}-6_{3,3}, v=1(A-)$ & 0.66 & 387.44 & 1 & - \\
\hline 337.6107293 & $\mathrm{CH}_{3}{ }^{13} \mathrm{CH}_{2} \mathrm{CN}$ & $10_{6,5}-9_{5,4}$ & $1.82 *$ & 30.14 & 1 & -1 \\
\hline 337.6306670 & $\mathrm{CH}_{3} \mathrm{OH}$ & $7_{2,5}-6_{2,4}, v=1(+E)$ & $1.02 *$ & 331.08 & 1 & + \\
\hline 337.6423650 & $\mathrm{CH}_{3} \mathrm{OH}$ & $7_{1,7}-6_{1,6}, v=1(A+)$ & 0.74 & 356.29 & 1 & -1 \\
\hline 337.6438640 & $\mathrm{CH}_{3} \mathrm{OH}$ & $7_{0,7}-6_{0,6}, v=1(A+)$ & 0.75 & 365.39 & 1 & -1 \\
\hline 337.6459920 & $\mathrm{CH}_{3} \mathrm{OH}$ & $7_{4,3}-6_{4,2}, v=1(A-)$ & 0.58 & 470.21 & 1 & - \\
\hline 337.6481670 & $\mathrm{CH}_{3} \mathrm{OH}$ & $7_{5,3}-6_{5,2}, v=1(A-)$ & 0.44 & 610.95 & 1 & - \\
\hline 337.6552040 & $\mathrm{CH}_{3} \mathrm{OH}$ & $7_{3,5}-6_{3,4}, v=1(+E)$ & $0.97 *$ & 428.52 & 1 & + \\
\hline 337.6711940 & $\mathrm{CH}_{3} \mathrm{OH}$ & $7_{2,6}-6_{2,5}, v=1(A+)$ & 0.72 & 464.71 & 1 & + \\
\hline 337.6854900 & $\mathrm{CH}_{3} \mathrm{OH}$ & $7_{4,3}-6_{4,2}, v=1(+E)$ & $0.88 *$ & 513.47 & 1 & -1 \\
\hline 337.6854900 & $\mathrm{CH}_{3} \mathrm{OH}$ & $7_{5,2}-6_{5,1}, v=1(A+)$ & 0.44 & 493.94 & 1 & -1 \\
\hline 337.7075470 & $\mathrm{CH}_{3} \mathrm{OH}$ & $7_{1,6}-6_{1,5}, v=1(A-)$ & 0.74 & 478.20 & 1 & -1 \\
\hline 337.7086296 & $\mathrm{CH}_{3} \mathrm{OCH}_{3}$ & $31_{2,30,3}-31_{1,31,3}$ & $1.31 *$ & 415.14 & 1 & -1 \\
\hline 337.7207678 & $\mathrm{CH}_{3} \mathrm{OCH}_{3}$ & $7_{4,4,2}-6_{3,3,2}$ & $1.38 *$ & 15.57 & $\mathrm{~B}$ & - \\
\hline 337.7270950 & $\mathrm{C}_{2} \mathrm{H}_{5} \mathrm{OH}$ & $19_{7,12,2}-19_{6,13,2}$ & 1.27 & 221.18 & 1 & -1 \\
\hline 337.7281852 & $\mathrm{CH}_{3} \mathrm{OCH}_{3}$ & $7_{4,4,3}-6_{3,3,3}$ & $1.83 *$ & 15.57 & 1 & -1 \\
\hline 337.7487830 & $\mathrm{CH}_{3} \mathrm{OH}$ & $7_{0,7}-6_{0,6}, v=1(+E)$ & 0.75 & 488.48 & 1 & + \\
\hline 337.7711578 & $\mathrm{CH}_{3} \mathrm{OCHO}-\mathrm{A}$ & $44_{5,39}-44_{4,40}$ & 0.84 & 604.33 & B & - \\
\hline 337.7774213 & $\mathrm{CH}_{3} \mathrm{OCH}_{3}$ & $7_{4,4,2}-6_{3,4,2}$ & $1.63 *$ & 15.56 & B & - \\
\hline 337.7838926 & $\mathrm{CH}_{3} \mathrm{OCH}_{3}$ & $7_{4,3,0}-6_{3,4,0}$ & $1.93^{*}$ & 15.56 & 1 & + \\
\hline 337.8010704 & $\mathrm{C}_{2} \mathrm{H}_{5} \mathrm{OH}$ & $19_{2,17,0}-18_{2,16,0}$ & 1.48 & 223.08 & 1 & - \\
\hline 337.8371156 & $\mathrm{C}_{2} \mathrm{H}_{5} \mathrm{OH}$ & $11_{11,1,2}-12_{10,2,2}$ & -1.05 & 207.07 & A & -1 \\
\hline 337.8380890 & $\mathrm{CH}_{3} \mathrm{OH}$ & $20_{6,14}-21_{5,16}(A-)$ & 0.74 & 675.93 & 1 & -1 \\
\hline 337.8661646 & $\mathrm{CH}_{3} \mathrm{CHO}$ & $20_{1,19,3}-19_{2,18,3}$ & 1.26 & 405.45 & B & - \\
\hline 337.8776218 & $\left(\mathrm{CH}_{3}\right)_{2} \mathrm{CO}$ & $34_{28,7,0}-33_{29,4,0}$ & $1.78^{*}$ & 491.76 & 1 & - \\
\hline 337.8833340 & $\mathrm{CH}_{3} \mathrm{CHO}$ & $17_{1,16,6}-16_{1,15,6}$ & 2.31 & 518.52 & $\mathrm{~B}$ & - \\
\hline 337.8922466 & ${ }^{34} \mathrm{SO}$ & $3_{3}-2_{3}$ & -0.66 & 25.31 & $\mathrm{~A}$ & + \\
\hline 337.9063211 & $\mathrm{C}_{2} \mathrm{H}_{5} \mathrm{OH}$ & $42_{3,39,0}-41_{4,37,1}$ & 1.03 & 824.46 & B & - \\
\hline 337.9694140 & $\mathrm{CH}_{3} \mathrm{OH}$ & $7_{1,6}-6_{1,5}, v=1(-E)$ & 0.74 & 390.14 & 1 & + \\
\hline 338.0831953 & $\mathrm{H}_{2} \mathrm{CS}$ & $10_{1,10}-9_{1,9}$ & 1.91 & 102.43 & 1 & + \\
\hline 338.0992570 & $\mathrm{C}_{2} \mathrm{H}_{5} \mathrm{OH}$ & $18_{7,11,2}-18_{6,12,2}$ & 1.24 & 205.19 & 1 & - \\
\hline 338.1052800 & $\mathrm{CH}_{3} \mathrm{CHO}$ & $5_{3,2,5}-4_{2,2,5}$ & 0.80 & 240.80 & B & -1 \\
\hline 338.1071430 & $\left(\mathrm{CH}_{3}\right)_{2} \mathrm{CO}$ & $34_{0,34,0}-33_{1,33,1}$ & $4.14 *$ & 255.08 & 1 & -1 \\
\hline 338.1096730 & $\mathrm{C}_{2} \mathrm{H}_{5} \mathrm{OH}$ & $18_{7,12,2}-18_{6,13,2}$ & 1.24 & 205.19 & 1 & - \\
\hline 338.1176487 & $\left(\mathrm{CH}_{3}\right)_{2} \mathrm{CO}$ & $26_{9,17,0}-25_{10,16,1}$ & $3.61 *$ & 218.71 & 1 & - \\
\hline 338.1245020 & $\mathrm{CH}_{3} \mathrm{OH}$ & $7_{0,7}-6_{0,6}(A+)$ & 0.75 & 78.08 & 1 & - \\
\hline 338.1428510 & $\mathrm{C}_{2} \mathrm{H}_{5} \mathrm{CN}$ & $37_{3,34}-36_{3,33}$ & 2.74 & 316.76 & A & - \\
\hline 338.2620170 & $\mathrm{CH}_{2} \mathrm{DCN}$ & $5_{2,4}-5_{1,5}$ & -1.11 & 34.08 & B & - \\
\hline 338.2995240 & $\mathrm{CH}_{3} \mathrm{CHO}$ & $12_{2,11,0}-11_{1,10,0}$ & 1.00 & 81.04 & $\mathrm{~B}$ & - \\
\hline 338.3059931 & $\mathrm{SO}_{2}$ & $18_{4,14}-18_{3,15}$ & 1.43 & 196.79 & 1 & - \\
\hline 338.3182717 & $\left(\mathrm{CH}_{3}\right)_{2} \mathrm{CO}$ & $34_{25,10,1}-34_{22,13,2}$ & 0.62 & 503.70 & 1 & - \\
\hline 338.3203564 & ${ }^{34} \mathrm{SO}_{2}$ & $13_{2,12}-12_{1,11}$ & 1.13 & 92.45 & A & - \\
\hline 338.3380143 & $\mathrm{CH}_{3} \mathrm{OCHO}-\mathrm{E}$ & $27_{8,19}-26_{8,18}$ & 1.82 & 267.18 & $\mathrm{~B}$ & - \\
\hline 338.3446280 & $\mathrm{CH}_{3} \mathrm{OH}$ & $7_{1,7}-6_{1,6}(A-)$ & 0.74 & 70.55 & 1 & - \\
\hline 338.3557715 & $\mathrm{CH}_{3} \mathrm{OCHO}-\mathrm{A}$ & $27_{8,19}-26_{8,18}$ & 1.82 & 267.18 & B & + \\
\hline 338.3963889 & $\mathrm{CH}_{3} \mathrm{OCHO}-\mathrm{E}$ & $27_{7,21}-26_{7,20}$ & 1.83 & 257.74 & B & + \\
\hline 338.4045800 & $\mathrm{CH}_{3} \mathrm{OH}$ & $7_{6,2}-6_{6,1}(A+)$ & 0.17 & 243.78 & 1 & - \\
\hline 338.4086810 & $\mathrm{CH}_{3} \mathrm{OH}$ & $7_{0,7}-6_{0,6}(+E)$ & 0.75 & 64.98 & 1 & - \\
\hline
\end{tabular}


Table A.1. continued.

\begin{tabular}{|c|c|c|c|c|c|c|}
\hline Frequency & Molecule & Transition & $\log \left(\mu^{2} S\right)^{a}$ & $\overline{E_{\mathrm{u}}[\mathrm{K}]^{b}}$ & Flag $^{c}$ & $\mathrm{Plot}^{d}$ \\
\hline 338.4140995 & $\mathrm{CH}_{3} \mathrm{OCHO}-\mathrm{A}$ & $27_{7,21}-26_{7,20}$ & 1.83 & 257.74 & $\mathrm{~B}$ & - \\
\hline 338.4168741 & $\mathrm{C}_{2} \mathrm{H}_{5} \mathrm{OH}$ & $17_{7,11,2}-17_{6,12,2}$ & 1.21 & 190.04 & 1 & - \\
\hline 338.4309330 & $\mathrm{CH}_{3} \mathrm{OH}$ & $7_{6,1}-6_{6,0}(A-)$ & 0.18 & 253.94 & 1 & + \\
\hline 338.4423440 & $\mathrm{CH}_{3} \mathrm{OH}$ & $7_{6,1}-6_{6,0}(+E)$ & $0.48 *$ & 226.21 & 1 & + \\
\hline 338.4564990 & $\mathrm{CH}_{3} \mathrm{OH}$ & $7_{5,2}-6_{5,1}(A-)$ & 0.44 & 188.99 & 1 & + \\
\hline 338.4752900 & $\mathrm{CH}_{3} \mathrm{OH}$ & $7_{5,3}-6_{5,2}(A+)$ & 0.44 & 201.05 & 1 & + \\
\hline 338.4863370 & $\mathrm{CH}_{3} \mathrm{OH}$ & $7_{5,3}-6_{5,2}(+E)$ & $0.74 *$ & 170.39 & 1 & + \\
\hline 338.5040990 & $\mathrm{CH}_{3} \mathrm{OH}$ & $7_{4,4}-6_{4,3}(A-)$ & 0.58 & 152.89 & 1 & + \\
\hline 338.5126330 & $\mathrm{CH}_{3} \mathrm{OH}$ & $7_{4,4}-6_{4,3}(-E)$ & $0.88^{*}$ & 112.84 & 1 & -1 \\
\hline 338.5128560 & $\mathrm{CH}_{3} \mathrm{OH}$ & $7_{2,6}-6_{2,5}(-E)$ & 0.72 & 102.70 & 1 & -1 \\
\hline 338.5272488 & ${ }^{33} \mathrm{SO}$ & $3_{3,5}-2_{3,5}$ & -0.54 & 25.41 & A & - \\
\hline 338.5302490 & $\mathrm{CH}_{3} \mathrm{OH}$ & $7_{4,3}-6_{4,2}(A+)$ & 0.58 & 160.99 & 1 & - \\
\hline 338.5419995 & $\mathrm{CH}_{3} \mathrm{OH}$ & $7_{3,5}-6_{3,4}(+E)$ & $0.96 *$ & 82.30 & 1 & + \\
\hline 338.5599280 & $\mathrm{CH}_{3} \mathrm{OH}$ & $7_{3,5}-6_{3,4}(A-)$ & 0.67 & 127.70 & 1 & + \\
\hline 338.5831950 & $\mathrm{CH}_{3} \mathrm{OH}$ & $7_{3,4}-6_{3,3}(A+)$ & 0.66 & 112.71 & 1 & + \\
\hline 338.6118103 & $\mathrm{SO}_{2}$ & $20_{1,19}-19_{2,18}$ & 1.42 & 198.87 & 1 & - \\
\hline 338.6149990 & $\mathrm{CH}_{3} \mathrm{OH}$ & $7_{1,6}-6_{1,5}(A+)$ & 0.75 & 86.05 & 1 & - \\
\hline 338.6399390 & $\mathrm{CH}_{3} \mathrm{OH}$ & $7_{2,5}-6_{2,4}(+E)$ & 0.72 & 102.71 & 1 & + \\
\hline 338.6729900 & $\mathrm{C}_{2} \mathrm{H}_{5} \mathrm{OH}$ & $16_{7,9,2}-16_{6,10,2}$ & $1.47 *$ & 143.23 & 1 & - \\
\hline 338.7216300 & $\mathrm{CH}_{3} \mathrm{OH}$ & $7_{2,5}-6_{2,4}(A+)$ & 0.71 & 87.26 & 1 & -1 \\
\hline 338.7229400 & $\mathrm{CH}_{3} \mathrm{OH}$ & $7_{2,6}-6_{2,5}(A-)$ & 0.72 & 90.91 & 1 & -1 \\
\hline 1289.05 & $\mathrm{C}_{2} \mathrm{H}_{5} \mathrm{OH}$ & $52_{8,45,1}-52_{7,45,0}$ & 1.49 & $* * * * * *$ & B & - \\
\hline 338.7400994 & $\mathrm{C}_{2} \mathrm{H}_{5} \mathrm{OH}$ & $36_{6,30,2}-35_{7,29,2}$ & 1.11 & 608.82 & 1 & - \\
\hline 338.7486806 & $\mathrm{C}_{2} \mathrm{H}_{5} \mathrm{CN}$ & $23_{7,16}-24_{5,19}$ & -1.70 & 173.13 & B & - \\
\hline 341.1316650 & ${ }^{13} \mathrm{CH}_{3} \mathrm{OH}$ & $13_{1,12}-13_{0,13}(-E)$ & 1.39 & 222.31 & 1 & - \\
\hline 341.2755244 & $\mathrm{SO}_{2}$ & $21_{8,14}-22_{7,15}$ & 0.80 & 369.13 & $\mathrm{~A}$ & + \\
\hline 341.3502290 & $\mathrm{HCS}^{+}$ & $8-7$ & 1.49 & 73.72 & A & + \\
\hline 341.4156390 & $\mathrm{CH}_{3} \mathrm{OH}$ & $7_{1,6}-6_{1,5}(-E)$ & 0.74 & 80.09 & 1 & - \\
\hline 341.4649300 & $\mathrm{CH}_{3} \mathrm{CHO}$ & $18_{1,18,1}-17_{0,17,2}$ & 1.51 & 155.22 & B & - \\
\hline 341.6150200 & $\mathrm{CH}_{3} \mathrm{CHO}$ & $18_{1,18,0}-17_{0,17,0}$ & 1.51 & 155.15 & $\mathrm{~B}$ & - \\
\hline 341.6739613 & $\mathrm{SO}_{2}$ & $36_{5,31}-36_{4,32}$ & 1.83 & 678.50 & A & + \\
\hline 341.7247312 & ${ }^{33} \mathrm{SO}_{2}$ & $13_{2,12,12}-12_{1,11,11}$ & $1.73 *$ & 59.91 & A & + \\
\hline 341.7323005 & $\mathrm{CH}_{3} \mathrm{OCHO}-\mathrm{A}$ & $29_{4,26}-28_{4,25}$ & 1.87 & 264.16 & B & - \\
\hline 341.9181187 & $\mathrm{CH}_{3} \mathrm{OCHO}-\mathrm{E}$ & $29_{5,24}-28_{5,23}$ & 1.87 & 264.14 & 1 & - \\
\hline 341.9272670 & $\mathrm{C}_{2} \mathrm{H}_{5} \mathrm{CN}$ & $20_{4,16}-19_{3,17}$ & 0.96 & 108.18 & $\mathrm{~B}$ & -1 \\
\hline 341.9275081 & $\mathrm{CH}_{3} \mathrm{OCHO}-\mathrm{A}$ & $29_{3,26}-28_{3,25}$ & 1.87 & 264.14 & B & -1 \\
\hline 342.2300972 & $\mathrm{CH}_{3} \mathrm{OCHO}-\mathrm{E}$ & $29_{6,24}-28_{5,23}$ & 0.91 & 264.16 & A & - \\
\hline 342.3551031 & $\mathrm{CH}_{3} \mathrm{OCHO}-\mathrm{E}$ & $30_{5,26}-29_{5,25}$ & $2.19 *$ & 236.63 & 1 & - \\
\hline 342.3596229 & $\mathrm{CH}_{3} \mathrm{OCHO}-\mathrm{E}$ & $30_{5,26}-29_{4,26}$ & $1.94 *$ & 236.63 & 1 & - \\
\hline 342.3628322 & $\mathrm{CH}_{3} \mathrm{OCHO}-\mathrm{A}$ & $30_{3,28}-29_{3,27}$ & $2.19 *$ & 236.62 & 1 & - \\
\hline 342.5221280 & $\mathrm{D}_{2} \mathrm{CO}$ & $6_{0,6}-5_{0,5}$ & 1.81 & 58.12 & 1 & - \\
\hline 342.5252977 & $\mathrm{CH}_{3} \mathrm{OCHO}-\mathrm{E}$ & $11_{8,3}-10_{7,3}$ & 0.54 & 81.42 & 1 & - \\
\hline 342.5724154 & $\mathrm{CH}_{3} \mathrm{OCHO}-\mathrm{A}$ & $11_{8,4}-10_{7,3}$ & $0.84 *$ & 48.53 & 1 & - \\
\hline 342.6081188 & $\mathrm{CH}_{3} \mathrm{OCH}_{3}$ & $19_{0,19,3}-18_{1,18,3}$ & $2.59 *$ & 134.25 & 1 & - \\
\hline 342.7298300 & $\mathrm{CH}_{3} \mathrm{OH}$ & $13_{1,12}-13_{0,13}(-E)$ & 1.39 & 227.47 & 1 & - \\
\hline 342.7616254 & $\mathrm{SO}_{2}$ & $34_{3,31}-34_{2,32}$ & 1.71 & 581.91 & A & + \\
\hline 342.8828503 & $\mathrm{CS}^{-}$ & $7_{0}-6_{0}$ & 1.43 & 65.83 & 1 & + \\
\hline 342.9477426 & $\mathrm{CH}_{3} \mathrm{OCH}_{3}$ & $41_{3,39,0}-41_{6,36,0}$ & $2.58 *$ & 788.63 & 1 & - \\
\hline 342.9680977 & $\mathrm{CH}_{3} \mathrm{OCHO}-\mathrm{E}$ & $12_{4,9}-11_{1,10}$ & -0.99 & 56.85 & B & - \\
\hline 343.0875458 & ${ }^{33} \mathrm{SO}$ & $8_{9,10}-7_{8,9}$ & $1.92 *$ & 45.10 & 1 & + \\
\hline 346.8643205 & $\mathrm{C}_{2} \mathrm{H}_{5} \mathrm{CN}$ & $22_{8,14}-22_{7,15}$ & $1.49 *$ & 146.59 & A & - \\
\hline 346.8679114 & $\mathrm{CH}_{3} \mathrm{CHO}$ & $18_{15,4,4}-17_{15,3,4}$ & 1.84 & 864.58 & B & -1 \\
\hline 346.8691780 & $\mathrm{H}_{2} \mathrm{C}^{18} \mathrm{O}$ & $5_{2,4}-4_{2,3}$ & 1.36 & 97.40 & 1 & -1 \\
\hline 346.8934200 & $\mathrm{CH}_{3} \mathrm{CHO}$ & $18_{8,11,1}-17_{8,10,1}$ & $2.74 *$ & 269.02 & B & - \\
\hline 346.8982299 & $\mathrm{C}_{2} \mathrm{H}_{5} \mathrm{CN}$ & $21_{8,13}-21_{7,14}$ & $1.47 *$ & 137.13 & A & - \\
\hline 346.9250899 & $\mathrm{C}_{2} \mathrm{H}_{5} \mathrm{CN}$ & $20_{8,12}-20_{7,13}$ & $1.44 *$ & 128.10 & A & + \\
\hline 346.9342700 & $\mathrm{CH}_{3} \mathrm{CHO}$ & $18_{7,11,2}-17_{7,10,2}$ & 2.29 & 268.65 & B & - \\
\hline 346.9388742 & $\mathrm{C}_{2} \mathrm{H}_{5} \mathrm{OH}$ & $20_{6,14,1}-19_{6,13,1}$ & 1.46 & 280.47 & A & -1 \\
\hline 346.9406616 & $\mathrm{C}_{2} \mathrm{H}_{5} \mathrm{CN}$ & $8_{8,0}-8_{7,1}$ & $0.46^{*}$ & 53.29 & A & -1 \\
\hline 346.9456707 & $\mathrm{C}_{2} \mathrm{H}_{5} \mathrm{CN}$ & $19_{8,11}-19_{7,12}$ & $1.41 *$ & 119.49 & A & - \\
\hline 346.9569520 & $\mathrm{C}_{2} \mathrm{H}_{5} \mathrm{CN}$ & $10_{8,2}-10_{7,3}$ & $0.90^{*}$ & 61.45 & A & -1 \\
\hline 346.9573800 & $\mathrm{CH}_{3} \mathrm{CHO}$ & $18_{7,12,0}-17_{7,11,0}$ & $2.59 *$ & 235.30 & $\mathrm{~B}$ & -1 \\
\hline 346.9607049 & $\mathrm{C}_{2} \mathrm{H}_{5} \mathrm{CN}$ & $18_{8,10}-18_{7,11}$ & $1.38 *$ & 111.32 & A & -1 \\
\hline 346.9612355 & $\mathrm{SO}^{18} \mathrm{O}$ & $9_{2,7}-8_{1,8}$ & 0.69 & 48.98 & A & - \\
\hline
\end{tabular}


Table A.1. continued.

\begin{tabular}{|c|c|c|c|c|c|c|}
\hline Frequency & Molecule & Transition & $\log \left(\mu^{2} S\right)^{a}$ & $\overline{E_{\mathrm{u}}[\mathrm{K}]^{b}}$ & Flag $^{c}$ & $\mathrm{Plot}^{d}$ \\
\hline 346.9625940 & $\mathrm{C}_{2} \mathrm{H}_{5} \mathrm{OH}$ & $21_{0,21,2}-20_{1,20,2}$ & 1.33 & 185.84 & 1 & - \\
\hline 346.9643632 & $\mathrm{C}_{2} \mathrm{H}_{5} \mathrm{CN}$ & $11_{8,3}-11_{7,4}$ & $1.01 *$ & 66.18 & $\mathrm{~A}$ & -1 \\
\hline 346.9707599 & $\mathrm{C}_{2} \mathrm{H}_{5} \mathrm{CN}$ & $12_{8,4}-12_{7,5}$ & $1.09 *$ & 71.34 & A & - \\
\hline 346.9708872 & $\mathrm{C}_{2} \mathrm{H}_{5} \mathrm{CN}$ & $17_{8,9}-17_{7,10}$ & $1.34 *$ & 103.58 & A & -1 \\
\hline 346.9745486 & $\mathrm{C}_{2} \mathrm{H}_{5} \mathrm{OH}$ & $17_{3,15,0}-16_{2,15,1}$ & 0.83 & 195.16 & 1 & -1 \\
\hline 346.9757031 & $\mathrm{C}_{2} \mathrm{H}_{5} \mathrm{CN}$ & $13_{8,5}-13_{7,6}$ & $1.16^{*}$ & 76.93 & A & - \\
\hline 346.9768755 & $\mathrm{C}_{2} \mathrm{H}_{5} \mathrm{CN}$ & $16_{8,8}-16_{7,9}$ & $1.31 *$ & 96.27 & $\mathrm{~A}$ & - \\
\hline 346.9773655 & $\mathrm{CH}_{3} \mathrm{OCHO}-\mathrm{A}$ & $37_{1,36}-37_{1,37}$ & $0.65^{*}$ & 349.59 & 1 & - \\
\hline 346.9787172 & $\mathrm{C}_{2} \mathrm{H}_{5} \mathrm{CN}$ & $14_{8,6}-14_{7,7}$ & $1.21 *$ & 82.95 & A & - \\
\hline 346.9792906 & $\mathrm{C}_{2} \mathrm{H}_{5} \mathrm{CN}$ & $15_{8,7}-15_{7,8}$ & $1.26 *$ & 89.39 & A & -1 \\
\hline 346.9839750 & $\mathrm{H}_{2} \mathrm{C}^{18} \mathrm{O}$ & $5_{4,1}-4_{4,0}$ & $1.29 *$ & 206.26 & 1 & - \\
\hline 346.9867973 & HCOOD & $4_{3,2}-5_{1,5}$ & -3.62 & 34.29 & A & - \\
\hline 346.9969700 & $\mathrm{CH}_{3} \mathrm{CHO}$ & $18_{7,12,1}-17_{7,11,1}$ & 2.29 & 268.56 & B & -1 \\
\hline 346.9983440 & $\mathrm{H}^{13} \mathrm{CO}^{+}$ & $4-3$ & 1.78 & 41.63 & 1 & + \\
\hline 347.0434349 & $\mathrm{CH}_{2} \mathrm{DCN}$ & $20_{0,20}-19_{0,19}$ & 2.49 & 174.95 & 1 & + \\
\hline 347.0716400 & $\mathrm{CH}_{3} \mathrm{CHO}$ & $18_{6,13,0}-17_{6,12,0}$ & $2.61 *$ & 206.08 & 1 & + \\
\hline 347.0899400 & $\mathrm{CH}_{3} \mathrm{CHO}$ & $18_{6,12,2}-17_{6,11,2}$ & 2.31 & 239.39 & 1 & + \\
\hline 347.1101228 & $\mathrm{CH}_{2} \mathrm{DCN}$ & $20_{5,15}^{, 1,2}-19_{5,14}$ & $2.76^{*}$ & 276.41 & 1 & + \\
\hline 347.1177162 & $\mathrm{CH}_{3} \mathrm{CHO}$ & $18_{12,6,3}-17_{12,5,3}$ & $2.40 *$ & 650.97 & B & + \\
\hline 347.1326859 & $\mathrm{CH}_{3} \mathrm{CHO}$ & $18_{6,13,1}-17_{6,12,1}$ & 2.31 & 239.31 & B & -1 \\
\hline 347.1338640 & $\mathrm{H}_{2} \mathrm{C}^{18} \mathrm{O}$ & $5_{3,3}-4_{3,2}$ & 1.72 & 156.69 & B & -1 \\
\hline 347.1440112 & $\mathrm{H}_{2} \mathrm{C}^{18} \mathrm{O}$ & $5_{3,2}-4_{3,1}$ & 1.72 & 156.69 & B & - \\
\hline 347.1472094 & $\mathrm{C}_{2} \mathrm{H}_{5} \mathrm{OH}$ & $20_{6,15,0}-19_{6,14,0}$ & 1.46 & 275.45 & A & - \\
\hline 347.1551248 & $\mathrm{CH}_{3} \mathrm{CHO}$ & $18_{4,14,8}-17_{4,13,8}$ & 2.33 & 573.91 & B & -1 \\
\hline 347.1557752 & $\mathrm{CH}_{3} \mathrm{CHO}$ & $9_{4,6,4}-9_{3,7,4}$ & 0.99 & 282.77 & B & -1 \\
\hline 347.1579974 & $\mathrm{C}_{2} \mathrm{H}_{5} \mathrm{OH}$ & $20_{6,14,0}-19_{6,13,0}$ & 1.46 & 275.45 & 1 & - \\
\hline 347.1618629 & $\mathrm{C}_{2} \mathrm{H}_{5} \mathrm{OH}$ & $21_{1,21,2}-20_{1,20,2}$ & -1.35 & 185.85 & A & - \\
\hline 347.1664788 & $\mathrm{CH}_{2} \mathrm{DCN}$ & $20_{4,17}-19_{4,16}$ & $2.77 *$ & 227.92 & 1 & - \\
\hline 347.1695196 & $\mathrm{CH}_{3} \mathrm{CHO}$ & $19_{0,19,0}-18_{1,18,0}$ & 1.54 & 171.81 & $\mathrm{~B}$ & - \\
\hline 347.1819200 & $\mathrm{CH}_{3} \mathrm{CHO}$ & $18_{4,14,5}-17_{4,13,5}$ & 2.34 & 400.37 & B & - \\
\hline 347.1882830 & ${ }^{13} \mathrm{CH}_{3} \mathrm{OH}$ & $14_{1,13}-14_{0,14}(-E)$ & 1.41 & 254.25 & 1 & -1 \\
\hline 347.1882949 & $\mathrm{CH}_{2} \mathrm{DCN}$ & $20_{2,19}-19_{2,18}$ & 2.48 & 196.56 & 1 & -1 \\
\hline 347.2176900 & $\mathrm{CH}_{3} \mathrm{CHO}$ & $18_{5,13,5}-17_{5,12,5}$ & 2.32 & 420.43 & B & -1 \\
\hline 347.2181534 & $\mathrm{CH}_{2} \mathrm{DCN}$ & $20_{3,18}-19_{3,17}$ & $2.78^{*}$ & 190.20 & 1 & -1 \\
\hline 347.2234438 & $\mathrm{CH}_{3} \mathrm{OCH}_{3}$ & $10_{10,1,0}-11_{9,2,0}$ & $0.29 *$ & 157.22 & 1 & - \\
\hline 347.2403963 & $\mathrm{CH}_{3} \mathrm{CHO}$ & $19_{0,19,2}-18_{1,18,1}$ & 1.54 & 171.88 & B & + \\
\hline 347.2518220 & $\mathrm{CH}_{3} \mathrm{CHO}$ & $18_{5,14,4}-17_{5,13,4}$ & 2.32 & 419.66 & B & + \\
\hline 347.2915691 & $\mathrm{CH}_{3} \mathrm{CHO}$ & $18_{5,14,0}-17_{5,13,0}$ & $2.62 *$ & 181.36 & $\mathrm{~B}$ & + \\
\hline 347.3306310 & $\mathrm{SiO}$ & $8-7$ & 1.89 & 75.02 & 1 & + \\
\hline 347.3470563 & $\mathrm{CH}_{3} \mathrm{OCH}_{3}$ & $37_{7,30,0}-37_{6,31,0}$ & $2.58 *$ & 677.04 & 1 & -1 \\
\hline 347.3474946 & $\mathrm{CH}_{3} \mathrm{CHO}$ & $18_{5,13,2}-17_{5,12,2}$ & $2.62 *$ & 181.28 & B & -1 \\
\hline 347.3509290 & $\mathrm{C}_{2} \mathrm{H}_{5} \mathrm{OH}$ & $14_{3,12,2}-13_{2,11,2}$ & 1.02 & 99.66 & A & - \\
\hline 347.3702042 & $\mathrm{C}_{2} \mathrm{H}_{5} \mathrm{OH}$ & $34_{4,30,0}-33_{5,28,1}$ & 0.89 & 579.09 & 1 & + \\
\hline 347.3882105 & $\mathrm{CH}_{2} \mathrm{DCN}$ & $20_{2,18}-19_{2,17}$ & 2.48 & 196.61 & 1 & + \\
\hline 347.4455230 & $\mathrm{C}_{2} \mathrm{H}_{5} \mathrm{OH}$ & $21_{1,21,2}-20_{0,20,2}$ & 1.37 & 185.85 & 1 & + \\
\hline 347.4596300 & $\mathrm{CH}_{3} \mathrm{CHO}$ & $18_{7,12,3}-17_{7,11,3}$ & $2.59 *$ & 439.79 & $\mathrm{~B}$ & + \\
\hline 347.4735609 & $\mathrm{C}_{2} \mathrm{H}_{5} \mathrm{OH}$ & $20_{5,16,1}-19_{5,15,1}$ & 1.48 & 267.08 & 1 & - \\
\hline 347.4783957 & $\mathrm{CH}_{3} \mathrm{OCHO}-\mathrm{E}$ & $27_{1,26}-26_{1,25}$ & 1.84 & 247.25 & 1 & - \\
\hline 347.4939937 & $\mathrm{CH}_{3} \mathrm{OCHO}-\mathrm{A}$ & $27_{5,22}-26_{5,21}$ & 1.84 & 247.25 & 1 & + \\
\hline 347.5194000 & $\mathrm{CH}_{3} \mathrm{CHO}$ & $18_{3,16,0}-17_{3,15,0}$ & 2.35 & 178.75 & B & + \\
\hline 347.5275021 & $\mathrm{CH}_{3} \mathrm{CHO}$ & $14_{2,13,6}-14_{1,14,6}$ & 1.21 & 483.43 & B & - \\
\hline 347.5324834 & $\mathrm{CH}_{3} \mathrm{CHO}$ & $19_{0,19,5}-18_{1,18,4}$ & 1.54 & 376.56 & $\mathrm{~B}$ & - \\
\hline 347.5635800 & $\mathrm{CH}_{3} \mathrm{CHO}$ & $18_{3,16,1}-17_{3,15,1}$ & 2.34 & 178.71 & B & - \\
\hline 347.5686348 & $\left(\mathrm{CH}_{3}\right)_{2} \mathrm{CO}$ & $31_{22,10,0}-30_{23,7,0}$ & 1.79 & 415.59 & A & 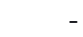 \\
\hline 347.5899095 & $\mathrm{CH}_{3} \mathrm{OCHO}-\mathrm{A}$ & $16_{6,10}-15_{5,11}$ & 0.43 & 104.44 & 1 & + \\
\hline 347.6045600 & $\mathrm{CH}_{3} \mathrm{OCHO}-\mathrm{E}$ & $28_{10,18}-27_{10,17}$ & 1.81 & 306.76 & 1 & + \\
\hline 347.6169166 & $\mathrm{C}_{2} \mathrm{H}_{5} \mathrm{OH}$ & $12_{2,10,1}-11_{1,11,1}$ & -1.39 & 132.23 & 1 & -1 \\
\hline 347.6170100 & $\mathrm{CH}_{3} \mathrm{OCHO}-\mathrm{A}$ & $28_{10,19}-27_{10,18}$ & 1.81 & 306.76 & 1 & -1 \\
\hline 347.6283400 & $\mathrm{CH}_{3} \mathrm{OCHO}-\mathrm{E}$ & $28_{10,19}-27_{10,18}$ & 1.81 & 306.76 & 1 & -1 \\
\hline 347.6283880 & $\mathrm{CH}_{3} \mathrm{OCHO}-\mathrm{A}$ & $28_{10,18}-27_{10,17}$ & 1.81 & 306.76 & 1 & -1 \\
\hline 347.6503726 & $\mathrm{CH}_{3} \mathrm{CHO}$ & $18_{4,15,0}-17_{4,14,0}$ & 2.34 & 194.51 & B & + \\
\hline 347.6661969 & $\mathrm{CH}_{3} \mathrm{CHO}$ & $18_{6,13,4}-17_{6,12,4}$ & 2.30 & 443.35 & $\mathrm{~B}$ & + \\
\hline
\end{tabular}


Table A.1. continued.

\begin{tabular}{|c|c|c|c|c|c|c|}
\hline Frequency & Molecule & Transition & $\log \left(\mu^{2} \mathrm{~S}\right)^{a}$ & $E_{\mathrm{u}}[\mathrm{K}]^{b}$ & Flag $^{c}$ & $\mathrm{Plot}^{d}$ \\
\hline 347.6860359 & $\mathrm{CH}_{3} \mathrm{OCHO}-\mathrm{E}$ & $28_{10,18}-27_{10,18}$ & 0.05 & 306.76 & $\mathrm{~A}$ & + \\
\hline 347.7549038 & $\mathrm{C}_{2} \mathrm{H}_{5} \mathrm{OH}$ & $20_{4,17,1}-19_{4,16,1}$ & 1.49 & 256.16 & A & -1 \\
\hline 347.7568500 & $\mathrm{CH}_{3} \mathrm{CHO}$ & $18_{4,15,1}-17_{4,14,1}$ & 2.33 & 194.43 & B & -1 \\
\hline 347.7675836 & $\mathrm{CH}_{3} \mathrm{OCHO}-\mathrm{E}$ & $45_{10,36}-45_{9,37}$ & 0.84 & 629.78 & 1 & + \\
\hline 347.7884000 & ${ }^{13} \mathrm{CH}_{3} \mathrm{OH}$ & $13_{49}-14_{3,11}(E)$ & 0.57 & 302.50 & 1 & - \\
\hline 347.7950424 & $\mathrm{C}_{2} \mathrm{H}_{5} \mathrm{OH}$ & $38_{2,36,1}-38_{1,37,1}$ & -0.68 & 681.50 & A & - \\
\hline 347.8349955 & $\mathrm{CH}_{3} \mathrm{CHO}$ & $18_{4,14,2}-17_{4,13,2}$ & $2.63^{*}$ & 161.11 & B & -1 \\
\hline 347.8354356 & $\mathrm{C}_{2} \mathrm{H}_{5} \mathrm{CN}$ & $42_{9,33}-43_{7,36}$ & -1.12 & 478.30 & A & -1 \\
\hline 347.9115075 & $\left(\mathrm{CH}_{3}\right)_{2} \mathrm{CO}$ & $35_{0,35,1}-34_{1,34,1}$ & $4.15^{*}$ & 270.92 & A & - \\
\hline 347.9455996 & $\mathrm{C}_{2} \mathrm{H}_{5} \mathrm{CN}$ & $30_{4,26}-30_{1,29}$ & 0.00 & 218.53 & 1 & + \\
\hline 347.9537539 & $\mathrm{C}_{2} \mathrm{H}_{5} \mathrm{OH}$ & $14_{3,12,1}-13_{2,11,1}$ & -1.28 & 159.97 & 1 & + \\
\hline 348.0103300 & $\mathrm{CH}_{3} \mathrm{CHO}$ & $18_{7,12,4}-17_{7,11,4}$ & 2.28 & 471.78 & B & + \\
\hline 348.0324330 & $\mathrm{H}_{2} \mathrm{C}^{18} \mathrm{O}$ & $5_{2,3}-4_{2,2}$ & 1.36 & 97.50 & 1 & + \\
\hline 348.0448423 & $\mathrm{C}_{2} \mathrm{H}_{5} \mathrm{CN}$ & $22_{7,15}-23_{5,18}$ & -1.78 & 163.24 & A & - \\
\hline 348.0500083 & $\mathrm{CH}_{3} \mathrm{OCHO}-\mathrm{E}$ & $28_{4,24}-27_{4,23}$ & 1.85 & 266.05 & 1 & - \\
\hline 348.0659670 & $\mathrm{CH}_{3} \mathrm{OCHO}-\mathrm{A}$ & $28_{6,23}-27_{6,22}$ & 1.85 & 266.05 & 1 & + \\
\hline 348.0761410 & $\mathrm{CH}_{3} \mathrm{CHO}$ & $18_{8,11,4}-17_{8,10,4}$ & 2.26 & 505.18 & B & - \\
\hline 348.0830973 & $\mathrm{CH}_{3} \mathrm{C}^{13} \mathrm{CH}$ & $21_{1}-20_{1}$ & 1.07 & 190.99 & 1 & - \\
\hline 348.0875400 & $\mathrm{CH}_{3} \mathrm{CHO}$ & $18_{6,13,3}-17_{6,12,3}$ & $2.60 *$ & 409.86 & B & - \\
\hline 348.1001940 & ${ }^{13} \mathrm{CH}_{3} \mathrm{OH}$ & $11_{0,11}-10_{1,9}(E)$ & 0.70 & 162.36 & 1 & + \\
\hline 348.1174691 & ${ }^{34} \mathrm{SO}_{2}$ & $19_{4,16}-19_{3,17}$ & 1.44 & 212.60 & 1 & - \\
\hline 348.2115900 & $\mathrm{CH}_{3} \mathrm{CHO}$ & $18_{3,16,3}-17_{3,15,3}$ & 2.34 & 383.20 & B & + \\
\hline 348.2290900 & $\mathrm{CH}_{3} \mathrm{CHO}$ & $18_{4,15,4}-17_{4,14,4}$ & 2.33 & 399.64 & B & + \\
\hline 348.2605616 & $\mathrm{C}_{2} \mathrm{H}_{5} \mathrm{CN}$ & $39_{2,37}-38_{2,36}$ & 2.76 & 343.77 & 1 & + \\
\hline 348.2884900 & $\mathrm{CH}_{3} \mathrm{CHO}$ & $18_{3,15,5}-17_{3,14,5}$ & 2.34 & 385.26 & B & + \\
\hline 348.3445240 & $\mathrm{C}_{2} \mathrm{H}_{5} \mathrm{CN}$ & $40_{2,39}-39_{2,38}$ & 2.77 & 351.03 & A & + \\
\hline 348.3682909 & $\mathrm{CH}_{3} \mathrm{CHO}$ & $20_{0,20,6}-19_{1,19,6}$ & 1.60 & 559.91 & B & + \\
\hline 348.3833571 & $\mathrm{CH}_{3} \mathrm{CHO}$ & $24_{5,20,7}-24_{4,20,8}$ & 1.28 & 709.71 & B & - \\
\hline 348.3878000 & $\mathrm{SO}_{2}$ & $24_{2,22}-23_{3,21}$ & 1.28 & 292.73 & A & - \\
\hline 348.4268300 & HCOOD & $26_{2,24}-26_{1,25}$ & -0.11 & 386.56 & 1 & + \\
\hline 348.5290690 & $\mathrm{CH}_{3} \mathrm{OCHO}-\mathrm{E}$ & $39_{6,34}-39_{4,36}$ & $0.94 *$ & 406.72 & 1 & - \\
\hline 348.5343647 & $\mathrm{H}_{2} \mathrm{CS}$ & $10_{1,9}-9_{1,8}$ & 1.91 & 105.19 & 1 & - \\
\hline 348.5490239 & $\mathrm{CH}_{3} \mathrm{OCH}_{3}$ & $13_{11,2,0}-14_{10,5,0}$ & $0.97 *$ & 219.31 & A & + \\
\hline 348.5533063 & $\mathrm{C}_{2} \mathrm{H}_{5} \mathrm{CN}$ & $40_{1,39}-39_{1,38}$ & 2.77 & 350.99 & 1 & - \\
\hline 348.5607352 & $\mathrm{CH}_{3} \mathrm{CHO}$ & $18_{4,14,2}-17_{4,14,1}$ & 0.47 & 194.47 & B & + \\
\hline 348.5741708 & $\mathrm{CH}_{3} \mathrm{CHO}$ & $18_{5,14,3}-17_{5,13,3}$ & $2.62 *$ & 384.77 & B & + \\
\hline 348.5926077 & $\mathrm{CH}_{3} \mathrm{CHO}$ & $19_{0,19,3}-18_{1,18,3}$ & 1.49 & 378.44 & B & + \\
\hline 348.6909162 & $\mathrm{CH}_{2} \mathrm{DCN}$ & $20_{1,19}-19_{1,18}$ & 2.49 & 181.14 & B & - \\
\hline 348.7201594 & $\mathrm{C}_{2} \mathrm{H}_{5} \mathrm{OH}$ & $4_{4,0,1}-3_{3,0,0}$ & $0.93 *$ & 56.10 & 1 & + \\
\hline 348.7487090 & $\mathrm{CH}_{3} \mathrm{CHO}$ & $18_{3,16,6}-17_{3,15,6}$ & 2.34 & 565.54 & B & + \\
\hline 351.1186500 & $\mathrm{CH}_{3} \mathrm{CHO}$ & $18_{1,17,5}-17_{1,16,5}$ & 2.35 & 368.31 & B & - \\
\hline 351.1780478 & ${ }^{33} \mathrm{SO}_{2}$ & $8_{4,4,10}-8_{3,5,10}$ & $1.46^{*}$ & 37.92 & A & + \\
\hline 351.1955218 & $\mathrm{D}_{2} \mathrm{CO}$ & $6_{5,1}-5_{5,0}$ & $1.30 *$ & 159.97 & 1 & + \\
\hline 351.2363430 & $\mathrm{CH}_{3} \mathrm{OH}$ & $9_{5,5}-10_{4,6}(A+)$ & 0.14 & 240.50 & 1 & -1 \\
\hline 351.2372003 & $\mathrm{C}_{2} \mathrm{H}_{5} \mathrm{OH}$ & $20_{6,15,2}-19_{6,14,2}$ & -1.41 & 221.82 & A & -1 \\
\hline 351.2412110 & $\mathrm{HNCO}$ & $16_{4,12,15}-15_{4,11,15}$ & $2.36^{*}$ & 801.97 & A & - \\
\hline 351.2572233 & $\mathrm{SO}_{2}$ & $5_{3,3}-4_{2,2}$ & 0.86 & 35.89 & 1 & + \\
\hline 351.4171451 & $\mathrm{HNCO}$ & $16_{3,14,15}-15_{3,13,15}$ & $2.38 *$ & 499.10 & A & + \\
\hline 351.4649831 & $\mathrm{O}^{13} \mathrm{CS}$ & $29-28$ & 1.17 & 253.05 & 1 & + \\
\hline 351.4897729 & $\mathrm{D}_{2} \mathrm{CO}$ & $6_{4,2}-5_{4,1}$ & $1.86^{*}$ & 111.51 & 1 & - \\
\hline 351.4923762 & $\mathrm{C}_{2} \mathrm{H}_{5} \mathrm{OH}$ & $37_{5,32,0}-36_{6,30,1}$ & 0.91 & 678.95 & 1 & - \\
\hline 351.5172503 & $\mathrm{CH}_{3} \mathrm{OCHO}-\mathrm{E}$ & $29_{3,26}-28_{3,25}$ & 1.87 & 274.21 & B & - \\
\hline 351.5314432 & $\mathrm{C}_{2} \mathrm{H}_{5} \mathrm{CN}$ & $16_{5,12}-15_{4,11}$ & 0.98 & 86.27 & 1 & - \\
\hline 351.5378152 & $\mathrm{HNCO}$ & $16_{2,15,15}-15_{2,14,15}$ & $2.08 *$ & 282.77 & 1 & - \\
\hline 351.5424856 & ${ }^{33} \mathrm{SO}_{2}$ & $6_{4,2,5}-6_{3,3,5}$ & $1.40 *$ & 24.12 & A & - \\
\hline 351.5482880 & $\mathrm{HN}^{13} \mathrm{CO}$ & $16_{2,15,15}-15_{2,14,15}$ & $2.08 *$ & 282.35 & A & - \\
\hline 351.5519350 & $\mathrm{HNCO}$ & $16_{2,14,15}-15_{2,13,15}$ & $2.08 *$ & 282.77 & A & - \\
\hline 351.5745100 & $\mathrm{CH}_{3} \mathrm{CHO}$ & $13_{2,12,0}-12_{1,11,0}$ & 1.04 & 93.01 & B & - \\
\hline 351.5889840 & $\mathrm{CH}_{3} \mathrm{CHO}$ & $6_{3,3,0}-5_{2,4,0}$ & 0.83 & 39.81 & B & - \\
\hline 351.6286600 & $\left(\mathrm{CH}_{3}\right)_{2} \mathrm{CO}$ & $43_{3,40,0}-43_{2,41,0}$ & $2.69 *$ & 472.86 & A & - \\
\hline 351.6334579 & $\mathrm{HNCO}$ & $16_{0,16,15}-15_{0,15,15}$ & $2.09 *$ & 109.70 & A & -1 \\
\hline 351.6352310 & ${ }^{33} \mathrm{SO}_{2}$ & $5_{4,2,4}-5_{3,3,4}$ & $1.25 *$ & 18.60 & A & -1 \\
\hline 351.6428731 & $\mathrm{HN}^{13} \mathrm{CO}$ & $16_{0,16,15}-15_{0,15,15}$ & $2.09 *$ & 109.71 & A & - \\
\hline 351.6962430 & $\mathrm{CH}_{3} \mathrm{OCHO}-\mathrm{E}$ & $19_{2,17}-19_{2,18}$ & -1.65 & 126.22 & B & - \\
\hline 351.7686450 & $\mathrm{H}_{2} \mathrm{CO}$ & $5_{1,5}-4_{1,4}$ & 1.89 & 62.45 & 1 & + \\
\hline
\end{tabular}


Table A.1. continued.

\begin{tabular}{|c|c|c|c|c|c|c|}
\hline Frequency & Molecule & Transition & $\log \left(\mu^{2} \mathrm{~S}\right)^{a}$ & $E_{\mathrm{u}}[\mathrm{K}]^{b}$ & Flag $^{c}$ & Plot $^{d}$ \\
\hline 351.8738732 & $\mathrm{SO}_{2}$ & $14_{4,10}-14_{3,11}$ & 1.29 & 135.87 & $\mathrm{~A}$ & + \\
\hline 351.9947623 & $\mathrm{HNCO}$ & $23_{1,23,24}-24_{0,24,24}$ & $1.80^{*}$ & 299.51 & A & + \\
\hline 352.2321000 & $\mathrm{CH}_{3} \mathrm{CHO}$ & $19_{1,19,1}-18_{1,18,1}$ & 2.38 & 172.12 & B & - \\
\hline 352.2436863 & $\mathrm{D}_{2} \mathrm{CO}$ & $6_{3,3}-5_{3,2}$ & 1.39 & 107.60 & B & + \\
\hline 352.2511849 & $\mathrm{CH}_{3} \mathrm{CHO}$ & $19_{1,19,0}-18_{1,18,0}$ & 2.38 & 172.05 & B & - \\
\hline 352.2554824 & $\mathrm{HNC}^{18} \mathrm{O}$ & $17_{1,17,16}-16_{1,16,16}$ & $2.12 *$ & 161.65 & A & + \\
\hline 352.5995703 & OCS & $29-28$ & 1.17 & 253.87 & 1 & + \\
\hline 352.8978650 & $\mathrm{HNCO}$ & $16_{1,15,15}-15_{1,14,15}$ & $2.09 *$ & 153.37 & A & + \\
\hline 352.9200176 & $\mathrm{CH}_{3} \mathrm{OCHO}-\mathrm{E}$ & $31_{5,27}-30_{5,26}$ & $2.21^{*}$ & 252.55 & 1 & - \\
\hline
\end{tabular}

Notes. This table is also available in electronic form at http://www.nbi.dk/\$ $\$$ sim $\$ j$ eskj/sma-iras16293.html. (a) Catalog line strength for transition. " $*$ " indicates multiple hyperfine components from the catalog entry added together. ${ }^{(b)}$ Energy of upper level for transition. ${ }^{(c)}$ Flag describing identification of line: "1" indicates transition detected toward both components, "A" transition only detected to IRAS $16293 \mathrm{~A}$ and "B" transition only detected toward IRAS 16293B. Transitions that are close in frequency / blended are grouped with the vertical lines in this column. (d) "+" indicates transitions included in the maps in Fig. 12-15 for specific species. 